Universidade de São Paulo

Instituto de Física

\title{
Espectroscopia de Alcalinos em Hélio Líquido
}

\author{
Lucas Modesto da Costa
}

Orientador: Prof. Sylvio Roberto Accioly Canuto

\section{Banca Examinadora:}

Prof. Sylvio Roberto Accioly Canuto (IF/USP)

Prof. ${ }^{a}$ Helena Maria Petrilli (IF/USP)

Prof. Marcos Antônio de Castro (IF/UFG)

São Paulo, 2010 


\section{FICHA CATALOGRÁFICA}

\section{Preparada pelo Serviço de Biblioteca e Informação}

do Instituto de Física da Universidade de São Paulo

Costa, Lucas Modesto da

Espectroscopia de alcalinos em hélio líquido São Paulo, 2010.

Dissertação (Mestrado) - Universidade de São Paulo. Instituto de Física. Depto. de Física Geral

Orientador: Prof. Sylvio Roberto Accioly Canuto

Área de Concentração: Física

Unitermos: 1. Física atômica; 2. Espectroscopia;

3. Estrutura da matéria (Química teórica). 
"Não há conhecimento que não tenha valor." Burke, Edmund

"Power. Unlimited Power. " Darth Sidious - Star Wars III 



\section{Agradecimentos}

Agradeço a minha família pelo suporte fornecido desde a infância. Mesmo sendo contra a minha mudança de Goiânia para São Paulo, acabaram apoiando minha decisão. Sou muito grato a eles, pois me forneceram um ambiente estável e seguro.

Ao Prof. Sylvio Canuto pela confiança em mim depositada, devido às discussões sobre os mais variados temas e pela paciência em me orientar.

Aos colaboradores, como a Prof. ${ }^{a}$ Kaline Coutinho no suporte a simulações clássicas e do programa DICE e ao Prof. Pasantra Murkherjee (IACS, India) pelas discussões sobre o tema do trabalho.

À Viviane Morcelle por ser uma namorada compreensiva e apoiadora.

A todos os membros do grupo que me ajudaram muito na hora de realizar as simulações, comentários sobre os resultados, discussões sobre os métodos e nos momentos de descontração.

Ao Prof. Francisco Elias (UFES) por nos conceder funções de bases para o Rb antes da publicação.

Aos amigos, funcionários e demais professores que conheci na USP e que não arriscaria escrever os nomes de todos, pois sempre iria deixar de citar alguém em especial.

À CAPES e à FAPESP (Processo: 08/51807-3) pelo apoio financeiro.

Muito obrigado a todos,

Lucas Modesto da Costa. 



\section{Resumo}

Átomos alcalinos são boas sondas para compreender as propriedades do He líquido. Considerável atenção experimental tem sido empregada para analisar as mudanças da posição e da largura da linha do espectro de absorção de átomos alcalinos imersos em um ambiente de He líquido. No lado teórico, vários estudos têm usado modelos simplificados como o modelo de bolhas e o modelo de agregado. Considerações de modelos mais realista agora são oportunas e relevantes. Neste trabalho, nós usamos a combinação da simulação de Monte Carlo (MC) e cálculos ab-initio de mecânica quântica (MQ). As configurações do líquido foram geradas para cálculos posteriores de MQ. Um importante aspecto é a complexa interação interatômica do par He-He. Usando potenciais parametrizados, as simulações clássicas de MC foram efetuadas para sistemas alcalinos ( $\mathrm{Na}, \mathrm{Rb}, \mathrm{Cs}$ e $\mathrm{Na}_{2}$ ) em He líquido e as condições foram $\mathrm{T}=3 \mathrm{~K} \mathrm{e} \mathrm{p}=1 \mathrm{~atm}$. Estruturas estatisticamente descorrelacionadas formadas por um elemento alcalino central, envolvido pela primeira camada de solvatação completa, são amostradas e submetidas em um cálculo do espectro com DFT dependente do tempo usando diferentes funcionais híbridos e conjuntos de bases. Usando os funcionais PBE1PBE e O3LYP com conjuntos de bases extensos obtemos o deslocamento espectral em excelente concordância com os resultados experimentais para os sistemas de um único átomo alcalino. Para comparação, também usamos um modelo de agregado com 14 átomos de He em volta do átomo alcalino obtendo excelentes resultados também. O raio do modelo de agregado convergiu para perto do máximo da primeira camada de solvatação da função de distribuição radial. Um ponto adicional a ser considerado é o cálculo da largura da linha obtido com a simulação em He líquido que é discutida neste trabalho. Para o átomo de $\mathrm{Rb}$, a energia de excitação em He líquido é em torno de $-18,9 \mathrm{~nm}$. Com a simulação em ambiente de He líquido obtivemos os melhores resultados entre $-16,3 \mathrm{~nm}$ e $-23,3 \mathrm{~nm}$. O valor do deslocamento espectral usando o modelo de agregado ficou entre os -17,3 nm e $22,3 \mathrm{~nm}$. Os dois modelos apresentam o mesmo raio da bolha, por volta de 6-7 $\mathrm{A}$. Para outros sistemas, como Na e Cs, encontramos a mesma convergência entre o modelo de agregado, a simulação do He líquido e os resultados experimentais. Para o sistema contendo $\mathrm{Na}_{2}$, os valores obtidos ficaram em boa concordância com os valores experimentais.

Palavras-chaves: espectroscopia, átomos alcalinos, He líquido 



\section{Abstract}

Alkali atoms are good probes for the understanding of liquid He properties. As such considerable experimental attention has been devoted to the analysis of the changes of line position and widths of the absorption spectra of alkali atoms in liquid He environment. On the theoretical side, several studies have used simplified models such as bubble and cluster models. Considerations of more realistic models are now timely and relevant. In this work, we use a combination of Monte Carlo (MC) simulation and ab initio quantum mechanical (QM) calculations. Liquid configurations are generated for subsequent QM calculations. One important aspect is the consideration of the complex interatomic interaction of the He-He pair. Using parametrized potentials, classical MC simulations are made for the alkali systems $\left(\mathrm{Na}, \mathrm{Rb}, \mathrm{Cs}\right.$ and $\left.\mathrm{Na}_{2}\right)$ in liquid $\mathrm{He}$. The conditions were $\mathrm{T}=3 \mathrm{~K}$ and $\mathrm{p}=1 \mathrm{~atm}$. Statistically uncorrelated configurations composed of a central alkaline element, surrounded by the full first solvation shell, are sampled and submitted to time-dependent DFT calculations of the spectrum using different hybrids functionals and differents basis sets. Using the PBE1PBE and O3LYP functionals with large basis sets we obtained a spectral shift in excellent agreement with experiment for the systems of single alkaline atom. For comparison, we also used a cluster model and obtained $14 \mathrm{He}$ atoms around the alkali atom with excellent results too. The radius of the cluster model converged to a value close to the maximum of the first solvation shell in radial distribution function. An additional point considered is the calculation of the spectral line width using the liquid simulation also discussed in this work. For $\mathrm{Rb}$ atom, the excitation energy in liquid He is about $-18.9 \mathrm{~nm}$. With the liquid He environment simulation we obtained the best results between $-16.3 \mathrm{~nm}$ and $-23.3 \mathrm{~nm}$. The values of the spectral shift using the cluster model were between -17.3 $\mathrm{nm}$ and $22.3 \mathrm{~nm}$. The two models show the same bubble radius, about 6-7 $\AA$. For the others system, like $\mathrm{Na}$ and $\mathrm{Cs}$, we found the same convergence between the cluster model, the simulation of the He liquid and the experimental results. For $\mathrm{Na}_{2}$, the values obtained were in good agreement to the experimental values.

Keywords: spectroscopy, alkali atoms, liquid $\mathrm{He}$ 



\section{Sumário}

\begin{tabular}{ll|}
\hline Lista de Abreviaturas & $x$
\end{tabular}

Lista de Figuras $\quad$ xii

Lista de Tabelas $\quad$ xvii

$\begin{array}{lll}\mathbf{1} & \text { Introdução } & \mathbf{1}\end{array}$

1.1 Impurezas Alcalinas em He Líquido . . . . . . . . . . . . . . . . 2

1.2 Átomos Alcalinos . . . . . . . . . . . . . . . . . 5

1.3 Separação Fina . . . . . . . . . . . . . . . . . . . . . . 5

1.4 Resultado Experimental . . . . . . . . . . . . . . . 7

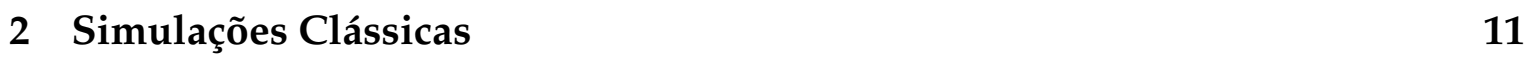

2.1 Monte Carlo . . . . . . . . . . . . . . . . . . . . . . 12

2.2 Potencial de Interação . . . . . . . . . . . . . . . . . . . . . . . . . 14

2.3 Ferramentas para Análise de Resultados . . . . . . . . . . . . . . . . . . . . . . . . . . . .

$2.3 .1 \quad$ Função de Distribuição Radial . . . . . . . . . . . . . . . . . . 15

2.3 .2 Auto-Correlação da Energia . . . . . . . . . . . . . . . . 16

3 Cálculos por Mecânica Quântica 19

3.1 Método Coupled Cluster . . . . . . . . . . . . . . . . . . 21

3.2 Teoria do Funcional da Densidade . . . . . . . . . . . . . . . . 23

3.3 Aproximações no Termo $E_{x c} \ldots \ldots \ldots \ldots . \ldots \ldots$

3.3 .1 Funcionais Não-Híbridos . . . . . . . . . . . . . . . 26

3.3 .2 Funcionais Híbridos . . . . . . . . . . . . . . . . . . . . . . . . 29 
3.4 Conjuntos de Bases . . . . . . . . . . . . . . . . . . . . . . 30

3.4 .1 Bases Usadas . . . . . . . . . . . . . . . . . . 33

4 Modelo de Agregado 35

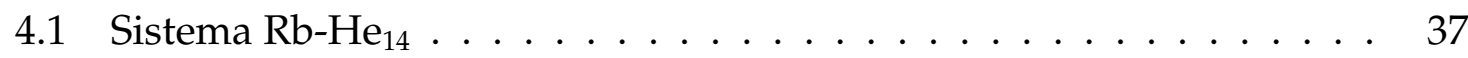

4.2 Sistema Cs-He ${ }_{14} \ldots \ldots \ldots \ldots \ldots \ldots$. . . . . . . . . . . . . 42

4.3 Sistema Na-He $\mathrm{He}_{14} \ldots \ldots \ldots \ldots \ldots$. . . . . . . . . . . . . . 43

4.4 Sistema $\mathrm{Na}_{2}-\mathrm{He}_{14} \ldots \ldots \ldots \ldots \ldots \ldots \ldots$

4.5 Conclusões Parciais . . . . . . . . . . . . . . . . . . . . . . . . . . . . . 49

5 Simulação em He Líquido 51

5.1 Potencial do Kleinekathöoefer, Tang, Toennies e Yiu . . . . . . . . . . 54

5.2 Potencial de Patil . . . . . . . . . . . . . . . . . . . . . . 60

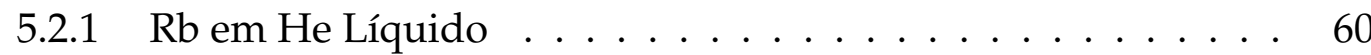

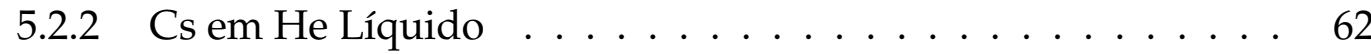

$5.2 .3 \quad$ Na em He Líquido . . . . . . . . . . . . . . . . . . . . 65

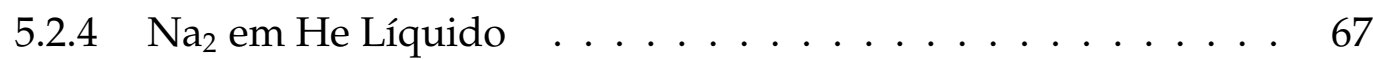

5.3 Conclusões Parciais . . . . . . . . . . . . . . . . . . . . . . 70

\begin{tabular}{lll}
\hline & Conclusões & 73
\end{tabular}

\begin{tabular}{ll}
\hline Referências Bibliográficas & 75
\end{tabular}

\begin{tabular}{|lll}
\hline Apêndice A & Standard Bubble Model & 83
\end{tabular} 


\section{Lista de Abreviaturas}

$\begin{array}{ll}\text { BO } & \text { Born-Oppenheimer } \\ \text { CC } & \text { Coupled Cluster } \\ \text { DFT } & \text { Density Functional Theory } \\ \text { DM } & \text { Dinâmica Molecular } \\ \text { ECP } & \text { Effective Core Potential } \\ \text { HF } & \text { Hartree-Fock } \\ \text { HWHM } & \text { Half Width at Half Maximum } \\ \text { HOMO } & \text { Highest Occupied Molecular Orbital } \\ \text { KS } & \text { Kohn-Sham } \\ \text { KTTY } & \text { Kleinekathöoefer, Tang, Toennies and Yiu } \\ \text { LJ } & \text { Lennard-Jones } \\ \text { LUMO } & \text { Lowest Unoccupied Molecular Orbital } \\ \text { MC } & \text { Monte Carlo } \\ \text { MM } & \text { Mecânica Molecular } \\ \text { MQ } & \text { Mecânica Quântica } \\ \text { SBM } & \text { Standard Bubble Model } \\ \text { TDDFT } & \text { Time Dependent Density Functional Theory } \\ \text { HW } & \text { Hor }\end{array}$




\section{Lista de Figuras}

1.1 Diagrama de fase para o He, mostrando as regiões onde ocorrem as transições dos estados. Esta figura está na referência [3]. . . . . . . . . . . . . . . . 3

1.2 Separação das linhas $\mathrm{D}_{1}$ e $\mathrm{D}_{2}$ para o átomo de $\mathrm{Rb} . \ldots \ldots \ldots$

1.3 Deslocamento espectral em função da temperatura para o Ca. Esta figura está na referência [14] e demonstra que a variação do deslocamento espectral é pequena na transição entre o $\mathrm{He}_{I}$ e $\mathrm{He}_{I I} . \ldots \ldots \ldots$. . . . . . . . . . . 8

4.1 Disposição dos átomos de He em torno do $\mathrm{Rb}$ no modelo de agregado. Representação dos orbitais atômicos onde:|(a)|é o mais alto ocupado e tem a forma do orbital atômico do tipo $s$ e](b)|é o mais baixo desocupado e tem a forma do orbital atômico do tipo $p$ ligeiramente deformado. . . . . . . . . . . . . . . . . . . 40

4.2 Energia do agregado dividida pela constante de Boltzmann em função do comprimento dos pares $R_{R b-H e}$ e para cada ponto o valor do deslocamento espectral usando o funcional PBE1PBE e a base do Rb igual a DZP e a base do He igual a $c c-p V 5 Z . \ldots \ldots \ldots \ldots \ldots$. . . . . . . . . . . . . . . . . 41

4.3 Disposição dos átomos de $\mathrm{He}$ em torno do $\mathrm{Na}_{2}$ no modelo de agregado. Representação dos orbitais moleculares HOMO $|(\mathrm{a})| \mathrm{LUMO}|(\mathrm{b})| \mathrm{LUMO}+1|(\mathrm{c})| \mathrm{e} \mathrm{LUMO}+2|(\mathrm{~d})|$ 
4.4 Energia do agregado (hartree) em função das distâncias $R_{\mathrm{Na}-\mathrm{Na}} \mathrm{e} R_{\mathrm{Na}_{2}-\mathrm{He}}$. Conforme a figura, na região de $R_{\mathrm{Na}-\mathrm{Na}}=3 \AA$ não ocorre uma mudança muito grande ao variar a distância $R_{\mathrm{Na}_{2}-\mathrm{He}}$

4.5 Energia de excitação (eV) $\mid$ (a) $\mid$ e intensidade excitação $(\mathrm{b}) \mid$ para a transição $X^{1} \Sigma_{g}^{+} \rightarrow$ $B^{1} \Pi_{u}$ no modelo de agregado, em função das distâncias $R_{\mathrm{Na}-\mathrm{Na}}$ e $R_{\mathrm{Na}_{2}-\mathrm{He}}$.

5.1 Diferentes potenciais analisados. O potencial LJ-HFD-B3-FCI1 é um potencial de LJ com os parâmetros do potencial HFD-B3-FCI1 $[27,35]$. Tang and Toennies é proveniente das referências [36,37], enquanto o derivado do CCSD(T)/cc-pV5Z usa cálculos de mecânica quântica para descrever a interação. . . . . . . . . . . . . 53

5.2 Função de distribuição radial $(G(r))$ mostrando as primeiras camadas de solvatação para o sistema Rb em He líquido usando o potencial de LJ com parâmetros do potencial KTTY para a interação Rb-He. . . . . . . . . . . . . . . . . . . . 55

5.3 Disposição dos átomos de He em torno do $\mathrm{Rb}$ no He líquido. Representação dos orbitais atômicos onde|(a)|é o mais alto ocupado que tem a forma do orbital atômico do tipo $s$ e $|(b)| e ́$ o mais baixo desocupado, que tem a forma ligeiramente deformada do orbital atômico do tipo $p . \ldots \ldots \ldots 56$

5.4 Função de auto-correlação da energia para a simulação de Rb em He líquido usando os parâmetros do potencial KTTY para a interação Rb-He. . . . . . . . . . . . . 57

5.5 Histograma da distribuição da energia de excitação obtido com o funcional PBE1PBE e a base $D Z P$ para o $R b . \quad \ldots \ldots \ldots$

5.6 Convergência do deslocamento espectral em função do número de átomos de He mais próximos do $\mathrm{Rb}$, usando o funcional PBE1PBE e a base DZP para o $\mathrm{Rb}$. . . . 59

5.7 Função de distribuição radial $(G(r))$ para a simulação do Rb em He líquido usando os parâmetros do potencial de Patil para a interação Rb-He. . . . . . . . . . . . 61 
5.8 Função de distribuição radial $(G(r))$ para a simulação do Cs em He líquido usando os parâmetros do potencial de Patil para a interação Cs-He. . . . . . . . . . . . 64

5.9 Função de distribuição radial $(G(r))$ para a simulação do Na em He líquido usando os parâmetros do potencial de Patil para a interação Na-He. . . . . . . . . . . . 66

5.10 Função de distribuição radial $(G(r))$ para a simulação do $\mathrm{Na}_{2}$ em He líquido usando os parâmetros do potencial de Patil para a interação Na-He. . . . . . . . . . . . 68

5.11 Função de auto-correlação estatística da energia para a simulação do $\mathrm{Na}_{2} \mathrm{em} \mathrm{He}$ líquido em função dos passos de MC. . . . . . . . . . . . . . . . . . . . 69 


\section{Lista de Tabelas}

1.1 Resultados espectroscópicos [28] para a transição 5s-5p do Rb como: valor da energia de excitação do $\mathrm{Rb}$ isolado, o deslocamento espectral em ambiente de $\mathrm{He}$ líquido e largura da linha $(\mathrm{HWHM}) . \ldots \ldots$. . . . . . . . . . . . 9

1.2 Resultados espectroscópicos [28] para a transição 6s-6p do Cs como: valor da energia de excitação do Cs isolado, o deslocamento espectral em ambiente de $\mathrm{He}$ líquido e largura da linha $(\mathrm{HWHM}) . \ldots \ldots$. . . . . . . . . . . 9

3.1 Comparação entre algumas bases usadas para descrever o estado fundamental do átomo de He. A energia foi calculada com DFT usando o funcional híbrido

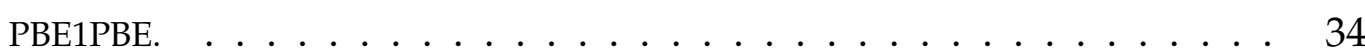

$4.1 \quad$ Estrutura geométrica do modelo de agregado, onde $\mathrm{X}$ representa os sistemas estudados: $R b, C s, N a$ e $\mathrm{Na}_{2} . \ldots \ldots \ldots$

4.2 Mínima energia $E_{\min }$, raio do agregado $R_{\operatorname{mim}}$, energia de excitação do Rb isolado e seu deslocamento quando presente no agregado de He. Para estes resultados usamos a base DPZ para o $\mathrm{Rb}$, diferentes bases para o He e distintos funcionais

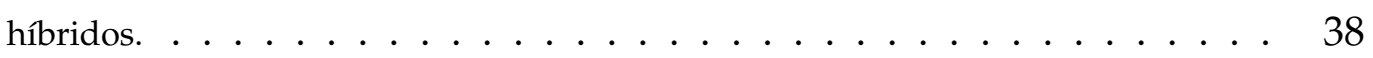


4.3 Mínima energia $E_{\min }$, raio do agregado $R_{\operatorname{mim}}$, energia de excitação do $\mathrm{Rb}$ isolado e seu deslocamento quando presente no agregado de He. Para estes resultados usamos a base def2-qzvp para o Rb, diferentes bases para o He e distintos funcionais híbridos. . . . . . . . . . . . . . . . . . . . 38

4.4 Mínima energia $E_{\min }$, raio do agregado $R_{\operatorname{mim}}$, energia de excitação do $\mathrm{Rb}$ isolado e seu deslocamento quando presente no agregado de He. Para estes resultados usamos a base sadlej para o Rb, diferentes bases para o He e distintos funcionais híbridos. . . . . . . . . . . . . . . . . . . 39

4.5 Mínima energia $E_{\min }$, raio do agregado $R_{\operatorname{mim}}$, energia de excitação do $\mathrm{Rb}$ isolado e seu deslocamento quando presente no agregado de He. Para estes resultados usamos a base LanL2MB para Rb e He e diferentes funcionais híbridos. . . . . . . 40

4.6 Mínima energia $E_{\min }$, raio do agregado $R_{\operatorname{mim}}$, energia de excitação do Cs isolado e seu deslocamento quando presente no agregado de He com diferentes funcionais \begin{tabular}{|l}
\hline e bases para os átomos. Nas bases sinalizadas com um *, os átomos de He estão \\
\hline
\end{tabular} representados pela base $6-311++G(2 d, 2 p) . \ldots \ldots \ldots . \ldots . \ldots 42$

4.7 Mínima energia $E_{\min }$, raio do agregado $R_{\operatorname{mim}}$, energia de excitação do Na isolado e seu deslocamento quando presente no agregado de He com diferentes funcionais e bases para os átomos. Nas bases sinalizadas com um *, os átomos de He estão representados pela base $6-311++G(2 d, 2 p) . \ldots \ldots \ldots$. . . . . . . . 44

4.8 Mínima energia $E_{\min }$, raio do agregado $R_{\operatorname{mim}}$, energia de excitação do $\mathrm{Na}_{2}$ isolado e seu deslocamento quando presente no agregado de He com diferentes funcionais e bases para os átomos. Trabalhamos com as duas transições $X^{1} \Sigma_{g}^{+} \rightarrow A^{1} \sum_{u}^{+} \mathrm{e}$ $X^{1} \Sigma_{g}^{+} \rightarrow B^{1} \Pi_{u}$. Nas bases sinalizadas com um *, os átomos de He estão representados pela base $6-311++G(2 d, 2 p) . \ldots \ldots \ldots \ldots \ldots$

5.1 Condições iniciais de simulação do He líquido $\quad \ldots \ldots$. . . . . . . . . . . . . 52 
5.2 Parâmetros dos potenciais LJ usando cálculo ab-initio CCSD(T)/cc- $p$ VZZ para a interação He-He e o potencial KTTY para a interação Rb-He [36]. . . . . . . . . . . 54

5.3 Energia de excitação do Rb isolado e imerso em He líquido (Desl.) além da largura da linha de excitação HWHM com diferentes bases para o Rb e funcionais híbridos. Estes resultados foram obtidos com médias sobre configurações de uma simulação clássica com o potencial de KTTY. . . . . . . . . . . . . . . . . . . . . . . 58

5.4 Parâmetros dos potenciais LJ usando cálculo ab-initio CCSD(T)/cc- $p$ VZZ para a interação He-He e o potencial de Patil [38] para a interação Rb-He. . . . . . . . .

5.5 Energia de excitação do Rb isolado e imerso em He líquido (Desl.) além da largura da linha de excitação HWHM com diferentes bases para o Rb e funcionais híbridos. Estes resultados foram obtidos com médias sobre configurações de uma simulação clássica com o potencial de Patil. . . . . . . . . . . . . . . . . . . 62

5.6 Parâmetros dos potenciais LJ para a simulação do Cs em He líquido usando cálculo $a b$-initio CCSD(T)/cc-pV5Z para a interação He-He e o potencial de Patil [38] para a interação Cs-He. . . . . . . . . . . . . . . . . . . . 63

5.7 Energia de excitação do Cs isolado e imerso em He líquido (Desl.) além da largura da linha de excitação HWHM com diferentes bases para o Cs e funcionais híbridos. O sinal * indica que a base dos átomos de He é igual a $6-311++G(2 d, 2 p)$. . . . .

5.8 Parâmetros dos potenciais LJ para a simulação do Na em He líquido usando cálculo ab-initio CCSD(T)/cc-pV5Z para a interação He-He e o potencial de Patil [38] para a interação Na-He. . . . . . . . . . . . . . . . . . . . . . . . 65

5.9 Energia de excitação do Na isolado e imerso em He líquido (Desl.) além da largura da linha de excitação HWHM com diferentes bases para o Na e funcionais híbridos. O sinal * indica que a base dos átomos de He é igual a $6-311++G(2 d, 2 p)$. . . . .

5.10 Energia de excitação do $\mathrm{Na}_{2}$ isolado e imerso em He líquido para as transições $X^{1} \Sigma_{g}^{+} \rightarrow A^{1} \sum_{u}^{+} \mathrm{e} X^{1} \Sigma_{g}^{+} \rightarrow B^{1} \Pi_{u} \ldots \ldots \ldots \ldots \ldots \ldots \ldots$ 


\section{Capítulo 1}

\section{Introdução}

Técnicas recentes de implantação de átomos e pequenas moléculas em He líquido despertaram um grande interesse no estudo espectroscópico desses sistemas. Como átomos alcalinos isolados têm seu espectro óptico muito conhecido, acabam tornando-se excelentes candidatos à sonda na tentativa de descrever as propriedades do He líquido. Mudanças no espectro dos átomos alcalinos, tanto deslocamento espectral como largura de linha, são devidas a sua interação com os átomos de He. Neste trabalho estudamos as mudanças no espectro de absorção do Sódio (Na), Rubídio ( $\mathrm{Rb}$ ), Césio (Cs) e do dímero de Sódio $\left(\mathrm{Na}_{2}\right)$, todas estas amostras em He líquido. Para isso, usamos dois modelos: o modelo de agregado e a simulação do sistema líquido.

Esta dissertação está dividida em 6 capítulos. No capítulo 1, fazemos uma introdução onde descrevemos algumas propriedades do He líquido, dos átomos alcalinos, dos resultados experimentais para as mudanças do espectro de átomos alcalinos quando estão presentes em He líquido. Nos capítulos 2 e 3 são apresentados as metodologias utilizadas para a descrição do sistema de forma clássica e quântica, respectivamente. No capítulo 4, apresentamos os resultados usando o modelo de agregado. No capítulo 5, mostramos os resultados para a simulação do He líquido com impurezas do tipo átomos alcalinos. 


\subsection{Impurezas Alcalinas em He Líquido}

Hélid ${ }^{1}$ é um dos mais interessantes sistemas líquidos conhecidos na natureza. Analisando seu diagrama de fase na figura 1.1, notamos que não existe um ponto triplo e também, só é possível solidificar com pressões acima de $25 \mathrm{~atm}$. A existência do estado líquido a $0 \mathrm{~K}$ é por si só um fato peculiar [1]. Por ser um gás nobre e, portanto interagir muito fracamente, o He é um sistema gasoso até temperaturas muito baixas. Em pressão normal de $1 \mathrm{~atm}$, o He muda para líquido a uma temperatura de transição de 4,22 K. Nesse ponto ele é chamado de $\mathrm{He}_{I}$. Reduzindo-se ainda mais sua temperatura, uma nova transição de fase ocorre em 2,17 K e o sistema entra no estado superfluido $\left(\mathrm{He}_{I I}\right)$ [2]. A fronteira onde ocorre a transição das fases do líquido é conhecida como "linha-lambda", devido à forma da variação do calor específico nessa temperatura.

Propriedades extremamente interessantes ocorrem na região de $\mathrm{He}_{I I}$. De fato, o estudo de He superfluido é um tópico de extrema relevância em física de baixas temperaturas e líquidos quânticos. Efeitos como infinita condutividade térmica e viscosidade nula aparecem neste regime, sendo assim o $\mathrm{He}_{I I}$ é chamado de superfluido. Os estudos iniciais sobre as propriedades destes superfluidos foram efetuados por Landau em 1941 [4]. Em temperaturas baixas, o comprimento de onda de de Broglie dos átomos de He é da ordem da distância interatômica do líquido, porém ocorreram também avanços em outras regiões de baixas temperaturas. Os estudos de He líquido, em geral, têm obtido grande progresso na região do $\mathrm{He}_{I}$, ou seja, para temperaturas entre 2,2 e 4,2 K com pressão igual a $1 \mathrm{~atm}$. Também foram obtidos novos avanços na parte experimental: técnicas de implantação de átomos alcalinos em He líquido [5,6], análise espectroscópica com variação de pressão [7], observação do movimento de elétrons [8,9], explosão de bolhas de elétrons [10], etc.

\footnotetext{
${ }^{1}$ Neste trabalho, entenda-se Hélio (He) o isótopo ${ }^{4} \mathrm{He}$ que é mais abundante na natureza, sendo este um bóson que obedece a estatística de Bose-Einsten.
} 


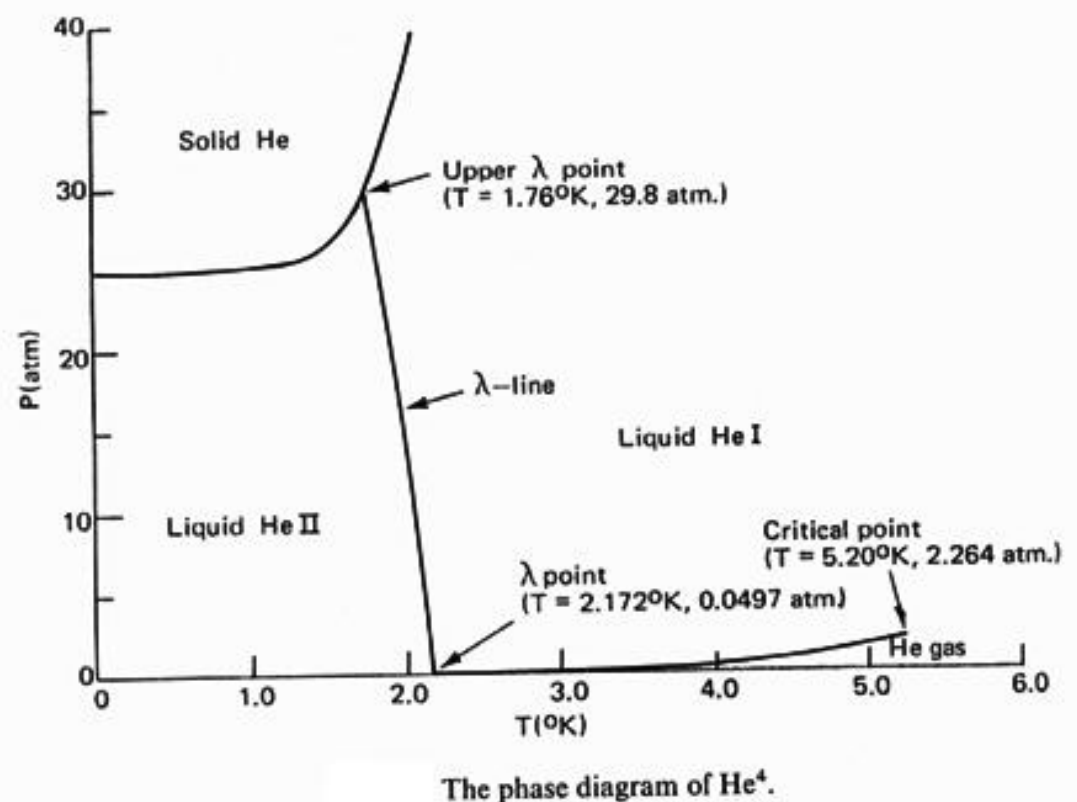

Figura 1.1: Diagrama de fase para o He, mostrando as regiões onde ocorrem as transições dos estados. Esta figura está na referência [3].

Sabe-se que uma impureza do tipo alcalina presente em He líquido sofre uma grande repulsão devido ao princípio de exclusão de Pauli $[8,11]$. Assim, será criada uma cavidade ou bolha envolvendo a impureza limitada pela camada de átomos de He mais próxima. O tamanho e a forma da cavidade dependem da interação entre os átomos presentes no sistema. Um fenômeno interessante ocorre quando a impureza é um átomo alcalino, pois sendo um elemento que possui um espectro bem definido, o desvio na posição de seu pico de absorção e a modificação da sua forma dão informações sobre a interação com o He líquido. Esse processo foi inicialmente detalhado no modelo teórico Standard Bubble Model (SBM) [12] ${ }^{2}$.

Uma possibilidade de compreender as propriedades do $\mathrm{He}_{I}$ é usar os sistemas atômicos como uma sonda, de forma que variações obtidas no espectro atômico permitam investigar as propriedades do líquido. Adicionalmente, é importante que a transição seja bem característica e por isso, a escolha de átomos alcalinos é

\footnotetext{
${ }^{2}$ Mais detalhes sobre o SBM podem ser vistos na seção A. na página 83 .
} 
essencial $[5,6,13-17]$.

No panorama teórico, os estudos de átomos alcalinos em He líquido são limitados a problemas-modelo com deficiências que são conhecidas, mas até certo ponto, inevitáveis [18-22]. Tradicionalmente, o modelo SBM ou modelos do tipo pseudopotencial têm sido usados com relativo sucesso. Uma das falhas essenciais desses modelos é que desconsideram as características estatísticas do líquido, já que as propriedades devem ser obtidas como médias estatísticas configuracionais. Uma tentativa recente [23] de aliviar esse problema foi feita usando o método sequencial Mecânica Molecular/Mecânica Quântica (S-MM/MQ) [24-26]. Tal procedimento permitiu obter bons resultados para o deslocamento da linha de transição de $\mathrm{Na}$ em He líquido. Igualmente importante, esse estudo [23] também obteve o alargamento da linha espectral, o qual não pôde ser obtido nos modelos anteriores.

Embora bem sucedido, o modelo S-MM/MQ necessita de aprimoramentos antes de ser considerado uma metodologia de amplo uso. Isto é consequência do complexo problema da interação interatômica He-He já estudada há muito tempo [1]. É sabido que a molécula $\mathrm{He}_{2}$ tem apenas um estado vibracional ligado e os métodos de química quântica ou física molecular têm enorme dificuldade em caracterizar o $\mathrm{He}_{2}$. A obtenção de um potencial He-He realista é fundamental para progredir nessa direção. Diversos modelos trabalham com interação entre pares, mas já existem propostas para o uso da interação de três corpos, a qual descreve mais precisamente o sistema He. Felizmente, potenciais parametrizados existem e descrevem muito bem a forma do potencial interatômico [27].

Em nossa pesquisa, existe a possibilidade de tratar outras amostras alcalinas em ambiente de He líquido, podendo expandir os estudos a íons e pequenas moléculas. Para diversos sistemas $[28,29]$, já foram obtidos o espectro tanto de emissão quanto de absorção para $\mathrm{Na}_{2}, \mathrm{Li}_{2}, \mathrm{Ba}^{+}, \mathrm{Ba}, \mathrm{Ca}$ e $\mathrm{Sr}$.

Estudamos mudanças no espectro de átomos alcalinos na presença do $\mathrm{He}$ 
líquido. Essas mudanças são, em geral, o deslocamento dos máximos das linhas de excitação e também, o alargamento dessa linha. Os átomos alcalinos estudados foram o $\mathrm{Na}$, o $\mathrm{Rb}$ e o $\mathrm{Cs}$, além do dímero $\mathrm{Na}_{2}$. Para esta pesquisa, vamos usar dois métodos: o modelo de agregado e o sequencial S-MM/MQ. Em ambos os casos, as propriedades são obtidas com cálculos de MQ usando TDDFT.

\section{2 Átomos Alcalinos}

Átomos alcalinos possuem uma transição ns-n $p$ bem característica e seu espectro isolado pode alterar-se quando está presente em um solvente. Com base nessa característica, vamos estudar as mudanças desse soluto na presença do solvente He líquido. Diversas vantagens do uso de átomos alcalinos podem ser citadas, dentre elas:

- aproximação hidrogenóide - facilitando o trabalho teórico do elemento, pois o mesmo pode ser tratado como um átomo de Hidrogênio de carga eletrônica maior sofrendo uma blindagem, a qual é devida aos elétrons das camadas preenchidas;

- linha espectral bem característica - na região do visível, próxima da região do infravermelho, pois existe apenas uma transição do tipo ns-n $p$ carregando praticamente toda a intensidade do espectro

\subsection{Separação Fina}

A interação dos momentos de dipolos magnéticos dos núcleos e dos elétrons desemparelhados gera a separação fina, por isso encontramos as linhas $\mathrm{D}_{1}$ e $\mathrm{D}_{2}$ no espectro de excitação dos átomos alcalinos. Uma forma bem simples de analisar 
essa separação é feita no estudo do acoplamento spin-órbita, sendo que a interação entre esses momentos magnéticos dá origem ao termo

$$
U=a \mathbf{S} . \mathbf{L},
$$

onde $a$ é uma constante de proporcionalidade que não é importante no que segue.

Trabalhando com o momento angular total $\mathbf{J}=\mathbf{L}+\mathbf{S}$ e lembrando que $\mathbf{J}^{2}=$ $\mathbf{L}^{2}+\mathbf{S}^{2}+2 \mathbf{L} \cdot \mathbf{S}$, o termo de interação tem a forma

$$
\langle\mathbf{L} \cdot \mathbf{S}\rangle=\frac{1}{2}\left[\left\langle\mathbf{J}^{2}\right\rangle-\left\langle\mathbf{L}^{2}\right\rangle-\left\langle\mathbf{S}^{2}\right\rangle\right]=\frac{1}{2}[j(j+1)-l(l+1)-s(s+1)] .
$$

Para os estados $P$ com $s=1 / 2$ e $l=1$, temos

$$
\langle\mathbf{L} \cdot \mathbf{S}\rangle=\frac{1}{2}\left[j(j+1)-\frac{11}{4}\right] .
$$

Os valores que o operador momento angular total pode assumir são:

- $j=\frac{1}{2} \Rightarrow\langle\mathbf{L} \cdot \mathbf{S}\rangle=-1$;

- $j=\frac{3}{2} \Rightarrow\langle\mathbf{L} \cdot \mathbf{S}\rangle=\frac{1}{2}$.

Logo, a separação devido ao acoplamento spin - orbita é assimétrica, conforme podemos observar com os valores acima. Uma ilustração da separação com a notação espectroscópica para o átomo de Rb é vista na figura 1.2

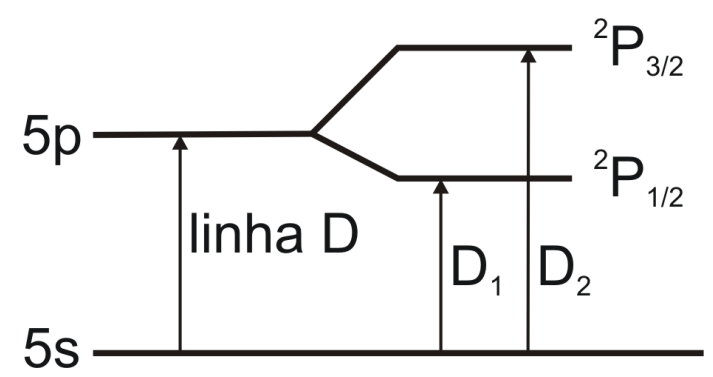

Figura 1.2: Separação das linhas $\mathrm{D}_{1}$ e $\mathrm{D}_{2}$ para o átomo de $\mathrm{Rb}$. 


\subsection{Resultado Experimental}

Nas referências $[7,28]$ estão descritos os processos para a obtenção do valor experimental do deslocamento da energia de excitação dos átomos alcalinos em He líquido. Não é o intuito de nossa pesquisa uma descrição do processo experimental usado para obter as propriedades espectroscópicas, porém, é de interesse para poder comparar com outros possíveis métodos de obtenção das mesmas propriedades.

O procedimento consiste em inserir um bulk da amostra alcalina a ser analisada no He Líquido. Esse bulk será irradiado por um laser pulsante primário do tipo Nd:YLF. o qual quebra o material na forma primária em grandes clusters. Os clusters são irradiados novamente por um laser secundário do mesmo tipo do primário, criando uma alta densidade de átomos alcalinos isolados no He Líquido. Esses átomos isolados são excitados por outro laser do tipo Ti: $\mathrm{Al}_{2} \mathrm{O}_{3}$. Os fótons emitidos serão detectados por um contador após um monocromador. A potência do laser de excitação é de alguns miliwatts e a taxa de repetição do laser pulsante é da ordem de $1 \mathrm{kHz}$. Em alguns casos, é possível ver a luz emitida a olho nu devido à emissão do átomo de Rubídio.

A temperatura na qual foi realizado o experimento [28] de excitação de átomos alcalinos foi de 1,6 K na pressão de saturação do vapor, em torno de $7,4 \times 10^{-3} \mathrm{~atm}$. O valor do deslocamento aumenta em função da pressão assim como a largura da linha (Half Width at Half-Maximum - HWHM), porém essa condição não será tratada por agora, ficando para um possível trabalho futuro. Também, esse acréscimo tanto no deslocamento como no HWHM não é tão grande ao trabalhar com a pressão em $1 \mathrm{~atm}$.

Outra informação importante é que mudanças na temperatura não devem modificar muito o deslocamento espectral e a largura da linha [14]. Em qualquer região de He líquido, tanto líquido normal como superfluido, os valores destas 
propriedades vão se manter praticamente constantes, conforme pode ser observado no resultado experimental na figura 1.3 e na referência [14].

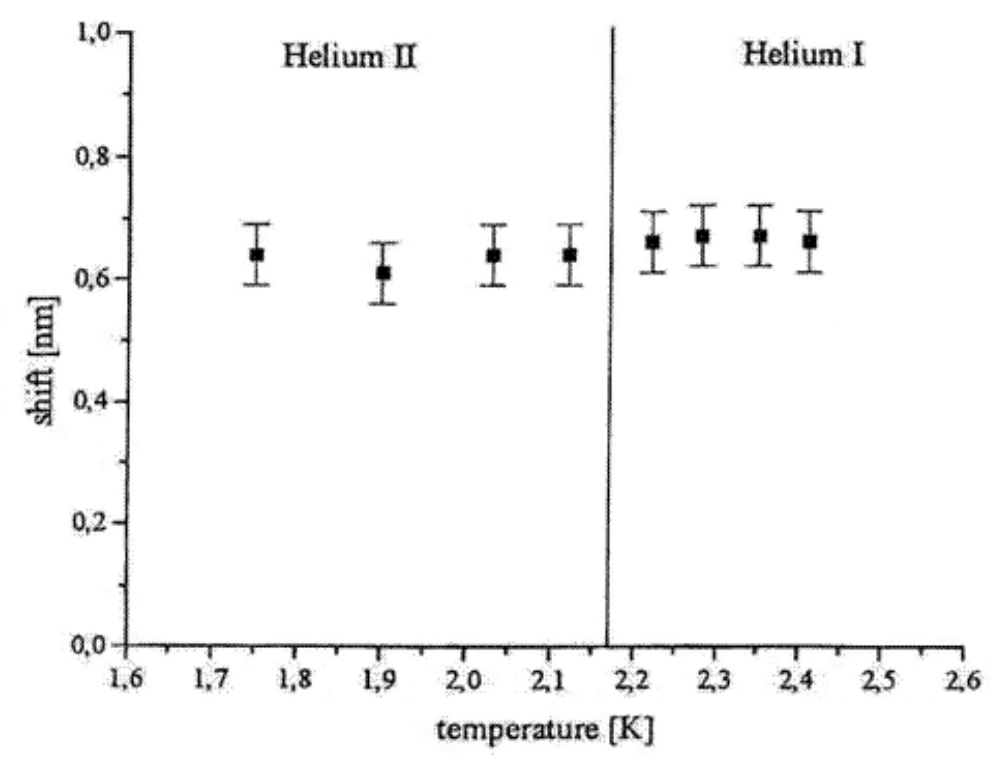

Figura 1.3: Deslocamento espectral em função da temperatura para o Ca. Esta figura está na referência [14] e demonstra que a variação do deslocamento espectral é pequena na transição entre o $\mathrm{He}_{I}$ e $\mathrm{He}_{I I}$.

Aplicando o procedimento descrito anteriormente, foi possível obter a energia de excitação do Rb e do Cs em He líquido, conforme as tabelas 1.1 e 1.2 e também a largura de cada uma das linhas de excitação (HWHM). Infelizmente nossos cálculos de mecânica quântica não são capazes de diferenciar as linhas $\mathrm{D}_{1}$ e $\mathrm{D}_{2}$ e sendo assim, vamos referenciar o resultado experimental somente por uma simples média. No caso do $\mathrm{Na}$, não temos o valor experimental para o deslocamento da energia de excitação. Porém o seu valor pode ser estimado [23,30], pois existem resultados para vários átomos alcalinos.

É interessante notar a separação em duas componentes que ocorre na linha $\mathrm{D}_{2}$. De acordo com a observação dos autores na referência [28], a linha $\mathrm{D}_{2}$ é muito larga para apresentar apenas uma transição. Devido à existência de uma distribuição 
Tabela 1.1: Resultados espectroscópicos [28] para a transição 5s-5p do Rb como: valor da energia de excitação do $\mathrm{Rb}$ isolado, o deslocamento espectral em ambiente de He líquido e largura da linha (HWHM).

\begin{tabular}{cccc}
\hline \hline Linha & Isolado(nm) & Deslocamento(nm) & HWHM(nm) \\
\hline $\mathrm{D}_{1}$ & 794,76 & $-16,8 \pm 0,5$ & $4,0 \pm 0,5$ \\
\hline \multirow{2}{*}{$\mathrm{D}_{2}$} & 780,03 & $-16,0 \pm 0,5$ & $3,0 \pm 0,5$ \\
& & $-24,0 \pm 0,5$ & $8,0 \pm 0,5$ \\
\hline média & 787,34 & $-18,9$ & 5,0 \\
\hline \hline
\end{tabular}

Tabela 1.2: Resultados espectroscópicos [28] para a transição 6s-6p do Cs como: valor da energia de excitação do Cs isolado, o deslocamento espectral em ambiente de He líquido e largura da linha (HWHM).

\begin{tabular}{cccc}
\hline \hline Linha & Isolado(nm) & Deslocamento(nm) & HWHM(nm) \\
\hline $\mathrm{D}_{1}$ & 894,35 & $-18,4 \pm 0,5$ & $5,5 \pm 0,5$ \\
\hline \multirow{2}{*}{$\mathrm{D}_{2}$} & 852,11 & $-18,1 \pm 0,5$ & $2,8 \pm 0,5$ \\
& & $-30,1 \pm 0,5$ & $8,0 \pm 0,5$ \\
\hline \multirow{2}{*}{ média } & 866,19 & $-22,2$ & 5,4 \\
\hline \hline
\end{tabular}

anisotrópica dos átomos de He que envolvem a impureza, ocorre uma quebra da degenerescência do subnível $P_{3 / 2}$. Diversos autores citam esse fenômeno como efeito Jahn-Teller Dinâmico [28], devido à semelhança com o efeito Jahn-Teller nas moléculas. Resumidamente, esse efeito diz que não é possível conciliar no mesmo sistema degenerescência e estabilidade em moléculas não lineares. 


\section{Capítulo 2}

\section{Simulações Clássicas}

Ao trabalhar com simulações clássicas de moléculas, dois métodos são muitos utilizados: Dinâmica Molecular (DM) e Monte Carlo (MC). Dinâmica molecular consiste em resolver as equações de Newton para intervalos de tempo discretizados em todos os átomos do sistema. Usando de um potencial conhecido, as forças que atuam em cada átomo são calculadas e assim, é possível obter posições e velocidades de todos os átomos em tempos seguintes. Sendo um processo determinístico, é possível estudar propriedades que dependam da evolução temporal do sistema.

Já no método $\mathrm{MC}$, não usamos informações das velocidades de cada um dos átomos e de propriedades que dependam da evolução temporal. Na síntese, a simulação via $\mathrm{MC}$ é um processo no qual as propriedades de interesse são obtidas com médias de diferentes estados configuracionais acessíveis no equilíbrio termodinâmico. A idéia do MC nasceu no século XVIII, porém foi com o surgimento de grandes computadores e do interesse em obter previsões sobre fissão nuclear para fabricação da bomba atômica no período da Segunda Guerra Mundial [31], que a metodologia ganhou um grande impulso. 


\subsection{Monte Carlo}

Detalhes sobre o método MC e do algoritmo de Metropolis podem ser encontrados nas referências [31,32]. Apresentaremos somente um resumo dos tópicos mais importantes aplicados em nosso trabalho e algumas ferramentas usadas para análise de resultados. Para realização das simulações clássicas, usamos o programa DICE [33].

Na simulação $\mathrm{MC}$, as propriedades de interesse são obtidas com médias configuracionais do sistema em equilíbrio termodinâmico. Para o cálculo da média, deve-se ponderar cada valor calculado com um peso associado. Sendo um processo estocástico, a evolução temporal do sistema não é considerada, perdendo informações interessantes, como a velocidade de cada partícula em função do tempo de simulação. Como estamos interessados em obter médias configuracionais para cálculos de MQ posteriores, dados sobre as velocidades dos átomos ou moléculas não são necessários.

Inicialmente são colocados $N$ átomos de forma aleatória numa caixa cúbica de volume não fixo, respeitando a densidade inicial. Para evitar problemas com as bordas da caixa de simulação, são geradas caixas em todas as direções, todas imagens da caixa central. Caso um átomo saia da caixa central, o mesmo será substituído por um átomo da caixa imagem da face oposta e desse modo são reproduzidas as condições de contorno, nas quais será mantido o número de átomos na caixa central. Além do número de átomos, são mantidas constantes a pressão $p$ e a temperatura $T$. Ao fixar essas constantes, estamos trabalhando num ensemble $N p T$, ou ensemble isotérmico-isobárico. Neste caso, a variação da energia será dada por

$$
\Delta \mathcal{H}=\Delta U+p \Delta V+N \ln \left(\frac{V_{y \prime}}{V_{y}}\right),
$$

onde $\Delta V$ é a variação do volume de forma que $\Delta V=V_{y^{\prime}}-V_{y}$. 
Para reduzir a quantidade de cálculos, o potencial é calculado até um limite de distância, chamado raio de corte $\left(r_{c u t}\right)$. Correções no valor da energia potencial podem ser adicionadas para compensar a parte eliminada da interação de dois átomos com distância acima do $r_{c u t}$.

Partindo de uma configuração inicial, são geradas configurações de um sistema modificando a posição de uma partícula por um movimento aleatório, tanto em módulo como em direção, de valor máximo igual a um $\delta_{m x}$. Este valor não pode ser muito grande, pois poderia causar a sobreposição de dois átomos. Em contrapartida, não pode ser demasiadamente pequeno, pois não estaríamos gerando flutuações suficientes para considerar novos estados, além de um alto grau de correlação das configurações. Normalmente, o valor de $\delta_{m x}$ é modificado automaticamente para manter um valor de aceitação de novas configurações igual a 50\%.

A cada configuração estará associado um valor de energia e assim a um peso de Boltzmann, a partir do equilíbrio. Sendo um processo markoviano [34], a probabilidade de um evento ocorrer depende apenas do evento anterior. Da mecânica estatística, a probabilidade associada a um estado é

$$
P_{o}(y)=\frac{1}{Z} \exp \left(-\frac{\mathcal{H}(y)}{K_{B} T}\right),
$$

onde $Z$ é a função de partição. No equilíbrio, a condição de balanço detalhado impõe que a probabilidade de mudar de configuração $\left(y \rightarrow y^{\prime}\right)$ não depende do tempo [34]. Aplicando-se esta condição na equação mestra, a transição será dada por

$$
\frac{w\left(y \rightarrow y^{\prime}\right)}{w\left(y^{\prime} \rightarrow y\right)}=\exp \left(-\frac{\Delta \mathcal{H}}{K_{B} T}\right)
$$

onde $\Delta \mathcal{H}$ é a diferença de energia $\mathcal{H}\left(y^{\prime}\right)-\mathcal{H}(y)$.

Usando o algoritmo de Metropolis, a probabilidade de uma configuração mu- 
dar de y para y' é dada por

$$
w\left(y \rightarrow y^{\prime}\right)=\left\{\begin{array}{cl}
\exp \left(-\frac{\Delta \mathcal{H}}{K_{B} T}\right) & \text { se } \quad \Delta \mathcal{H}>0 \\
1 & \text { se } \Delta \mathcal{H} \leq 0
\end{array}\right.
$$

Na prática, sempre aceitamos a nova configuração quando $\Delta \mathcal{H} \leq 0$. No outro caso, selecionamos um número aleatório $\zeta$. Se $\zeta$ for menor que $w\left(y \rightarrow y^{\prime}\right)$, a nova configuração será aceita. Assim, um passo de MC é definido como a tentativa de mudar a posição de $N$ átomos.

\subsection{Potencial de Interação}

Uma dos pontos mais importantes nas simulações é a descrição da interação entre os átomos. A escolha de um potencial leva em conta vários fatores como as propriedades de interesse a serem obtidas, custo computacional e o nível de aproximações. Desta forma, os potenciais podem ser construídos a partir de parâmetros experimentais ou cálculos ab-initio ou ainda uma mistura dos dois. Como cálculos ab-initio são bastante demorados para serem repetidos em todos os ciclos de $\mathrm{MC}, \mathrm{o}$ uso de potenciais parametrizados é de grande utilidade para simulações clássicas.

No nosso caso, não há nenhum campo externo atuando nos átomos e o potencial possui apenas termos de interação entre os átomos. Esta interação pode conter termos de potencial de dois corpos, potencial de três corpos, e assim sucessivamente. Entretanto, a contribuição energética de potenciais de três ou mais corpos é muito pequena comparada ao potencial de dois corpos para sistemas líquidos [32].

Apesar de existirem diversos potenciais para a interação tanto do He-He [35] quanto dos átomos alcalinos-He [36-38], decidimos usar o potencial de LennardJones (LJ), o qual é frequentemente utilizado. Ainda que originalmente proposto para descrever gases ideais, o potencial de LJ vem sendo usado com bastante sucesso 
na descrição de líquidos $[23,25,26]$. A parte atrativa do potencial para sistemas não carregados é dada pelo termo $r_{i j}^{-6}$, proveniente da interação de dispersão de van der Waals. A forma do potencial LJ é

$$
U\left(r_{i j}\right)=4 \epsilon_{i j}\left[\left(\frac{\sigma_{i j}}{r_{i j}}\right)^{12}-\left(\frac{\sigma_{i j}}{r_{i j}}\right)^{6}\right],
$$

onde $r_{i j}$ é a distância entre os átomos $i$ e $j$. Os termos $\epsilon_{i j}$ e $\sigma_{i j}$ são obtidos, neste trabalho, a partir das médias geométricas dos parâmetros de cada átomo $\epsilon_{i}, \epsilon_{j}, \sigma_{i} \mathrm{e}$ $\sigma_{j}$. Como estamos tratando apenas átomos, os parâmetros $\epsilon_{x}$ e $\sigma_{x}$ são a energia de ligação e a distância para energia potencial zero respectivamente. Os parâmetros do potencial são, neste trabalho, baseados em modelos avançados no tratamento da interação He-He e átomos alcalinos-He. Mais informações sobre esses potenciais serão apresentadas ao tratarmos a simulação do sistema líquido nas seções $5.1 \mathrm{e} 5.2$ Como usamos apenas a interação entre os pares, a energia potencial total do sistema é

$$
U(\mathbf{r})=\sum_{i=1}^{N-1} \sum_{j<i}^{N} U\left(r_{i j}\right),
$$

onde a restrição $j<i$ evita a soma de pares $U\left(r_{i j}\right)$ repetidos.

\subsection{Ferramentas para Análise de Resultados}

\subsubsection{Função de Distribuição Radial}

A função de distribuição radial $(G(r))$ ou função de correlação de pares, fornece a distribuição média de átomos em função da distância radial $r$, a partir de uma origem pré-estabelecida. No nosso caso, a origem é o centro de massa do soluto e teremos assim, a distribuição de átomos de He em torno deste mesmo soluto. Através de $G(r)$ podemos obter, por exemplo, o fator de estrutura estático. Experimentalmente, a função $G(r)$ pode ser medida através de em experimento de difração 
de raios-X e nêutrons, e espalhamento de raios-X. Nos sólidos tal difração permitenos obter os picos de Bragg, devido ao arranjo regular e ordenado dos átomos, no entanto nos fluidos a difração é difusa, mostrando a não existência de um arranjo ordenado de longo alcance.

Para obter a $G(r)$, deve-se integrar a função de distribuição radial sobre a posição de todos os átomos, exceto os dois $\vec{r}_{1}$ e $\vec{r}_{2}$, nos quais está sendo calculada a $G(r)$ [31]. Com o fator de normalização adequado, temos a seguinte expressão

$$
G\left(\vec{r}_{1}, \vec{r}_{2}\right)=\frac{N(N-1)}{\rho^{2} Z_{N V T}} \int d \vec{r}_{3} d \vec{r}_{4} d \vec{r}_{5} \ldots d \vec{r}_{N} e^{-\beta U\left(\vec{r}_{1}, \vec{r}_{2}, \vec{r}_{3} \ldots \vec{r}_{N}\right)},
$$

onde $Z_{N V T}$ é a integral configuracional no ensemble canônico. Uma forma equivalente muito usada no cálculo de $G(r)$, por simulação computacional, é tomar a média no ensemble sobre os pares

$$
G(r)=\rho^{2}\left\langle\sum_{i} \sum_{j \neq i} \delta\left(\vec{r}_{i}\right) \delta\left(\vec{r}_{j}-\vec{r}\right)\right\rangle=\frac{V}{N^{2}}\left\langle\sum_{i} \sum_{j \neq i} \delta\left(\vec{r}-\vec{r}_{i j}\right)\right\rangle .
$$

Sendo $\rho$ a densidade, o número médio de átomos do solvente a uma distância $r$ do centro de massa do soluto pode ser expressa por

$$
N(r)=4 \pi \rho \int_{0}^{r} r^{2} G(r) d r
$$

Obtendo o valor de $N(r)$ para o primeiro vale da $G(r)$ teremos o número de átomos na primeira camada de solvatação. O mesmo processo pode ser realizado para os picos subsequentes, obtendo-se as camadas de solvatação correspondentes.

\subsubsection{Auto-Correlação da Energia}

A simulação clássica irá gerar um número muito grande de configurações, da ordem de $10^{5}$ neste trabalho. Obter a média de uma determinada propriedade com cálculos de MQ usando esse número de configurações seria um exagero computacional, pois a média sobre centenas de configurações sucessivas geradas por MC é 
igual a média sobre algumas configurações estatisticamente descorrelacionadas [39]. Consequentemente, é suficiente selecionar poucas configurações descorrelacionadas e realizar cálculos de MQ sobre essas configurações.

Para obter a correlação estatística das configurações do sistema, usamos a função de auto-correlação da energia, a qual é definida com a seguinte expressão

$$
C(i)=\frac{\left\langle\delta E_{n} \delta E_{i+n}\right\rangle}{\left\langle\delta E^{2}\right\rangle}=\frac{\sum_{n}\left(E_{n}-\langle E\rangle\right)\left(E_{n+i}-\langle E\rangle\right)}{\sum_{n}\left(E_{n}-\langle E\rangle\right)^{2}} .
$$

Realizada a simulação clássica, obtemos o valor da função de auto-correlação em função da quantidade de passos de simulação $(C(i))$. Uma forma de analisar o nível de correlação estatística das configurações geradas na simulação é usar o intervalo de correlação, que é uma propriedade da simulação, no qual se estima um valor de passos de MC onde as configurações estarão em média descorrelacionadas. Como $C(i)$ obedece a um decaimento exponencial para processos markovianos [32, 40], é necessário ajustar os dados da correlação com uma função exponencial de decaimento de duplo,

$$
C(i)=a_{1} e^{-i / t_{1}}+a_{2} e^{-i / t_{2}}
$$

Somente com um número infinito de configurações teremos o valor de $C(n)$ tendendo a zero, ou seja, configurações descorrelacionadas. Integrando a expressão acima obtém-se o intervalo de correlação

$$
\tau=\int_{0}^{\infty} C_{f}(i) d i=a_{1} t_{1}+a_{2} t_{2}
$$

Em geral, trabalhamos com $2 \tau$. Espera-se que $C(2 \tau)$ seja menor ou igual a 0,15 . Assim, consideramos que as configurações estão descorrelacionadas. 


\section{Capítulo 3}

\section{Cálculos por Mecânica Quântica}

Para uma descrição da estrutura eletrônica, em átomos e moléculas, énecessário o uso de métodos baseados em MQำ Para isso, precisamos resolver a equação de Schrödinger,

$$
\mathcal{H} \Psi(r, R)=E \Psi(r, R)
$$

Sabemos que existe solução exata para a equação de Schrödinger no caso do átomo de Hidrogênio, porém para outros átomos e moléculas são necessárias algumas aproximações. O operador hamiltoniano não-relativístico, em unidades atômicas, para o sistema de $N$ átomos e $n$ elétrons é

$$
\mathcal{H}=-\sum_{i=1}^{n} \frac{1}{2} \nabla_{i}^{2}-\sum_{A=1}^{N} \frac{1}{2 M_{A}} \nabla_{A}^{2}-\sum_{i=1}^{n} \sum_{A=1}^{N} \frac{Z_{A}}{r_{i A}}+\frac{1}{2} \sum_{i, j}^{n} \frac{1}{r_{i j}}+\frac{1}{2} \sum_{A, B}^{N} \frac{Z_{A} Z_{B}}{r_{A B}}
$$

onde os índices minúsculos e maiúsculos referenciam os elétrons e os núcleos, respectivamente. Algumas aproximações são necessárias para resolver a equação de Schrödinger independente do tempo desses sistemas moleculares. Considerando a aproximação adiabática [42], vamos separar a função de onda total em uma função de onda eletrônica e uma função de onda nuclear na forma

$$
\Psi(r, R)=\phi_{i}(r ; R) \chi_{i}(R),
$$

\footnotetext{
${ }^{1}$ Os cálculos de MQ aqui presentes foram realizados com o programa Gaussian 03 [41].
} 
e assim, os elétrons ficam movimentando-se sobre os núcleos fixos. Com o desacoplamento dos núcleos e dos elétrons, podemos tratar os espectros eletrônico e nuclear de forma separada. Esta separação é conhecida como aproximação de Born-Oppenheimer (BO) [43].

O operador hamiltoniano eletrônico é

$$
\mathcal{H}_{\text {ele }}=\left[-\frac{1}{2} \sum_{i=1}^{n} \nabla_{i}^{2}-\sum_{i=1}^{n} \sum_{A=1}^{N} \frac{Z_{A}}{r_{i A}}+\sum_{i>j}^{n} \frac{1}{r_{i j}}\right] .
$$

Para um sistema de $n$ elétrons, a função de onda eletrônica anti-simétrica de camada fechada, satisfazendo o princípio de exclusão de Pauli, é aproximada por um determinante de Slater

$$
\psi=\frac{1}{\sqrt{n !}}\left|\begin{array}{cccc}
\varphi_{1}(1) & \varphi_{1}(2) & \ldots & \varphi_{1}(n) \\
\varphi_{2}(1) & \varphi_{2}(2) & \ldots & \varphi_{2}(n) \\
\vdots & \vdots & \ddots & \vdots \\
\varphi_{n}(1) & \varphi_{n}(2) & \ldots & \varphi_{n}(n)
\end{array}\right|
$$

onde $\varphi_{n}(n)$ são os spin-orbitais eletrônicos. A energia eletrônica usando a aproximação de BO será dada por [42-45]:

$$
E_{\text {ele }}=\sum_{i=1}^{n}\left\langle\varphi_{i}\left|\left[\frac{-\nabla^{2}}{2}-\sum_{A=1}^{N} \frac{Z_{A}}{\left|r_{A}-r_{i}\right|}\right]\right| \varphi_{i}\right\rangle+\frac{1}{2} \sum_{i, j}^{n}\left[\left\langle\varphi_{j}\left|\mathbf{J}_{i}\right| \varphi_{j}\right\rangle-\left\langle\varphi_{j}\left|\mathbf{K}_{i}\right| \varphi_{j}\right\rangle\right]
$$

onde temos os operadores de dois elétrons, $\mathcal{J}$ e $\mathcal{K}$. A representação da repulsão clássica entre dois elétrons é dada pelo operador de Coulomb,

$$
\mathbf{J}_{i}\left|\varphi_{j}(2)\right\rangle=\left\langle\varphi_{i}(1)\left|\frac{1}{\left|r_{1}-r_{2}\right|}\right| \varphi_{i}(1)\right\rangle\left|\varphi_{j}(2)\right\rangle
$$

Um termo remanescente, que não possui análogo clássico, é o operador de troca,

$$
\mathbf{K}_{i}\left|\varphi_{j}(2)\right\rangle=\left\langle\varphi_{i}(1)\left|\frac{1}{\left|r_{1}-r_{2}\right|}\right| \varphi_{j}(1)\right\rangle\left|\varphi_{i}(2)\right\rangle .
$$


Este procedimento é básico para o desenvolvimento do método Hartree-Fock (HF).

No método HF, o elétron interage com o potencial gerado pelos núcleos e com o campo médio gerado pela distribuição dos outros elétrons, perdendo informações sobre a correlação eletrônica. A energia exata de um determinado problema é diferente da energia fornecida pelo método $\mathrm{HF}$, e a parte que está faltando é chamada de energia de correlação. Este termo é muito importante, quando queremos uma maior precisão em processos físicos e químicos e para obtê-lo é necessário recorrer a outros métodos, que considerem a correlação do sistema.

\subsection{Método Coupled Cluster}

Devido à falta de uma descrição da energia de correlação com o método HF, outros métodos devem ser empregados. Um deles é o coupled cluster (CC), que como o próprio nome diz, trabalha com aglomerados acoplados. O desenvolvimento do método para átomos e moléculas começou em 1966 por Cízek [46,47] e no final da década de 70 já havia sido implementado para o estudo de sistemas realistas [45].

Seja $|\psi\rangle$ a função de onda exata no estado fundamental e $\left|\varphi_{0}\right\rangle$ a função de onda do estado fundamental do método HF, temos

$$
|\psi\rangle=e^{\mathcal{T}}\left|\varphi_{0}\right\rangle,
$$

onde o operador de cluster $\mathcal{T}$ é dado por

$$
\mathcal{T}=\mathcal{T}_{1}+\mathcal{T}_{2}+\ldots+\mathcal{T}_{n}
$$

gerando estados excitados. O operador $\mathcal{T}_{1}$ cria uma combinação de estados com um elétron excitado,

$$
\mathcal{T}_{1} \Phi_{0}=\sum_{i, a} C_{i}^{a} \Phi_{i}^{a}
$$


e o operador $\mathcal{T}_{2}$ gera uma combinação de estados com dois elétrons excitados,

$$
\mathcal{T}_{2} \Phi_{0}=\sum_{i j, a b} C_{i j}^{a b} \Phi_{i j}^{a b}
$$

Da mesma forma, esse processo é efetuado para os outros operadores $\mathcal{T}_{\chi}$ até a ordem de interesse. Na notação usada, os orbitais indicados por $i, j, \ldots$, etc. estão ocupados e os orbitais indicados por $a, b, \ldots$, etc. são virtuais. Na excitação, ocorre a substituição do spin-orbital ocupado $\varphi_{i}$ pelo spin-orbital virtual $\varphi_{a}$. Os valores dos coeficientes $C$ (isto é, $C_{i}^{a}, C_{i j}^{a b}, \ldots$ ) são obtidos quando for satisfeita $|\psi\rangle$, como solução da equação de Schrödinger,

$$
\mathcal{H}|\psi\rangle=\mathcal{H} e^{\mathcal{T}}\left|\varphi_{0}\right\rangle=E e^{\mathcal{T}}\left|\varphi_{0}\right\rangle,
$$

onde devemos multiplicar por $e^{-\mathcal{T}}$ e usar a expansão de Campbel-Hausdorf [42].

Fazendo uma expansão da função exponencial,

$$
e^{x}=\sum_{k=0}^{\infty} \frac{x^{k}}{k !}=1+x+\frac{x^{2}}{2 !}+\frac{x^{3}}{3 !}+\frac{x^{4}}{4 !}+\cdots,
$$

$\operatorname{com} x$ igual a $\mathcal{T}$ então, podemos associar os juntar de excitação com relação à ordem e assim obtemos:

$$
\begin{aligned}
x & =\mathcal{T}_{1} \\
x^{2} & =\mathcal{T}_{2}+\frac{1}{2 !} \mathcal{T}_{1}^{2} \\
x^{3} & =\mathcal{T}_{3}+\frac{1}{3 !} \mathcal{T}_{1}^{3}+\mathcal{T}_{1} \mathcal{T}_{2} .
\end{aligned}
$$

É conveniente notar que alguns termos da excitação de determinada ordem podem ser gerados pela associação de operadores $\mathcal{T}$ de ordem inferior, como na excitação de $3^{\text {a }}$ ordem que possui os termos $\mathcal{T}_{3}, \mathcal{T}_{2}$ e $\mathcal{T}_{1}$

A contribuição mais importante de $\mathcal{T}$ é o termo $\mathcal{T}_{2}$, justificado pelo Teorema de Brillouin [45], e é a partir deste termo que será acrescentada a contribuição da 
correlação [42]. De modo geral, o número de operadores $\mathcal{T}_{i}$ é truncado para um número pequeno, mas a contribuição de excitações mais altas ainda é considerada pela presença de alguns operadores de cluster.

Dentre as aproximações, usamos o $\operatorname{CCSD}(\mathrm{T})$, que significa coupled cluster com excitações simples, duplas e com teoria de perturbação de muitos corpos para contribuições dos estados triplamente excitados [45]. Neste processo, o operador de cluster é truncado até o segundo termo,

$$
\mathcal{T}=\mathcal{T}_{1}+\mathcal{T}_{2}
$$

Computacionalmente, CCSD (apenas excitações simples e duplas) custaria $\mathrm{N}^{6}$, com $\mathrm{N}$ sendo o número de funções do conjunto de bases. Um método mais completo, CCSDT (excitações simples, duplas e triplas) custaria $\mathrm{N}^{8}$. Usando o CCSD(T), temos um custo $\mathrm{N}^{7}$, o que é um bom ganho sem uma grande perda de qualidade [48].

\subsection{Teoria do Funcional da Densidade}

A Teoria do Funcional da Densidade (DFT, do inglês Density Functional Theory) é um dos métodos de química quântica de maior utilização atualmente, devido ao seu baixo custo computacional e boa concordância com valores experimentais. Com a qual, é possível estudar sistemas com dezenas ou centenas de átomos, que são muito difíceis de tratar com métodos como CC.

Na década de 20, o modelo para o estudo de metais propunha que os elétrons de valência não estariam confinados aos átomos de origem na rede metálica. Ao definir que todo o sistema era coberto por um gás de elétrons [49], existia apenas uma função capaz de dar uma idéia de distribuição dos elétrons do sistema: a função densidade $\rho(\mathbf{r})$. A formulação foi desenvolvida por Thomas, Fermi e Dirac em 1930 e fornecia bons resultados, apesar das limitações geradas com as aproximações. Este trabalho é considerado um pré-desenvolvimento da DFT. 
Uma função $f(x)$ gera um número, a partir de um número, e um funcional $F[f]$ gera um número, a partir de uma função. Partindo do operador hamiltoniano eletrônico (ver eq. 3.4 na página 20), Slater (1951) propôs uma simplificação ao método $\mathrm{HF}$, a partir de uma análise no termo de troca [50], o qual depende exclusivamente de uma densidade de carga de exchange.

Hohenberg e Kohn, em 1964, formularam os teoremas fundamentais para a utilização da DFT [51]. Um dos teoremas diz que o potencial externo v(r) é funcional único da densidade eletrônica, $\rho(\mathbf{r})$, do estado fundamental. Nesse ponto aparece a unicidade da função de onda do estado fundamental com a densidade eletrônica, pois conhecendo $\rho(\mathbf{r})$ saberemos o potencial $v(\mathbf{r})$, e teremos acesso a todas as informações do estado fundamental do sistema.

O segundo teorema diz que a energia do estado fundamental, $E_{0}$, é mínima para a densidade exata, $\rho_{0}(\mathbf{r})$, e qualquer densidade eletrônica, $\rho^{\prime}$, diferente da exata, fornecerá um valor maior ou igual à energia exata $E_{0}$, isto é $E\left[\rho^{\prime}\right] \geq E_{o}=E\left[\rho_{0}\right]$. Este teorema nada mais é do que o teorema variacional para a energia como funcional de densidade eletrônica.

A energia, como funcional da densidade, é gerada a partir do hamiltoniano eletrônico, eq. 3.4. A proposta é escrever a energia como

$$
E_{D F T}[\rho]=T[\rho]+U_{n e}[\rho]+U_{e e}[\rho]
$$

com a energia cinética $(T[\rho])$, interação coulombiana núcleo-elétron $\left(U_{n e}[\rho]\right)$ e a interação elétron-elétron $\left(U_{e e}[\rho]\right)$. Porém, surgem alguns problemas em escrever alguns termos da eq. 3.17 como funcional de $\rho$. Uma forma de expressar a energia é colocar termos, que não podem ser escritos como funcional de $\rho$, no termo de energia de troca e correlação $E_{x c}[\rho]$. Dessa forma, a energia é escrita como

$$
E_{D F T}[\rho]=T_{S}[\rho]+J[\rho]+U_{n e}[\rho]+E_{x c}[\rho]
$$


onde o termo de troca e correlação é

$$
E_{x c}[\rho]=\left(T[\rho]-T_{S}[\rho]\right)+\left(U_{e e}[\rho]-J[\rho]\right)
$$

Observa-se na eq. 3.19, a contribuição da correlação da energia cinética no primeiro parêntesis, enquanto no segundo está presente o termo de troca e a correlação da energia potencial. Uma aproximação, para a expressão $E_{x c}$, consiste em separar os termos de troca e correlação

$$
E_{x c}[\rho]=E_{x}[\rho]+E_{c}[\rho]=\int \rho(\mathbf{r}) \varepsilon_{x}[\rho(\mathbf{r})] d \mathbf{r}+\int \rho(\mathbf{r}) \varepsilon_{c}[\rho(\mathbf{r})] d \mathbf{r}
$$

A interação coulombiana núcleo-elétron é

$$
U_{n e}[\rho]=\sum_{a} \int \frac{Z_{a} \rho(\mathbf{r})}{\left|\mathbf{R}_{a} \mathbf{r}\right|} d \mathbf{r} .
$$

Na interação elétron-elétron, o termo $U_{e e}[\rho]$ foi separado em um termo coulombiano $J[\rho]$ e outro de troca $K[\rho]$. O termo $K[\rho]$ está presente em $E_{x c}[\rho]$ e o coulombiano é

$$
J[\rho]=\frac{1}{2} \iint \frac{\rho(\mathbf{r}) \rho\left(\mathbf{r}^{\prime}\right)}{\left|\mathbf{r}-\mathbf{r}^{\prime}\right|} d \mathbf{r} d \mathbf{r}^{\prime}
$$

Uma contribuição muito importante de Kohn-Sham (KS), em 1965, é a mudança de um sistema de muitos corpos interativos em diversos sistemas de um corpo não-interativos $[42,43,45]$, onde a densidade eletrônica será a mesma tanto no sistema interagente quanto no sistema não interagente. Usando o mesmo procedimento do método HF para obter a função de onda anti-simétrica $\phi_{i}$, chegamos nas equações de KS

$$
\mathcal{H}_{K S} \phi_{i}=\left[-\frac{1}{2} \nabla^{2}+v^{K S}[\rho]\right] \phi_{i}=\varepsilon_{i} \phi_{i}
$$

Como a expressão para a energia cinética $T_{S}$ não é escrita como dependente diretamente da densidade

$$
T_{S}[\rho]=T_{S}\left[\left\{\varphi_{i}\right\}\right]=-\frac{1}{2} \sum_{i} \int \varphi_{i}^{*} \nabla^{2} \varphi_{i} d^{3} r,
$$


ela irá depender do conjunto de orbitais $\mathrm{KS} \varphi_{i}$, que são as soluções para o hamiltoniano $\mathcal{H}_{K S}$. O funcional da densidade eletrônica também depende do mesmo conjunto de orbitais $\varphi_{i}$, tal que

$$
\rho(\mathbf{r})=\sum_{i} \int \varphi_{i}^{*} \varphi_{i} d^{3} r
$$

Com a minimização da energia obtemos o potencial efetivo KS, presente também no hamiltoniano $\mathcal{H}_{K S}$, que é dado por

$$
v^{K S}[\rho]=v(\mathbf{r})+\int \frac{n\left(\mathbf{r}^{\prime}\right)}{\left|\mathbf{r}-\mathbf{r}^{\prime}\right|} d \mathbf{r}^{\prime}+\frac{\delta E_{x c}[\rho]}{\delta \rho(r)}(\mathbf{r}) .
$$

Desta forma, o próximo passo é trabalhar com o termo de troca e correlação $E_{x c}[\rho]$, tema da próxima seção.

Um modo de estudar a energia de excitação é o uso da TDDFT (Time-Dependent Density Functional Theory). O método foi proposto por Runge e Gross em 1984 [52], e é considerado uma aplicação da solução da equação de Schrödinger dependente do tempo para as equações de Kohn-Sham (eq. 3.26),

$$
i \frac{\partial}{\partial t} \phi_{i}(\mathbf{r}, t)=\mathcal{H}_{K S} \phi_{i}(\mathbf{r}, t) .
$$

O sucesso da TDDFT está associado a Teoria da Resposta Linear, na qual é aplicada uma perturbação na densidade eletrônica do estado fundamental. Essa perturbação está relacionada com as mudanças que ocorrem no potencial efetivo $v^{K S}[52,53]$.

\subsection{Aproximações no Termo $E_{x c}$}

\subsubsection{Funcionais Não-Híbridos}

Para a aplicação da DFT, em problemas de estrutura eletrônica, é necessário aproximar o funcional de troca e correlação. Aqui chegamos num ponto de grande importância para o uso da DFT, pois seus resultados dependem fortemente da aproximação utilizada. A primeira a ser comentada, e também a mais simples, é 
a LDA (Local Density Approximation), na qual se assume que, localmente, a função densidade $(\rho(\mathbf{r}))$ é aquela de um gás de elétrons uniforme sofrendo pouca mudança próximo ao ponto $\mathbf{r}$. A energia de troca é dada por

$$
E_{x}^{L D A}[\rho]=-C_{x} \int \rho^{4 / 3}(\mathbf{r}) d \mathbf{r} .
$$

No caso mais geral, onde as densidades de spins $\alpha$ e $\beta$ são diferentes, usa-se o LSDA (Local Spin Density Approximation) e a energia de troca é

$$
E_{x}^{L S D A}[\rho]=-2^{1 / 3} C_{x} \int\left[\rho_{\alpha}^{4 / 3}+\rho_{\beta}^{4 / 3}\right] d \mathbf{r} .
$$

Uma forma mais elaborada de aproximar a energia de troca e correlação é chamada GGA (Generalized Gradient Approximation), na qual a distribuição nãouniforme da densidade é mais bem tratada, pois, além da densidade eletrônica, os funcionais do tipo GGA trabalham com o gradiente da densidade. Um exemplo de funcional do tipo GGA é o PW86, introduzido por Perdew e Wang [54], que formularam o termo de troca, como

$$
\varepsilon_{x}^{P W 86}=\varepsilon_{x}^{L D A}\left[1+a x^{2}+b x^{4}+c x^{6}\right]^{1 / 15},
$$

onde $a, b$ e $c$ são constantes e $x$ é $\left(\frac{|\nabla \rho|}{\rho^{4 / 3}}\right)$.

A proposta de Becker [55] (B88) consiste em adicionar um termo para correção do comportamento assimptótico da densidade eletrônica. Sua expressão é

$$
\varepsilon_{x}^{B 88}=\varepsilon_{x}^{L D A}-\beta \rho^{1 / 3} \frac{x^{2}}{1+6 \beta x \sinh ^{-1} x}
$$

onde $\beta$ é definido por um ajuste em dados atômicos e $x$ é $\left(\frac{|\nabla \rho|}{\rho^{4 / 3}}\right)$.

Para a energia de correlação, existe o termo VWN [56], onde mais detalhes podem ser visto na referência [45]. Uma modificação neste termo foi proposta por Perdew e Wang, chamado de PW91 [57]. Apesar de tratar a densidade eletrônica 
localmente de forma homogênea, essas aproximações funcionam muito bem para átomos, moléculas e sólidos.

Outro funcional, bem conhecido para tratar a correlação, é o de Lee, Yang e Parr (LYP) [58,59], com a seguinte forma

$$
\begin{aligned}
\varepsilon_{c}^{L Y P}= & -a \frac{\gamma}{1+f \rho^{1 / 3}}-a b \frac{\gamma e^{c \rho^{1 / 3}}}{9\left(1+d \rho^{1 / 3}\right) \rho^{8 / 3}}\left[1 8 ( 2 ^ { 2 / 3 } ) C _ { F } \left(\rho_{\alpha}^{8 / 3}+\right.\right. \\
& \left.\left.\rho_{\beta}^{8 / 3}\right)-18 \rho t_{W}+\rho_{\alpha}\left(2 t_{W}^{\alpha}+\nabla^{2} \rho_{\alpha}\right)+\rho_{\beta}\left(2 t_{W}^{\beta}+\nabla^{2} \rho_{\beta}\right)\right] \\
\gamma= & 2\left[1-\frac{\rho_{\alpha}^{2}+\rho_{\beta}^{2}}{\rho^{2}}\right] \\
t_{W}^{\sigma}= & \frac{1}{8}\left(\frac{\left|\nabla \rho_{\sigma}\right|^{2}}{\rho_{\sigma}}-\nabla^{2} \rho_{\sigma}\right),
\end{aligned}
$$

onde $a, b, c$ e $f$ são parâmetros calculados em um ajuste em um conjunto de moléculas [45].

Perdew também propôs uma correção para o funcional de correlação (P86) [60]

$$
\begin{aligned}
\varepsilon_{c}^{P 86} & =\varepsilon_{c}^{L D A}+\frac{e^{\Phi} C(\rho)|\nabla \rho|^{2}}{f(\zeta) \rho^{7 / 3}} \\
f(\zeta) & =2^{1 / 3}\left[\left(\frac{1+\zeta}{2}\right)^{5 / 3}+\left(\frac{1-\zeta}{2}\right)^{5 / 3}\right] \\
\Phi & =a \frac{C(\infty)|\nabla \rho|}{C(\rho) \rho^{7 / 6}} \\
C(\rho) & =\Upsilon_{1}+\frac{\Upsilon_{2}+\Upsilon_{3} r_{S}+\Upsilon_{4} r_{S}^{2}}{1+\Upsilon_{5} r_{S}+\Upsilon_{6} r_{S}^{2}+\Upsilon_{7} r_{S}^{3}},
\end{aligned}
$$

onde $a$ e $\Upsilon_{1-7}$ são constantes e $r_{S}=\left(\frac{3}{4 \pi \rho}\right)^{1 / 3}$.

Outra aproximação, do tipo GGA, foi proposta por Perdew, Burke e Ernzerhof que originou a aproximação PBE [61]. Comparando com o PW91, essa aproximação inclui uma descrição mais detalhada da resposta linear de um gás de elétrons uni- 
forme suavizando o potencial. Para o termo de troca e correlação, temos

$$
E_{x c}^{P B E}[\rho]=-\frac{3 e^{2} k_{F}}{4 \pi} \int \rho(\mathbf{r})\left[1+\kappa-\frac{\kappa}{1+\frac{\mu s^{2}}{\kappa}}\right] d \mathbf{r},
$$

onde $s=\left(\frac{|\nabla \rho|}{2 \rho k_{F}}\right) \cdot \kappa$ e $\mu$ são parâmetros.

\subsubsection{Funcionais Híbridos}

Funcionais híbridos são funcionais que misturam termos de diferentes aproximações, tanto para troca quanto para correlação. Definidos os termos a serem usados, o valor da contribuição de cada um será obtido por um ajuste com alguns resultados experimentais conhecidos, como no caso do B3LYP e seus derivados.

O funcional híbrido B3LYP usa a aproximação LYP na correlação não local. Para a correlação local é usado a aproximação VWN. A contribuição de cada termo que compõe a energia de troca é de 20\% do HF e 80\% de Dirac-Slater. Para a energia de troca não local, o funcional B3LYP usa uma porcentagem da aproximação B88. De todos os modernos funcionais, o B3LYP é o mais famoso.

$$
E_{x c}^{B 3 L Y P}=0,2 * X_{H F}+0,8 * X_{L S D A}+0,72 * X_{N L}^{B 88}+0,19 * C_{L}^{V W N}+0,81 * C_{N L}^{L Y P} .
$$

O funcional híbrido BHandHLYP usa os mesmos funcionais de troca e correlação do B3LYP e ainda complementa metade da contribuição de troca com o termo proveniente do método HF. B3P86 possui o mesmo valor da contribuição de troca proveniente do HF do funcional B3LYP, ou seja, 20\%, porém usa o funcional de correlação P86.

Comparando com o funcional B3LYP, o funcional híbrido O3LYP modifica o valor da contribuição do termo de troca de HF e consequentemente o valor do termo de troca de Slater-Dirac [62]. Outra mudança interessante é a substituição do termo de troca não local de B88 pelo OPTX [63]. Há também uma mudança do termo 
de correlação local, que era o VWN e passa a ser o VWM5 [56]. A expressão do funcional O3LYP é

$$
E_{x c}^{O 3 L Y P}=0,1161 * X_{H F}+0,9262 * X_{D S}+0,8133 * X_{N L}^{O P T}+0,19 * C_{L}^{V W N 5}+0,81 * C_{N L}^{L Y P}
$$

O funcional híbrido PBE1PBE, também chamado de PBE0, adiciona 25\% da troca de HF. Como usa a aproximação PBE para a energia de troca e correlação, não utiliza outros termos além do termo $E_{x c}^{P B E}$ e o termo de troca de HF. A expressão para o funcional híbrido PBE1PBE é

$$
E_{x c}^{P B E 1 P B E}=0,25 * X_{H F}+X C^{P B E}
$$

Não sendo derivado do funcional B3LYP, o funcional PBE1PBE não possui parâmetros ajustados de um conjunto de moléculas.

\subsection{Conjuntos de Bases}

Vários métodos de química teórica usam conjuntos de bases atômicas ou apenas base ${ }^{2}$ para o estudo de moléculas e átomos. Essas bases são funções matemáticas que descrevem os orbitais, como aqueles usados na formulação de HF, provenientes do uso da equação de Schrödinger para resolver o problema eletrônico. Os conjuntos de bases devem apresentar resultados compatíveis com os valores experimentais, contendo uma quantidade expressiva de funções para uma melhor descrição do átomo em questão, porém o número de funções não pode ser demasiadamente grande ao ponto de prejudicar a eficiência computacional.

Um dos primeiros conjuntos de bases utilizados foi baseado nas funções hidrogenóides, já que são as soluções exatas para os sistemas mono-eletrônicos. Neste caso tem-se um potencial na forma $V=-Z / r$. Porém, estes tipos de bases possuem

\footnotetext{
${ }^{2}$ Para facilitar a nomeclatura, vamos chamar uma base de um conjunto de bases.
} 
limitações muito claras, aplicadas apenas em átomos de 1 elétron. Outro conjuntos de bases usados, para compensar tal falha, são as que possuem funções de Slater, que tem a forma parecida com as funções hidrogenóides. Neste caso, o potencial é $V=-\zeta n / r+[n(n-1)-l(l+1)] /\left(2 r^{2}\right)[45]$. A expressão da função de Slater é

$$
\chi_{\zeta, n, l, m}(r, \theta, \phi)=N Y_{l m}(\theta, \phi) r^{n-1} e^{-\zeta r}
$$

onde $Y_{l m}(\theta, \phi)$ são os harmônicos esféricos e $N$ é um fator de normalização.

Um tipo de funções muito usadas nas bases, para o estudo de sistemas moleculares, são as funções do tipo gaussianas. A vantagem do uso de funções gaussianas é que o produto de duas gaussianas centradas em pontos diferentes é igual a uma gaussiana centrada em um ponto intermediário. Assim, as integrais de três e quatro centros são reduzidas para integrais de dois centros [43], facilitando muito o trabalho com esse tipo de função.

As funções gaussianas, em coordenadas esféricas, possuem a seguinte forma

$$
\chi_{\zeta, n, l, m}(r, \theta, \phi)=N Y_{l m}(\theta, \phi) r^{2 n-2-l} e^{-\zeta r^{2}}
$$

onde $Y_{l m}(\theta, \phi)$ são harmônicos esféricos e $N$ é o fator de normalização.

Em coordenadas cartesianas, uma função gaussiana tem a seguinte forma

$$
\chi_{\zeta, l_{x}, l_{y}, l_{z}}(x, y, z)=N x^{l_{x}} y^{l_{y}} z^{l_{z}} e^{-\zeta r^{2}}
$$

$\operatorname{com} l_{x}+l_{y}+l_{z}$ igual ao momento angular $l$. Um ponto interessante ocorre para funções do tipo $d$ e superiores. Usando como exemplo as funções do tipo $d$, verifica-se que com as coordenadas cartesianas são geradas 6 funções diferentes: $x^{2}, y^{2}, z^{2}, x y, z x$ e $y z$ para $l_{x}+l_{y}+l_{z}=2$. Usando coordenadas esféricas, 5 funções do tipo $d$ diferentes são geradas: $Y_{2,-2}, Y_{2,-1}, Y_{2,0}, Y_{2,1}$ e $Y_{2,2}$. Uma análise mais detalhada mostra que há uma combinação linear das funções do tipo $d$ em coordenadas cartesianas que é na verdade uma função do tipo s. 
A base que descreve um átomo é formada por uma combinação linear de funções que representam os orbitais,

$$
\phi_{i}=\sum_{k=1}^{m} C_{i k} \chi_{k}
$$

e alguns parâmetros devem ser ajustados pelo método variacional. Sendo a energia eletrônica igual a

$$
\langle E\rangle=\frac{\langle\Psi|\mathcal{H}| \Psi\rangle}{\langle\Psi \mid \Psi\rangle}
$$

e dada qualquer função de onda aproximada $(\Psi)$, a energia correspondente sempre será maior ou igual à energia exata.

As bases podem ser obtidas a princípio para átomos neutros, descrevendo muito bem os orbitais ocupados. Para o estudo de propriedades em estados excitados, é necessário a adição de funções para os orbitais virtuais. Acontece que os orbitais atômicos sofrem certas deformações, dependendo do meio que estão presentes. Uma tentativa de expandir a utilização de funções de base atômicas é a adição de funções complementares. Duas funções adicionais interessantes são:

- funções polarizadas - para orbitais deformados pela presença de outros orbitais, melhorando a descrição do átomo quando estiver presente em uma molécula.

- funções difusas - aumentam a quantidade dos mesmos tipos de orbitais nas bases, na tentativa de uma melhor descrição na região de valência.

Os orbitais mais internos pouco contribuem para algumas propriedades químicas [45], além de sofrer pouca influência quando tratamos o átomo em uma molécula ou em um condensado. Outro ponto é que átomos de grande número atômico sofrem efeitos relativísticos. Uma forma de resolver esses problemas é usar um potencial para descrever os elétrons do caroço do átomo, chamado de ECP (Effective Core Potencial) ou também de pseudopotencial [45]. Neste processo, apenas 
os elétrons de valência são tratados explicitamente. Os operadores de troca e correlação, de dois corpos da interação dos elétrons de valência com os elétrons do caroço, são substituídos por operadores de um elétron [43]. O ECP é obtido com cálculos ab-initio e fornece valores bem próximos aos cálculos que consideram todos os elétrons explicitamente.

Outra característica bem interessante nas bases é o uso de gaussianas contraídas. Dessa forma, o número de parâmetros variacionais é reduzido e assim o rendimento computacional aumenta. A perda na precisão dos resultados é pequena para as bases contraídas, quando comparado com as bases não contraídas.

\subsubsection{Bases Usadas}

Foram usadas diversas bases neste trabalho. Vale notar que temos algumas bases com o mesmo nome mas são usadas para diferentes átomos. Uma base bem conhecida é o aug-cc-pVXZ (correlation consistent, polarized valence X-zeta with diffuse functions: $a u g$ ). A variável $X$ multiplica a quantidade de funções para descrever um orbital. É formada por funções contraídas e foi desenvolvida por Dunning e colaboradores [64-68], focando na correlação eletrônica dos elétrons de valência. Outra base bastante conhecida é a série 6-31, onde aqui usamos os conjuntos de bases $6-311++G(d, p)$ e $6-311++G(2 d, 2 p)$ e foram desenvolvidas por Pople [69-71]. Estas bases dobram o número dos orbitais para os elétrons de valência e incluem funções polarizadas e difusas.

A base $\operatorname{Lan} L 2 M B$, de Los Alamos, possui pseudopotencial para descrever os elétrons do caroço contendo correções relativísticas adicionando o efeito Darwin [7274]. Esta base descreve os elétrons de valência com a base STO-3G, desenvolvidas por Pople [75,76], onde cada função de Slater é descrita por 3 gaussianas. Como comparação, segue um simples cálculo para o He com quatro conjuntos de bases na tabela 3.1 usando a DFT. 
Tabela 3.1: Comparação entre algumas bases usadas para descrever o estado fundamental do átomo de He. A energia foi calculada com DFT usando o funcional híbrido PBE1PBE.

\begin{tabular}{ccc}
\hline \hline Base utilizada & $\mathbf{N}^{\mathbf{o}}$ de funções bases & Energia(a.u.) \\
\hline LanL2MB & 1 & $-2,83598$ \\
$6-311++G(2 d, 2 p)$ & 10 & $-2,89354$ \\
\multirow{2}{c}{$c-p v 5 z$} & 55 & $-2,89510$ \\
aug-cc-pv5z & 80 & $-2,89512$ \\
\multicolumn{2}{c}{ Valor exato: } & $-2,90372$ \\
\hline \hline
\end{tabular}

A base def2-qzvp foi muito utilizada neste trabalho e foi testada em um número muito grande de moléculas $[77,78]$. No caso do Rb e Cs, estas bases usam o pseudopotencial para descrever os elétrons mais internos. Uma base usada aqui apenas para o átomo de Rb é DZP (double-zeta polarized), fornecida por Barros, Oliveira e Jorge [79 $]^{3}$ Essa base contém funções polarizadas, não possui pseudopotencial e representa o $\mathrm{Rb}$ com o conjunto de funções: $17 \mathrm{~s} 15 p 5 d 1 f$. Como exemplo, a base def2-qzop representa o $\mathrm{Rb}$ com o seguinte conjunto de funções: $8 s$ sp 5d $1 f$.

A base SDDALL é uma base D95V (valence double-zeta) de Dunning e Huzinaga [80] para o He e usa um pseudopotencial de Stuttgart [81-83] para descrever o Cs. Para o Na e o Rb, usamos também a base sadlej [84-86], que foi desenvolvida para reproduzir as propriedades elétricas moleculares, especialmente a polarizabilidade.

\footnotetext{
${ }^{3}$ Agradecemos ao Prof. F. E. Jorge por nos conceder os dados da referência [79] antes de publicálos.
} 


\section{Capítulo 4}

\section{Modelo de Agregado}

Um modelo intermediário entre o SBM, descrito na seção A, e a simulação computacional do He líquido é o modelo de agregado. Intermediário, pois já considera explicitamente os átomos de He e não apenas a sua disposição formando uma distribuição de cargas. A princípio, este modelo apresenta pouca relação com a simulação de um líquido, pois mantém fixas as posições dos átomos e assim, não são analisadas as flutuações das posições dos átomos que formam o sistema. Além disso, possui uma alta simetria não permitindo a quebra da degenerescência nas excitações ns-np, e não sendo possível a obtenção da largura da linha espectral. O sistema é pequeno com o número de átomos com relação a simulação do He líquido apresentada no capítulo 5. Nenhuma propriedade termodinâmica é considerada, como temperatura ou pressão. Porém veremos que esse modelo é capaz de fornecer bons resultados para o deslocamento espectral. Uma grande vantagem deste método é sua simplicidade e a não utilização de parâmetros empíricos.

O tratamento que apresentaremos é baseado no estudo presente na referência [30]. O sistema a ser considerado é composto por um átomo ou molécula de interesse centralizado com 14 átomos de He em volta, onde todos os átomos de He estão à mesma distância do centro. A distribuição dos elementos segue com uma camada de 8 He nos vértices de um cubo e outra camada de 6 He nos centros das faces de 
Tabela 4.1: Estrutura geométrica do modelo de agregado, onde $\mathrm{X}$ representa os sistemas estudados: $\mathrm{Rb}, \mathrm{Cs}, \mathrm{Na}$ e $\mathrm{Na}_{2}$.

\begin{tabular}{cccc}
\hline \hline Átomo & $x$ & $y$ & $z$ \\
\hline $\mathrm{X}$ & 0 & 0 & 0 \\
$\mathrm{He}$ & 0 & 0 & $R_{X-\mathrm{He}}$ \\
$\mathrm{He}$ & 0 & 0 & $-R_{X-\mathrm{He}}$ \\
$\mathrm{He}$ & 0 & $R_{X-\mathrm{He}}$ & 0 \\
$\mathrm{He}$ & 0 & $-R_{X-\mathrm{He}}$ & 0 \\
$\mathrm{He}$ & $R_{X-\mathrm{He}}$ & 0 & 0 \\
$\mathrm{He}$ & $-R_{X-\mathrm{He}}$ & 0 & 0 \\
$\mathrm{He}$ & $R_{X-\mathrm{He}} / \sqrt{3}$ & $R_{X-\mathrm{He}} / \sqrt{3}$ & $R_{X-\mathrm{He}} / \sqrt{3}$ \\
$\mathrm{He}$ & $-R_{X-\mathrm{He}} / \sqrt{3}$ & $R_{X-\mathrm{He}} / \sqrt{3}$ & $R_{X-\mathrm{He}} / \sqrt{3}$ \\
$\mathrm{He}$ & $R_{X-\mathrm{He}} / \sqrt{3}$ & $-R_{X-\mathrm{He}} / \sqrt{3}$ & $R_{X-\mathrm{He}} / \sqrt{3}$ \\
$\mathrm{He}$ & $-R_{X-\mathrm{He}} / \sqrt{3}$ & $-R_{X-\mathrm{He}} / \sqrt{3}$ & $R_{X-\mathrm{He}} / \sqrt{3}$ \\
$\mathrm{He}$ & $R_{X-\mathrm{He}} / \sqrt{3}$ & $R_{X-\mathrm{He}} / \sqrt{3}$ & $-R_{X-\mathrm{He}} / \sqrt{3}$ \\
$\mathrm{He}$ & $-R_{X-\mathrm{He}} / \sqrt{3}$ & $R_{X-\mathrm{He}} / \sqrt{3}$ & $-R_{X-\mathrm{He}} / \sqrt{3}$ \\
$\mathrm{He}$ & $R_{X-\mathrm{He}} / \sqrt{3}$ & $-R_{X-\mathrm{He}} / \sqrt{3}$ & $-R_{X-\mathrm{He}} / \sqrt{3}$ \\
$\mathrm{He}$ & $-R_{X-\mathrm{He}} / \sqrt{3}$ & $-R_{X-\mathrm{He}} / \sqrt{3}$ & $-R_{X-\mathrm{He}} / \sqrt{3}$ \\
\hline \hline
\end{tabular}

um cubo maior. Para facilitar a compreensão das posições no modelo de agregado, apresentamos a tabela 4.1 . onde a amostra a ser estudada está na origem de um sistema de coordenadas cartesianas. Esta amostra $X$ pode ser $\mathrm{Rb}, \mathrm{Cs}, \mathrm{Na}$ ou $\mathrm{Na}_{2}$. No caso do $\mathrm{Na}_{2}$, consideramos o centro de massa deste dímero na origem.

O primeiro passo, após montar a configuração, foi variar a distância $R_{X-H e}$ até encontrar uma configuração de mínima energia ( $E_{\min }$ em unidades de hartree), utilizando vários modelos de cálculo. Sobre essa configuração, efetuamos um cálculo de TDDFT com diferentes funcionais híbridos e bases, e calculamos a energia de excitação desse sistema. A partir do resultado da energia de excitação para a 
amostra isolada, calculamos a diferença entre as duas energias de excitações e assim, obtemos o deslocamento espectral (Desl. em unidades de nanômetros (nm)). Uma informação interessante é o valor de $R_{X-H e}$ da configuração de mínima energia, chamado de $R_{\min }$. Esse valor pode ser comparado com a $G(r)$ da simulação clássica, ao mesmo tempo que estima o raio da bolha ou da cavidade em volta do elemento alcalino e a unidade de medida é em angstrom $(\AA)$.

\subsection{Sistema $\mathbf{R b}-\mathrm{He}_{14}$}

Vamos inicialmente considerar o caso do $\mathrm{Rb}$. Nas tabelas 4.2, 4.3 e 4.4 mostramos os resultados obtidos com as bases DZP, def2-qzvp e sadlej para o átomo de $\mathrm{Rb}$. Diferentes bases para os átomos de He e funcionais híbridos foram usadas para tratar o $\mathrm{Rb}$ no agregado de He.

Analisando a tabela 4.2 vemos que usando a base DZP para o Rb e a base $c c$ pV5Z para o He obtém-se um excelente resultado para o deslocamento da energia de excitação usando os funcionais PBE1PBE e O3LYP. O melhor resultado para o Rb isolado é com o funcional B3P86, com o valor de 791,99 nm. Um ponto importante é o valor do $R_{\text {min }}$, o qual está situado entre $6,5 \AA$ e $8,1 \AA$, o que corresponde à primeira camada de solvatação da simulação clássica do Rb em He líquido, como veremos posteriormente na seção 5.1 .

$\mathrm{O}$ uso da base def2-qzop para estudar o átomo de $\mathrm{Rb}$ no agregado de $\mathrm{He}$, tabela 4.3. funcionou muito bem na descrição do deslocamento espectral com os funcionais O3LYP e PBE1PBE. Para o valor da energia de excitação do Rb isolado, estes funcionais não forneceram uma boa concordância com o resultado experimental. Como a base def2-qzop usa ECP, a energia calculada não inclui os elétrons internos e, portanto, é maior do que no uso da base DZP. Com o uso do ECP, são tratados apenas os 9 elétrons de valência do átomo de $\operatorname{Rb}\left(4 s^{2}, 4 p^{6}\right.$ e $\left.5 s\right)$. A mudança da 
Tabela 4.2: Mínima energia $E_{\min }$, raio do agregado $R_{\operatorname{mim}}$, energia de excitação do $\mathrm{Rb}$ isolado e seu deslocamento quando presente no agregado de He. Para estes resultados usamos a base DPZ para o $\mathrm{Rb}$, diferentes bases para o He e distintos funcionais híbridos.

\begin{tabular}{cccccc}
\hline \hline Funcional & Base do He & $E_{\text {min }}$ & $R_{\min }(\AA)$ & Isolado(nm) & Desl.(nm) \\
\hline \multirow{2}{*}{ B3LYP } & $6-311++G(2 d, 2 p)$ & $-2980,648$ & 7,32 & 778,82 & $-6,4$ \\
& $c c-p V 5 Z$ & $-2980,670$ & 7,34 & 778,82 & $-6,2$ \\
\hline \multirow{2}{*}{ B3P86 } & $6-311++G(2 d, 2 p)$ & $-2981,932$ & 7,40 & 791,99 & $-7,0$ \\
& $c c-p V 5 Z$ & $-2981,955$ & 7,87 & 791,99 & $-2,5$ \\
\hline \multirow{2}{*}{ BHandHLYP } & $6-311++G(2 d, 2 p)$ & $-2980,496$ & 7,33 & 812,28 & $-8,7$ \\
& $c c-p V 5 Z$ & $-2980,518$ & 7,46 & 812,28 & $-7,5$ \\
\hline \multirow{2}{*}{ O3LYP } & $6-311++G(2 d, 2 p)$ & $-2981,201$ & 6,45 & 899,38 & $-15,3$ \\
& $c c-p V 5 Z$ & $-2981,222$ & 6,25 & 899,38 & $-19,5$ \\
\hline \multirow{2}{*}{ PBE1PBE } & $6-311++G(2 d, 2 p)$ & $-2980,025$ & 6,67 & 874,40 & $-11,0$ \\
& $c c-p V 5 Z$ & $-2980,047$ & 6,57 & 874,40 & $-17,3$ \\
\hline \hline
\end{tabular}

Tabela 4.3: Mínima energia $E_{\min }$, raio do agregado $R_{\operatorname{mim}}$, energia de excitação do $\mathrm{Rb}$ isolado e seu deslocamento quando presente no agregado de He. Para estes resultados usamos a base def2-qzop para o $\mathrm{Rb}$, diferentes bases para o He e distintos funcionais híbridos.

\begin{tabular}{|c|c|c|c|c|c|}
\hline Funcional & Base do $\mathrm{He}$ & $E_{\min }$ & $R_{\min }(\AA)$ & Isolado(nm) & Desl.(nm) \\
\hline B3LYP & $6-311++G(2 d, 2 p)$ & $-64,889$ & 9,22 & 770,65 & 0,4 \\
\hline \multirow{2}{*}{ O3LYP } & $6-311++G(2 d, 2 p)$ & $-64,840$ & 6,19 & 908,77 & $-22,4$ \\
\hline & aug-cc-pV5Z & $-64,862$ & 6,22 & 908,77 & $-17,5$ \\
\hline \multirow{2}{*}{ PBE1PBE } & $6-311++G(2 d, 2 p)$ & $-64,592$ & 6,40 & 869,27 & $-20,0$ \\
\hline & aug-cc-pV5Z & $-64,614$ & 6,41 & 869,27 & $-19,4$ \\
\hline \multicolumn{4}{|c|}{ EXPERIMENTAL [28] } & 787,34 & $-18,9$ \\
\hline
\end{tabular}

base de $6-311++G(2 d, 2 p)$ para aug-cc- $p V 5 Z$ nos átomos de He pouco influenciou os resultados. 
Tabela 4.4: Mínima energia $E_{\text {min }}$, raio do agregado $R_{\text {mim }}$, energia de excitação do $\mathrm{Rb}$ isolado e seu deslocamento quando presente no agregado de He. Para estes resultados usamos a base sadlej para o $\mathrm{Rb}$, diferentes bases para o He e distintos funcionais híbridos.

\begin{tabular}{cccccc}
\hline \hline \multirow{2}{*}{ Funcional } & Base do He & $E_{\text {min }}$ & $R_{\text {min }}(\AA)$ & Isolado(nm) & Desl.(nm) \\
\hline \multirow{2}{*}{ O3LYP } & $6-311++G(2 d, 2 p)$ & $-2981,440$ & 6,24 & 904,60 & $-21,4$ \\
& aug-cc- $p V 5 Z$ & $-2981,462$ & 6,25 & 904,60 & $-17,0$ \\
\hline \multirow{2}{*}{ PBE1PBE } & $6-311++G(2 d, 2 p)$ & $-2980,267$ & 6,43 & 866,20 & $-20,8$ \\
& aug-cc- $p V 5 Z$ & $-2980,289$ & 6,47 & 866,20 & $-19,3$ \\
\hline \hline & EXPERIMENTAL [28] & & 787,34 & $-18,9$ \\
\hline
\end{tabular}

Outra base usada nesse modelo de agregado foi a base sadlej, conforme pode ser visto na tabela 4.4 . Estes resultados apresentam uma excelente concordância com o deslocamento espectral, porém falham ao descrever o átomo isolado, conforme observado no caso das duas bases anteriores. Os resultados obtidos nas tabelas 4.3 e 4.4 são bem semelhantes. Uma observação importante sobre as tabelas $4.2,4.3$ e 4.4 é que mesmo usando diferentes bases para descrever o $\mathrm{Rb}$, certos funcionais (B3LYP, BHandHLYP, B3P86) não conseguem representar muito bem o deslocamento espectral e fornecem distâncias $R_{\min }$ muito acima do valor obtido com a simulação clássica, a ser discutida na seção 5.1. Por exemplo, na tabela 4.3. com o uso do funcional híbrido B3LYP foram obtidos os piores resultados para o deslocamento espectral e $R_{\text {min }}$, além de uma energia de ligação muito baixa.

A base $L a n L 2 M B$ utiliza ECP para descrever os elétrons do caroço, além de descrever os elétrons de valência como a base STO-3G. Observando os resultados na tabela 4.5, verifica-se que o tamanho de $R_{\min }$ ficou muito pequeno e o deslocamento muito grande. Vale ressaltar que a base STO-3G é pequena comparada com as bases 6-311++G(2d,2p) e (aug-) $c c-p V 5 Z$, apresentando apenas uma função para descrever o átomo de He.

Na figura 4.1 mostramos os orbitais atômicos para o sistema $\mathrm{Rb}-\mathrm{He}_{14}$. Observa- 
Tabela 4.5: Mínima energia $E_{\min }$, raio do agregado $R_{\operatorname{mim}}$, energia de excitação do $\mathrm{Rb}$ isolado e seu deslocamento quando presente no agregado de He. Para estes resultados usamos a base LanL2MB para $\mathrm{Rb}$ e He e diferentes funcionais híbridos.

\begin{tabular}{|c|c|c|c|c|}
\hline Funcional & $E_{\min }$ & $R_{\min }(\AA)$ & Isolado(nm) & Desl.(nm) \\
\hline B3LYP & $-63,811$ & 4,57 & 748,55 & $-137,0$ \\
\hline B3P86 & $-64,469$ & 4,98 & 766,35 & $-133,3$ \\
\hline BHandHLYP & $-63,667$ & 4,88 & 775,26 & $-131,3$ \\
\hline PBE1PBE & $-63,565$ & 4,63 & 837,73 & $-177,0$ \\
\hline \multicolumn{3}{|c|}{ EXPERIMENTAL [28] } & 787,34 & $-18,9$ \\
\hline
\end{tabular}
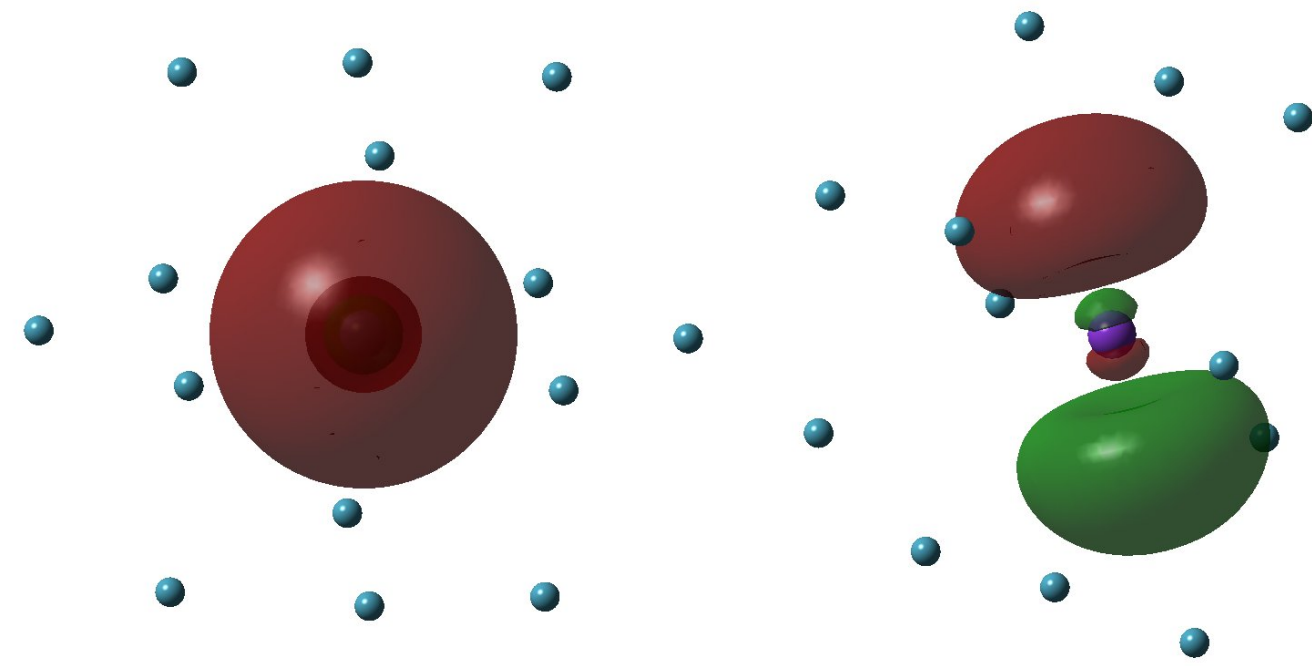

(a) Orbital atômico mais alto ocupado do Rb. (b) Orbital atômico mais baixo desocupado do $\mathrm{Rb}$.

Figura 4.1: Disposição dos átomos de He em torno do Rb no modelo de agregado. Representação dos orbitais atômicos onde: (a) é o mais alto ocupado e tem a forma do orbital atômico do tipo $s$ e (b) é o mais baixo desocupado e tem a forma do orbital atômico do tipo $p$ ligeiramente deformado.

se claramente um orbital do tipo s no orbital mais alto ocupado 4.1(a) e um orbital do tipo $p$ levemente deformado no orbital mais baixo desocupado4.1(b). Estes orbitais correspondem aos orbitais da transição $5 s$ para $5 p$ do átomo de $\mathrm{Rb}$.

A figura 4.2 demonstra muito bem o comportamento da energia de excitação e 


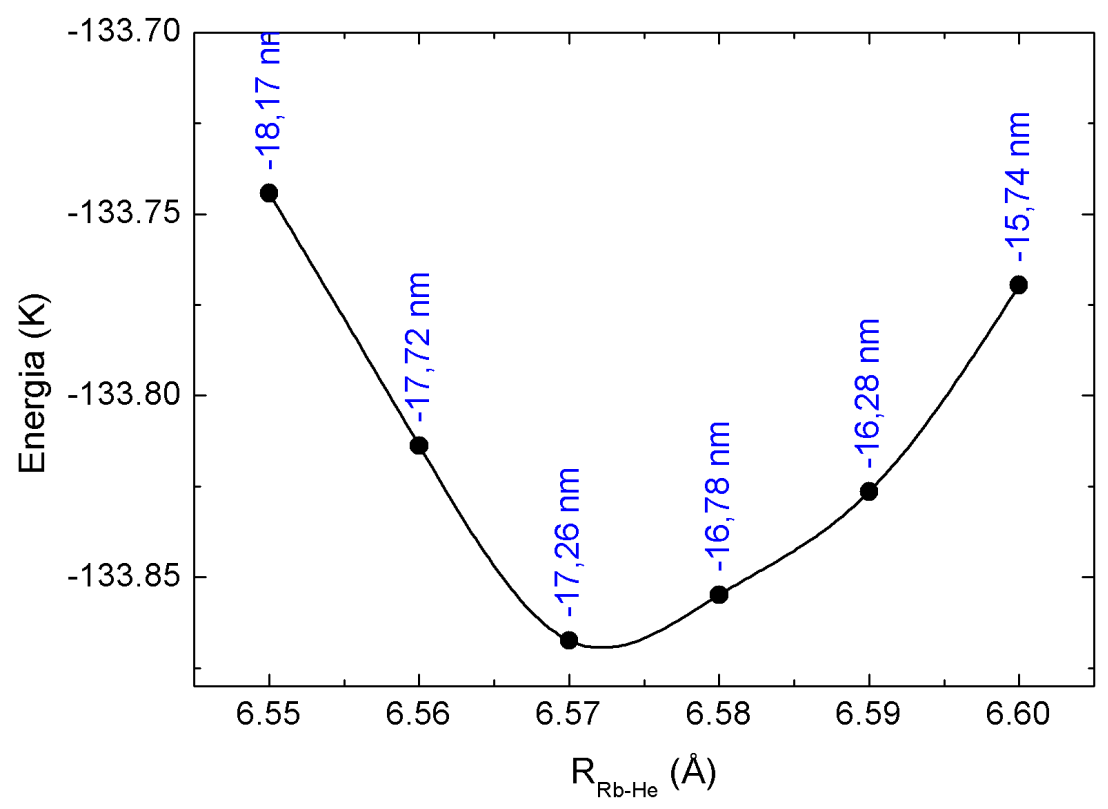

Figura 4.2: Energia do agregado dividida pela constante de Boltzmann em função do comprimento dos pares $R_{R b-H e}$ e para cada ponto o valor do deslocamento espectral usando o funcional PBE1PBE e a base do Rb igual a DZP e a base do He igual a cc-pV5Z.

da energia do agregado usando o funcional PBE1PBE com a base do Rb igual a DZP e base do He igual a cc-pV5Z. O mínimo de energia está em 6,57 $\AA$, onde temos um valor do deslocamento espectral igual a $-17,26 \mathrm{~nm}$. Conforme observamos os outros pontos da figura 4.2, o valor do deslocamento espectral modifica bastante mesmo com pequenas variações da distância $R_{R b-H e}$. O intervalo total analisado no gráfico é de $0,05 \AA$.

No sistema tratado por Anton et al [30], o comprimento $R_{\min }$ é igual a 5,15 $\mathrm{A}$ o o valor do deslocamento espectral foi de $-15,4 \mathrm{~nm}$. Para obter esses resultados, o nível de cálculo empregado usa aproximações relativísticas. Como simples comparação, um cálculo de TDDFT, o qual não faz o uso de aproximações relativísticas, com a distância entre os pares $\mathrm{Rb}$ e He igual a 5,15 Å usando o funcional híbrido PBE1PBE com a base $D Z P$ para o $\mathrm{Rb}$ e a base $6-311++G(2 d, 2 p)$ para os átomos de He gerou um deslocamento aproximado de $-80 \mathrm{~nm}$. 


\subsection{Sistema Cs-He $\mathrm{He}_{14}$}

Utilizando a metodologia empregada anteriormente para o sistema $\mathrm{Rb}-\mathrm{He}_{14}$, estudamos o deslocamento espectral do Cs com o modelo de agregado. Novas bases são necessários para descrever o átomo de Cs, entretanto trabalhamos com conjuntos de bases com ECP. Nos resultados presentes na tabela 4.6 foram usados diferentes funcionais híbridos e bases. As bases LanL2MB e SDDALL descrevem todos os elementos do sistema, enquanto que nos resultados usando a base def2qzop os átomos de He são descritos pela base $6-311++G(2 d, 2 p)$ e o átomo de Cs é descrito pela base def2-qzop.

Tabela 4.6: Mínima energia $E_{\min }$, raio do agregado $R_{\operatorname{mim}}$, energia de excitação do Cs isolado e seu deslocamento quando presente no agregado de He com diferentes funcionais e bases para os átomos. Nas bases sinalizadas com um *, os átomos de He estão representados pela base $6-311++G(2 d, 2 p)$.

\begin{tabular}{cccccc}
\hline \hline Base dos Átomos & Funcional & $E_{\min }$ & $R_{\min }(\AA)$ & Isolado(nm) & Desl.(nm) \\
\hline \multirow{2}{*}{ LanL2MB } & B3LYP & $-59,823$ & 4,88 & 838,47 & $-140,9$ \\
& O3LYP & $-59,801$ & 4,56 & 979,23 & $-196,9$ \\
& PBE1PBE & $-59,584$ & 4,93 & 943,94 & $-184,0$ \\
\hline \multirow{5}{*}{ SDDALL } & B3LYP & $-60,851$ & 5,55 & 805,83 & $-89,6$ \\
& O3LYP & $-60,799$ & 5,21 & 918,08 & $-95,2$ \\
& PBE1PBE & $-60,570$ & 5,54 & 881,32 & $-115,2$ \\
\hline \multirow{5}{*}{ def2-qzvp* } & B3LYP & $-60,940$ & 9,22 & 859,96 & $-0,1$ \\
& O3LYP & $-60,887$ & 6,53 & 1035,70 & $-23,6$ \\
\hline \hline & PBE1PBE & $-60,650$ & 6,69 & 980,03 & $-21,3$ \\
\hline \hline
\end{tabular}

Os resultados dos deslocamentos para as bases LanL2MB e SDDALL não foram satisfatórios. O menor valor encontrado é mais de 4 vezes maior do que o valor experimental. Além disso, o valor para $R_{\min }$ é menor do que o valor no início da 
primeira camada de solvatação, igual a 6,1 a outras bases. A que gerou excelentes resultados foi a def2-qzvp, conforme pode ser visto na tabela 4.6. Neste cálculo, foi usada a base $6-311++G(2 d, 2 p)$ para os átomos de He. Como podemos observar, o funcional híbrido B3LYP não apresenta um bom resultado para o deslocamento e para o raio mínimo do sistema $R_{\min }$. Para os outros funcionais híbridos, PBE1PBE e O3LYP, os resultados estão em excelente concordância com os resultados experimentais. No caso da energia de excitação para o átomo de Cs isolado, o funcional B3LYP, com a mesma base def2-qzop, apresenta um resultado muito bom. Novamente, os melhores métodos para tratar o deslocamento falharam ao descrever a energia de excitação do átomo isolado.

Conforme veremos na simulação de Cs em He líquido, a primeira camada inicia em $6,0 \AA$ e finaliza em $8,5 \AA$. O pico desta primeira camada está situado por volta de $6,5 \AA$, coincidindo com o valor do $R_{\text {min }}$ da tabela 4.6 para os funcionais híbridos O3LYP e PBE1PBE. O valor da profundidade é compatível com os melhores resultados já estudados do sistema $\mathrm{Rb}-\mathrm{He}_{14}$. Na referência [30], o raio da bolha calculada ficou em 5,72 Å e o valor do deslocamento espectral calculado foi igual a $-16,7 \mathrm{~nm}$, sendo este resultado obtido com cálculo na aproximação relativística.

\subsection{Sistema Na-He ${ }_{14}$}

Outro sistema interessante de estudar é o dímero de Sódio $\left(\mathrm{Na}_{2}\right)$, porém antes de tratarmos o dímero de $\mathrm{Na}$ em He líquido, realizamos uma análise no Na isolado e no modelo de agregado. Os resultados encontram-se na tabela 4.7, onde usamos diferentes funcionais híbridos e bases. Não existe resultado experimental para excitações do Na em He líquido, porém existe uma previsão [23,30] que esse valor está em torno de $-14 \mathrm{~nm}$ a $-16 \mathrm{~nm}$. Essa previsão se deve ao fato de existir resultados experimentais para o $\mathrm{Rb}$ e Cs [28]. Assim, sendo todos elementos alcalinos, pode-se 
extrapolar o valor de energia de excitação do Na. O mesmo processo é realizado para o átomo de Potássio.

Tabela 4.7: Mínima energia $E_{\min }$, raio do agregado $R_{\operatorname{mim}}$, energia de excitação do $\mathrm{Na}$ isolado e seu deslocamento quando presente no agregado de He com diferentes funcionais e bases para os átomos. Nas bases sinalizadas com um *, os átomos de He estão representados pela base $6-311++G(2 d, 2 p)$.

\begin{tabular}{cccccc}
\hline \hline Base dos Átomos & Funcional & $E_{\text {min }}$ & $R_{\min }(\AA)$ & Isolado(nm) & Desl.(nm) \\
\hline \multirow{2}{*}{ 6-311++G(2d,2p) } & O3LYP & $-202,981$ & 5,45 & 605,04 & -13 \\
& PBE1PBE & $-202,680$ & 5,63 & 595,26 & -12 \\
\hline \multirow{2}{*}{ aug-cc- $p V 5 Z$} & O3LYP & $-203,016$ & 5,46 & 600,97 & -9 \\
& PBE1PBE & $-202,715$ & 5,74 & 593,24 & -10 \\
\hline \multirow{2}{*}{ aug-cc-pV5Z* } & O3LYP & $-202,994$ & 5,55 & 600,97 & -9 \\
& PBE1PBE & $-202,693$ & 5,67 & 593,24 & -11 \\
\hline \multirow{2}{*}{ def2-qzvp } & O3LYP & $-203,014$ & 5,45 & 593,79 & -11 \\
& PBE1PBE & $-202,714$ & 5,77 & 592,01 & -10 \\
\hline \multirow{2}{*}{ def2-qzvp* } & O3LYP & $-202,993$ & 5,59 & 593,79 & -9 \\
\hline \multicolumn{4}{c}{ Sugestão experimental (veja o texto) } & 592,01 & -10 \\
\hline \hline
\end{tabular}

Podemos destacar que os acréscimos no tamanho e na qualidade da base dos átomos pouco interferem no deslocamento espectral e nas propriedades estruturais do agregado. Dentre os funcionais testados, se destacam o O3LYP e PBE1PBE. De forma geral, todas as bases testadas funcionaram muito bem. Na simulação clássica, a primeira camada de solvatação começa em 5,0 A, tem o máximo em 5,9 A e finaliza em 7,2 A. No modelo de agregado, tabela 4.7 , todos os cálculos apresentaram um tamanho de $R_{\min }$ em torno de 5,5 $\AA$ a 5,8 $\AA$, bem próximo ao máximo da primeira camada de solvatação, que é 5,9 Å. 


\subsection{Sistema $\mathrm{Na}_{2}-\mathrm{He}_{14}$}

Além de sistemas atômicos, estudos experimentais de deslocamento espectral também foram realizados em moléculas diatômicas [28] em He líquido. Entretanto, tratar moléculas é mais difícil do que apenas um átomo. Por um lado, a excitação eletrônica não é dominada por uma única transição como no caso de átomos alcalinos. Por outro, a largura da linha tem outras contribuições como, por exemplo, possíveis progressões vibracionais. Um sistema diatômico estudado recentemente foi o $\mathrm{Na}_{2}$ em He líquido. Para este sistema, trataremos apenas o espectro eletrônico.

A configuração eletrônica do $\mathrm{Na}_{2}$ do estado eletrônico fundamental é $X^{1} \Sigma_{g}^{+}$. Os dois primeiros estados excitados são decorrentes de excitações do orbital $]^{1}$ de simetria $4 \sigma$, originando aos estados eletrônicos $A^{1} \sum_{u}^{+}$e $B^{1} \Pi_{u}$. A figura 4.3 mostra os orbitais HOMO, LUMO, LUMO+1 e LUMO+2 para o $\mathrm{Na}_{2}$ no agregado de He. É fácil notar que os orbitais LUMO+2 e LUMO+1 são semelhantes, pois pertencem a um orbital $\pi$, e uma rotação de $90^{\circ}$ em torno do eixo que passa pelos átomos de Na leva à mesma figura. De acordo com os autores [28], o espectro de excitação do $\mathrm{Na}_{2}$ em He líquido tem o mesmo formato da transição HOMO para LUMO+1 (ou LUMO+2) do $\mathrm{Na}_{2}$ isolado. De modo que, a transição $X^{1} \Sigma_{g}^{+}\left(v^{\prime \prime}=0\right)$ para $B^{1} \Pi_{u}\left(v^{\prime}\right)$ sofre um deslocamento de $700 \mathrm{~cm}^{-1}$. Neste trabalho, apresentaremos os resultados tanto para a transição $X^{1} \Sigma_{g}^{+} \rightarrow B^{1} \Pi_{u}$ quanto para a transição $X^{1} \Sigma_{g}^{+} \rightarrow A^{1} \Sigma_{u}^{+}$.

Para trabalhar com o $\mathrm{Na}_{2}$ foi necessário, primeiramente, estabelecer a distância interatômica. Este parâmetro é muito importante, pois será usado tanto no modelo de agregado como na simulação de He líquido. Diferentes funcionais geram distintos valores para a distância interatômica. Para fixar esse valor optamos por trabalhar com o resultado experimental [87] $R_{\mathrm{Na}-\mathrm{Na}}=3,0789 \AA$.

\footnotetext{
${ }^{1}$ Os orbitais moleculares ocupados do estado fundamental do $\mathrm{Na}_{2}$ são: $1 \sigma_{u}^{2}, 1 \sigma_{g}^{2}, 2 \sigma_{g}^{2}, 2 \sigma_{u}^{2}, 3 \sigma_{g^{\prime}}^{2}$ $1 \pi_{u}^{4}, 1 \pi_{g}^{4}, 3 \sigma_{u}^{2}$ e $4 \sigma_{g}^{2}$. Os primeiros orbitais moleculares virtuais do estado fundamental são: $4 \sigma_{u}^{0}, 2 \pi_{u}^{0}$, $5 \sigma_{g}^{0}$ e $2 \pi_{g}^{0}$.
} 


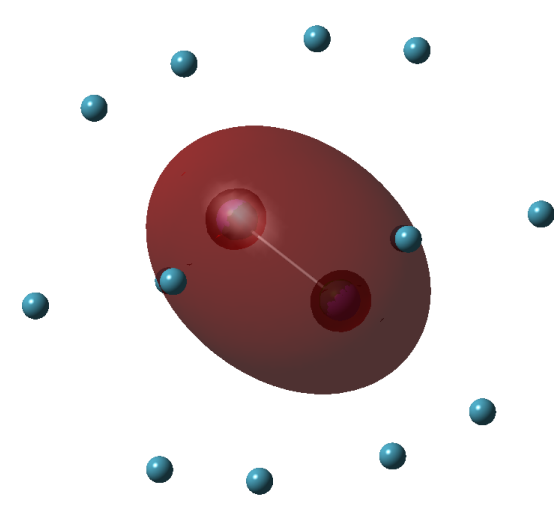

(a) HOMO.

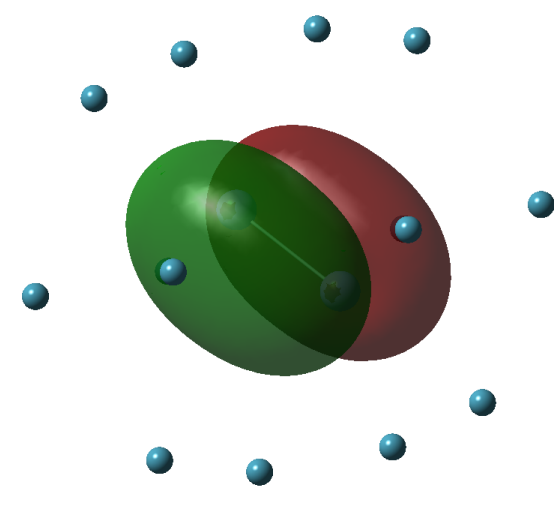

(c) $\mathrm{LUMO}+1$.

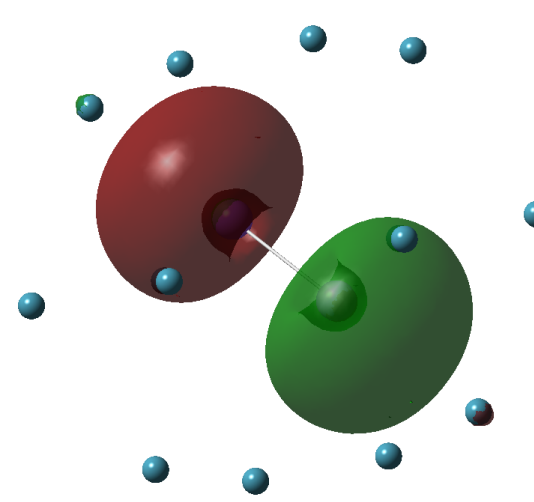

(b) LUMO.

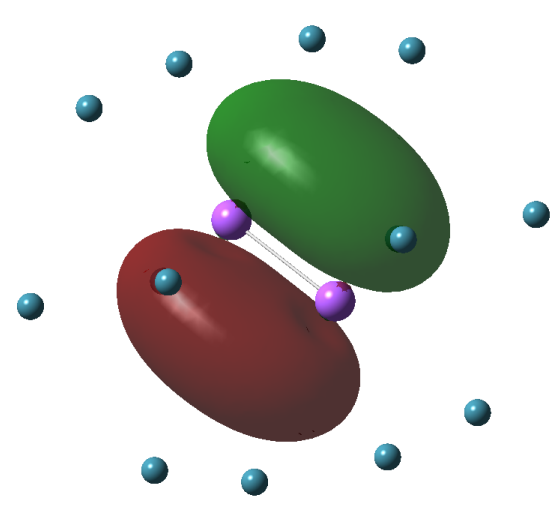

(d) $\mathrm{LUMO}+2$.

Figura 4.3: Disposição dos átomos de $\mathrm{He}$ em torno do $\mathrm{Na}_{2}$ no modelo de agregado. Representação dos orbitais moleculares HOMO (a), LUMO[(b), LUMO+1[(c)] e LUMO+2[(d)

Em um teste posterior, analisamos se a distância usada realmente encontravase no ponto de mínima energia, conforme a figura 4.4. onde variamos o raio do agregado $R_{\mathrm{Na}_{2}-\mathrm{He}}$ e a distância entre os átomos de $\mathrm{Na}\left(R_{\mathrm{Na}-\mathrm{Na}}\right)$. Realmente na distância $R_{\mathrm{Na}-\mathrm{Na}} \sim 3,0 \AA$ apresenta-se um mínimo de energia do sistema. As variações $R_{\mathrm{Na}_{2}-\mathrm{He}}$ não modificam em demasiado a energia do sistema, porém estas distâncias serão calculadas pelo mesmo processo realizado nos agregados anteriores. Para este cálculo, foi usado o funcional híbrido PBE1PBE com a base $6-311++G(2 d, 2 p)$ para descrever todos os átomos presentes. 


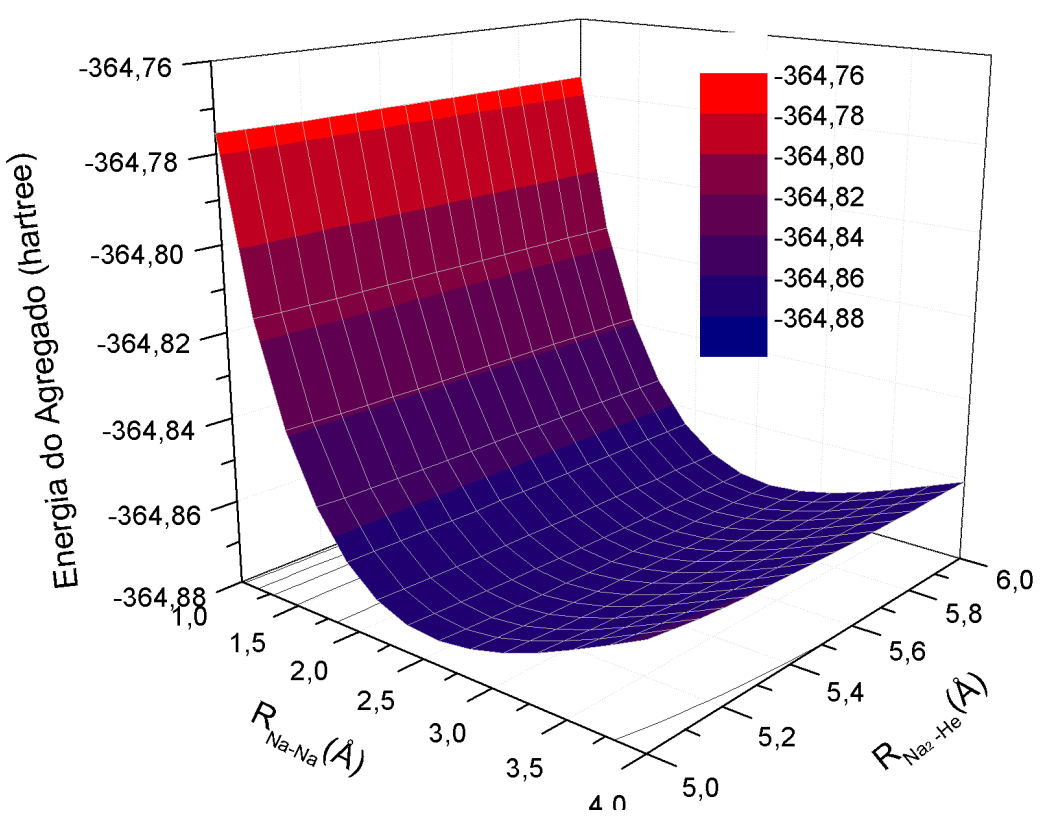

Figura 4.4: Energia do agregado (hartree) em função das distâncias $R_{\mathrm{Na}-\mathrm{Na}}$ e $R_{\mathrm{Na}_{2}-\mathrm{He}}$. Conforme a figura, na região de $R_{\mathrm{Na}-\mathrm{Na}}=3 \AA$ não ocorre uma mudança muito grande ao variar a distância $\mathrm{R}_{\mathrm{Na}_{2}-\mathrm{He}}$.

Na tabela 4.8, estão resumidos os melhores resultados obtidos para o modelo de agregado fixando a distância $R_{\mathrm{Na}-\mathrm{Na}}$ em 3,0789 $\AA$. Na simulação clássica do $\mathrm{Na}_{2}$ em He líquido, o raio do agregado ficou entre 5,2 $\AA$ e 8,0 $\AA$, com máximo em 6,8 Å. Assim, diversos agregados estão presentes na primeira camada de solvatação, porém em pontos anteriores ao máximo da $G(r)$ já que em média o modelo de agregado apresenta um valor de $R_{\min }$ por volta de 5,9 Å. Quanto à energia de ligação $\left(E_{\text {lig }}\right)$, os valores são da mesma ordem que os resultados apresentados para o modelo de agregado do sistema $\mathrm{Na}-\mathrm{He}_{14}$.

Para a transição $X^{1} \Sigma_{g}^{+} \rightarrow A^{1} \sum_{u}^{+}$, os resultados para o deslocamento espectral variaram entre $430 \mathrm{~cm}^{-1}$ e $550 \mathrm{~cm}^{-1}$. Infelizmente, não há valor experimental para a energia de excitação do Na2 isolado e em He líquido, não sendo possível efetuar comparações. Para o sistema isolado, a energia de excitação do $\mathrm{Na}_{2}$ calculada ficou em torno de 2,05-2,06 eV. 
Tabela 4.8: Mínima energia $E_{\text {min }}$, raio do agregado $R_{\text {mim }}$, energia de excitação do $\mathrm{Na}_{2}$ isolado e seu deslocamento quando presente no agregado de He com diferentes funcionais e bases para os átomos. Trabalhamos com as duas transições $X^{1} \Sigma_{g}^{+} \rightarrow A^{1} \sum_{u}^{+}$e $X^{1} \Sigma_{g}^{+} \rightarrow B^{1} \Pi_{u}$. Nas bases sinalizadas com um *, os átomos de He estão representados pela base $6-311++G(2 d, 2 p)$.

\begin{tabular}{cccccccc}
\hline \hline \multirow{2}{*}{ Base dos Átomos } & \multirow{2}{*}{ Funcional } & $E_{\text {min }}$ & $R_{\min }(\AA)$ & \multicolumn{2}{c}{ Isolado(eV) } & \multicolumn{2}{c}{ Desl.(cm $\left.{ }^{-1}\right)$} \\
& & & & $X \rightarrow A$ & $X \rightarrow B$ & $X \rightarrow A$ & $X \rightarrow B$ \\
\hline \multirow{2}{*}{$6-311++G(2 d, 2 p)$} & O3LYP & $-365,269$ & 5,95 & 2,059 & 2,482 & 500 & 195 \\
& PBE1PBE & $-364,875$ & 5,77 & 2,057 & 2,572 & 507 & 470 \\
\hline \multirow{2}{*}{ aug-cc- $p V Q Z$} & O3LYP & $-365,313$ & 5,92 & 2,056 & 2,497 & 430 & 29 \\
& PBE1PBE & $-364,921$ & 5,82 & 2,049 & 2,575 & 439 & 383 \\
\hline \multirow{2}{*}{ def2-qzvp ${ }^{*}$} & O3LYP & $-365,293$ & 5,99 & 2,055 & 2,536 & 437 & 178 \\
& PBE1PBE & $-364,900$ & 5,79 & 2,053 & 2,582 & 475 & 406 \\
\hline \multirow{2}{*}{ def2-qzvp } & O3LYP & $-365,314$ & 5,97 & 2,055 & 2,536 & 453 & 209 \\
& PBE1PBE & $-364,922$ & 5,83 & 2,053 & 2,582 & 466 & 409 \\
\hline \multirow{2}{*}{ sadlej ${ }^{*}$} & O3LYP & $-365,265$ & 5,93 & 2,059 & 2,501 & 507 & 191 \\
& PBE1PBE & $-364,872$ & 5,73 & 2,051 & 2,582 & 550 & 490 \\
\hline \hline
\end{tabular}

Para a transição $X^{1} \Sigma_{g}^{+} \rightarrow B^{1} \Pi_{u}$, destacamos o funcional híbrido PBE1PBE, o qual apresenta os valores mais próximos dos resultados experimentais, ainda que nosso melhor resultado esteja distante do resultado experimental por $210 \mathrm{~cm}^{-1}$. Todos as bases usadas apresentaram valores semelhantes, mas a base que merece destaque é a sadlej, pois é a que mais se aproxima do valor experimental. Outra base com resultado muito bom foi a $6-311++G(2 d, 2 p)$. Para a energia de excitação do $\mathrm{Na}_{2}$ isolado, obtemos valores compatíveis com os experimentais com o funcional híbrido O3LYP.

Para a transição $X^{1} \Sigma_{g}^{+}\left(v^{\prime \prime}=0\right) \rightarrow B^{1} \Pi_{u}$ foram realizadas mais duas análises. Com respeito à intensidade do espectro, figura 4.5(b), observamos que a região 


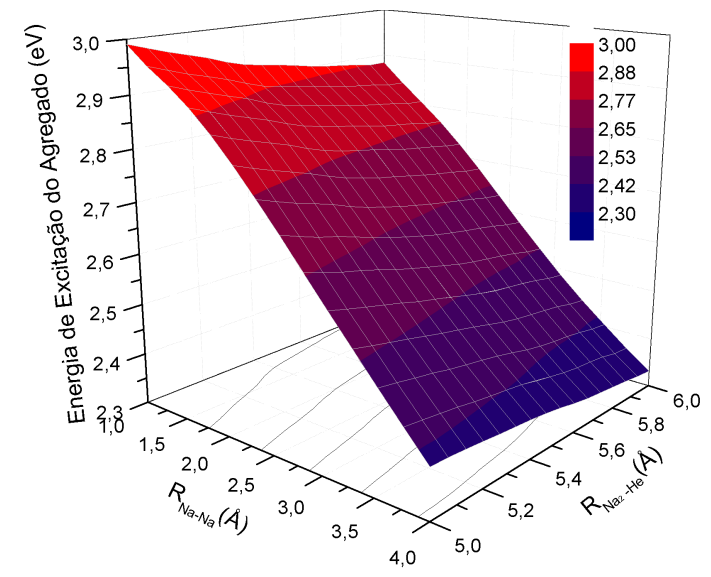

(a) Energia de excitação.

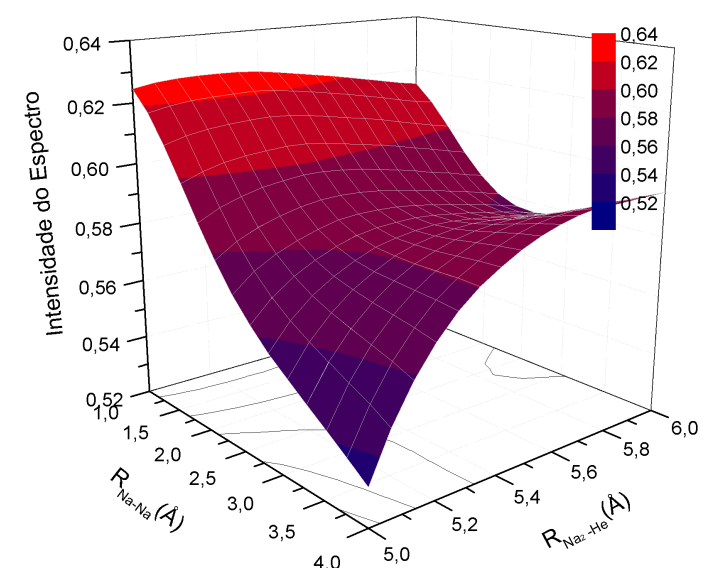

(b) Intensidade da excitação.

Figura 4.5: Energia de excitação (eV) (a) e intensidade excitação(b) para a transição $X^{1} \Sigma_{g}^{+} \rightarrow B^{1} \Pi_{u}$ no modelo de agregado, em função das distâncias $R_{\mathrm{Na} a \mathrm{Na}}$ e $R_{\mathrm{Na} a_{2}-\mathrm{He}}$.

de mínima energia apresenta uma intensidade praticamente constante, a qual é calculada pela força de oscilador. Com respeito à energia de excitação, figura 4.5(a). observou-se que a energia de excitação sofre mais influência da distância $R_{\mathrm{Na}-\mathrm{Na}}$ do que a distância $\mathrm{R}_{\mathrm{Na}_{2}-\mathrm{He}}$.

\subsection{Conclusões Parciais}

Esses estudos demonstraram que o modelo de agregado funciona bem como uma previsão de resultados. Apesar de não oferecer a largura da linha espectral, o processo gera uma boa estimativa do deslocamento espectral, na presença dos átomos de He. Como vimos, a largura de linha não aparece devido à preservação da simetria que mantém os orbitais $n p$ degenerados e da falta de flutuações.

O modelo de agregado parte de uma simples estrutura que representa a bolha ou cavidade de átomos alcalinos em He líquido. Essas bolhas são geradas pelas forças repulsivas entre os orbitais ocupados dos átomos de He e semi-ocupados do átomo alcalino. Isso foi verificado pois todos os sistemas apresentaram um raio de bolha no qual a energia correspondente é mínima. Assim, teoricamente existiria uma 
configuração mais estável devido à baixa energia. Ocorre que, sendo um líquido, existem diversas flutuações nas posições de todo os átomos e tal configuração de mínima energia é dificilmente acessada.

Os funcionais híbridos PBE1PBE e O3LYP apresentam excelentes resultados para o deslocamento espectral dos átomos alcalinos no agregado de He. No caso do dímero $\mathrm{Na}_{2}$, apenas o funcional PBE1PBE obteve um bom resultado do deslocamento espectral, porém um pouco distante do valor experimental. Para a energia de excitação do sistema isolado, deve-se recorrer a outros funcionais híbrido como B3LYP e B3P86. Em geral, o uso de bases com pseudopotencial gerou resultados compatíveis com os valores experimentais.

Para os sistemas com monômeros alcalinos, usando a base def2-qzop e os funcionais PBE1PBE e O3LYP, obtivemos uma excelente descrição do deslocamento espectral e da estrutura do agregado. No caso do $\mathrm{Rb}$, o uso da base DZP também apresenta bons resultados, assim como a base sadlej. Para o átomo de He, pode-se usar a base $6-311++G(2 d, 2 p)$, pois bases maiores para esse elemento pouco interferem nos resultados que estamos interessados. Para a transição $X \rightarrow B$ do $\mathrm{Na}_{2}$, as bases sadlej e $6-311++G(2 d, 2 p)$ associados ao funcional PBE1PBE apresentaram os valores do deslocamento espectral mais próximos do resultado experimental.

Algumas das bases utilizadas possuem correções relativísticas, porém o desenvolvimento dos métodos de MQ usados aqui não partiu de um hamiltoniano relativístico. Mesmo assim, nossos resultados apresentaram valores bem consistentes com os resultados experimentais. Uma comparação entre os resultados obtidos com os cálculos relativísticos e os cálculos realizados aqui, mostram uma pequena diferença entre o raio da bolha na configuração de mínima energia. 


\section{Capítulo 5}

\section{Simulação em He Líquido}

Uma forma mais realista do que o modelo de agregado, para tratar as propriedades espectroscópicas de uma impureza em um sistema líquido, consiste em realizar uma simulação computacional de líquidos. Mais realista, pois trabalha com um sistema bem maior a princípio. São em torno de 1000 átomos em uma caixa de mais de $25 \AA$ de aresta na simulação clássica. Nos cálculos de MQ, o número de átomos é reduzido para um valor em torno de 50, o qual é muito maior do que usado no modelo de agregado. Considera a princípio propriedades termodinâmicas, como temperatura, pressão, entre outros. Além do mais, são efetuadas médias sobre as propriedades de interesse.

Dada a impossibilidade de acessar todas as configurações possíveis do líquido, do número de átomos presentes e do tempo de observação da amostra, diversas simplificaç̃oes são necessárias para obter as propriedades de interesse. Outra limitação imposta é o poder computacional. Assim, o número de átomos do sistema, o tempo de simulação e as metodologias foram selecionadas de forma a não exigir um grande esforço computacional e sem comprometer a qualidade dos resultados.

Para obter as propriedades dos átomos alcalinos em He líquido, usamos o método S-MM/MQ [24-26]. Nessa metodologia, são geradas várias configurações do sistema soluto/solvente a partir de uma simulação clássica (MM) via Monte 
Carlo, onde os parâmetros empíricos são cuidadosamente selecionados a fim de representar fielmente o experimento. Então, as propriedades de interesse são obtidas executando cálculos de MQ, usando TDDFT sobre algumas configurações estatisticamente descorrelacionadas do líquido, compostas de número de átomos que correspondem a uma certa camada de solvatação.

Novamente, trabalhamos com os sistemas $\mathrm{Rb}, \mathrm{Cs}, \mathrm{Na}$ e $\mathrm{Na}_{2}$. Em todos esses sistemas foram usadas as condições de simulação apresentadas na tabela 5.1 .

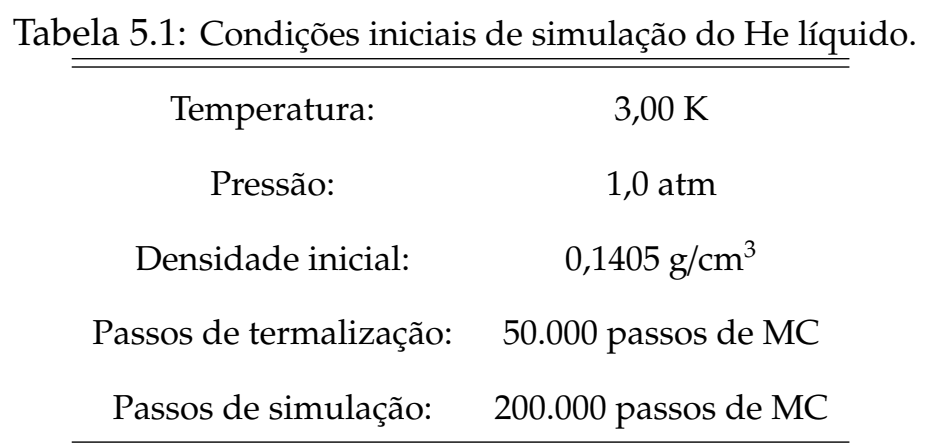

Devido a dificuldade de tratar o potencial de interação entre os átomos de He, iniciamos a simulação considerando um sistema homogêneo, contendo apenas átomos de He. De acordo com a literatura, o potencial HFD-B3-FCI1 [27, 35] representa muito bem a interação He-He. Gerando uma curva de LJ dos parâmetros desse potencial (LJ-HFD-B3-FCI1), vemos que as duas curvas são bem semelhantes, conforme a figura 5.1. Outros potenciais foram pesquisados, como o presente no trabalho de Tang e Toennies [36,37] e o gerado por cálculos de MQ com CCSD(T) com a base $c c-p V 5 Z$ [23]. Comparando esses potenciais, figura 5.1, observamos que os potenciais HFD-B3-FCI1 e LJ-HFD-B3-FCI1 apresentam um energia mínima mais baixa, além de ter uma das menores posições de mínimo.

Durante a simulação, verificamos que a densidade final ficou oscilando em torno de $0,35 \mathrm{~g} / \mathrm{cm}^{3}$, que está bem acima do valor experimental de 0,1405 g/ $\mathrm{cm}^{3}$ [89]. Após uma análise mais detalhada, observamos que o sistema estava muito denso, 


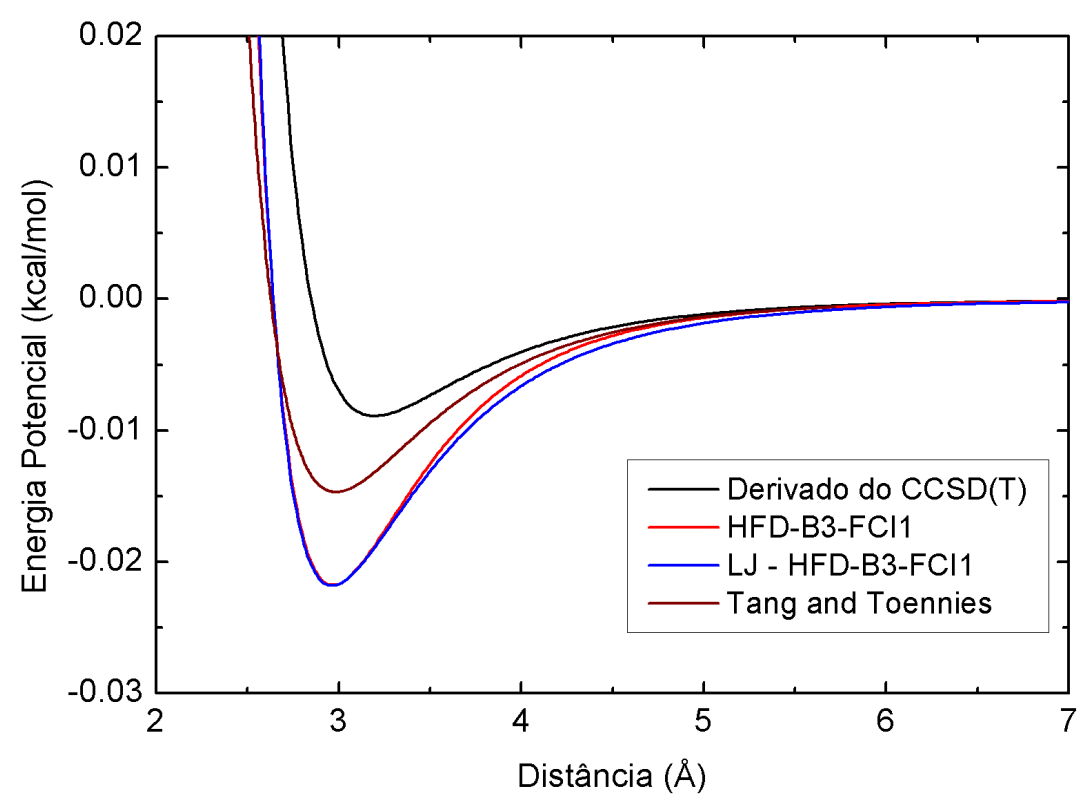

Figura 5.1: Diferentes potenciais analisados. O potencial LJ-HFD-B3-FCI1 é um potencial de LJ com os parâmetros do potencial HFD-B3-FCI1 $[27,35]$. Tang and Toennies é proveniente das referências [36,37], enquanto o derivado do $\operatorname{CCSD}(\mathrm{T}) / c c-p V 5 Z$ usa cálculos de mecânica quântica para descrever a interação.

parecendo mais um sólido do que um líquido. Então, abandonamos o potencial LJ-HFD-B3-FCI1 e decidimos usar um potencial já conhecido em nosso grupo de pesquisa no qual os parâmetros da interação He-He são obtidos com cálculos $a b$ initio usando o método $\operatorname{CSSD}(\mathrm{T})$ com a base $c c-p V 5 Z$. Foram realizadas algumas simplificações para aproximar a curva de potencial à forma do potencial de LJ [23]. Na simulação de He líquido sem átomos alcalinos presentes, encontramos uma densidade de $0,247 \mathrm{~g} / \mathrm{cm}^{3}$, que ainda está alta em relação ao valor experimental, porém apresenta o comportamento de líquido. 


\subsection{Potencial do Kleinekathöoefer, Tang, Toennies e Yiu}

Definido o potencial de interação He-He a ser usado, falta definir o potencial de interação entre o átomo alcalino e os átomos de He. Usando um potencial baseado na teoria de perturbação, o qual apresenta boa concordância com os cálculos ab-initio e semi-empíricos, chegamos ao potencial proposto por Kleinekathöefer, Tang, Toennies e Yiu (KTTY) [36,37]. Tecnicamente, este potencial depende dos coeficientes de dispersão, da amplitude das funções de onda assimptóticas atômicas e da energia de ionização dos átomos. Para este potencial, só foi tratado o sistema $\mathrm{Rb}$ em He líquido.

A fim de padronizar a simulação, usamos potenciais do tipo LJ para descrever todas as interações do sistema. Recorrendo ao potencial KTTY, obtivemos os parâmetros deste potencial para o seu uso em um potencial do tipo LJ. Os valores desses parâmetros de LJ podem ser vistos na tabela 5.2 .

Tabela 5.2: Parâmetros dos potenciais LJ usando cálculo ab-initio CCSD(T)/cc-pV5Z para a interação He-He e o potencial KTTY para a interação Rb-He [36].

\begin{tabular}{ccc}
\hline \hline Átomo & $\epsilon(\mathrm{kcal} / \mathrm{mol})$ & $\sigma(\AA)$ \\
\hline $\mathrm{Rb}$ & 0,0010 & 15,8895 \\
\hline $\mathrm{He}$ & 0,0089 & 2,84800 \\
\hline \hline
\end{tabular}

A termalização foi de 5.000 passos de MC. Após esse ponto, as propriedades apenas oscilam em torno de um determinado valor, mostrando que o sistema está em equilíbrio. O valor médio da densidade ficou em $0,243 \mathrm{~g} / \mathrm{cm}^{3}$, ainda acima do valor experimental e não muito diferente da simulação contendo apenas He líquido. A simulação foi realizada em diversas etapas, cada uma com 200.000 passos de Monte Carlo. Após uma análise da função de distribuição radial e da função de auto-correlação da energia, selecionamos as configurações a serem submetidas aos 
cálculos de MQ.

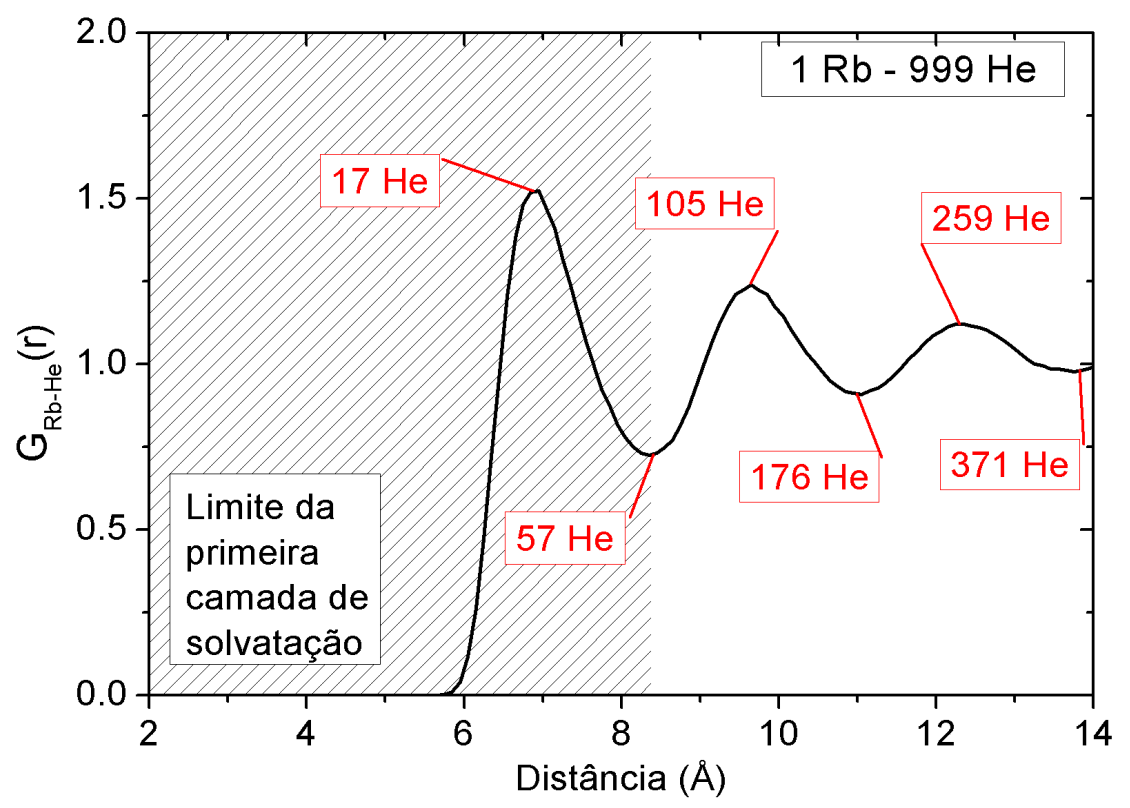

Figura 5.2: Função de distribuição radial $(G(r))$ mostrando as primeiras camadas de solvatação para o sistema $\mathrm{Rb}$ em He líquido usando o potencial de LJ com parâmetros do potencial KTTY para a interação Rb-He.

A função de distribuição radial pode ser vista na figura 5.2 . Fica clara a formação de camadas de solvatação em volta da impureza. Como átomos distantes pouco interferem nas propriedades espectroscópicas do soluto [23], consideramos apenas o solvente até completar a primeira camada de solvatação, a qual começa em torno de 5,9 A, tem seu máximo em aproximadamente 7,0 $\AA$ e finaliza por volta de 8,2 A. Assim, cada configuração selecionada, é composta do soluto e os 57 átomos de He da primeira camada. Comparando com os resultados obtidos através do modelo de agregado, observamos que existe uma boa concordância entre os valores do raio da bolha. No modelo de agregado, o raio médio está compreendido dentro primeira camada de solvatação da simulação do líquido, de modo que os valores de $R_{\text {mim }}$ ficaram entre 6,2 e 6,6 Å. A disposição dos átomos de He em torno do Rb e a forma dos orbitais atômicos estão na figura 5.3

Cada passo da simulação clássica corresponde a uma configuração, na qual 


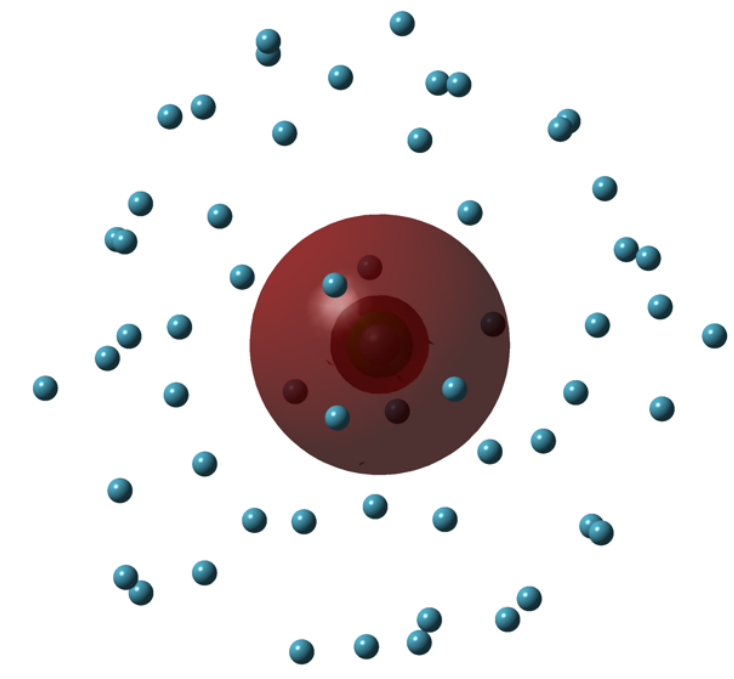

(a) Mais alto orbital ocupado do Rb.

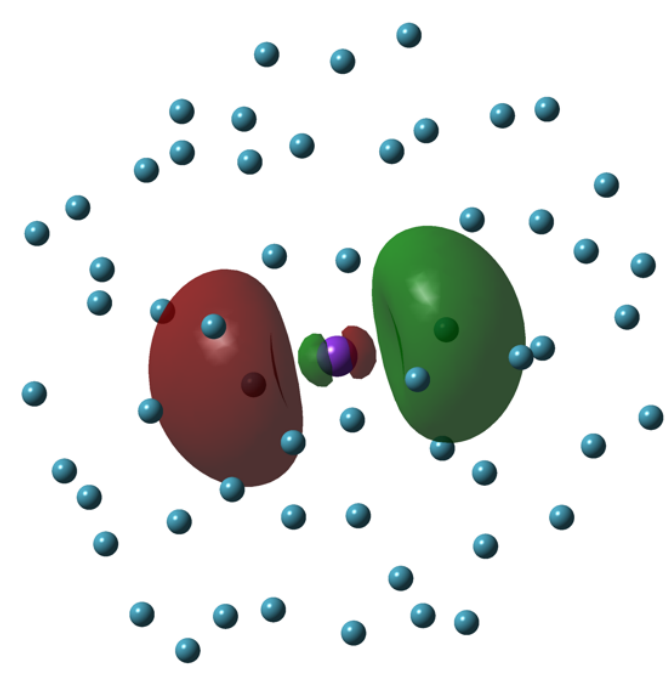

(b) Mais baixo orbital desocupado do Rb.

Figura 5.3: Disposição dos átomos de He em torno do Rb no He líquido. Representação dos orbitais atômicos onde(a) é o mais alto ocupado que tem a forma do orbital atômico do tipo $s$ e(b) é o mais baixo desocupado, que tem a forma ligeiramente deformada do orbital atômico do tipo $p$.

estão presentes as posições de todos os átomos da simulação. Porém, pode existir certa auto-correlação entre essas configurações. Como obteremos o valor do deslocamento espectral a partir de média estatística, podemos selecionar apenas algumas configurações estatisticamente descorrelacionadas, reduzindo muito o número de cálculos ab initio. A figura 5.4 mostra o comportamento da função de auto-correlação da energia obtida da simulação clássica.

A auto-correlação estatística entre as configurações possui um decaimento acentuado. Observamos que esses valores são levemente maiores nas etapas iniciais da simulação. Sendo assim, selecionamos a cada 3.000 passos da simulação clássica uma configuração para o cálculo de mecânica quântica. Desta forma, dos 200.000 passos da simulação, foram selecionadas 66 configurações para os cálculos de MQ, com menos de 0,001\% de correlação estatística.

Para os cálculos de MQ, também recorremos a muitas bases e funcionais híbridos utilizados anteriormente no modelo de agregado. Porém, em todos os cálculos 


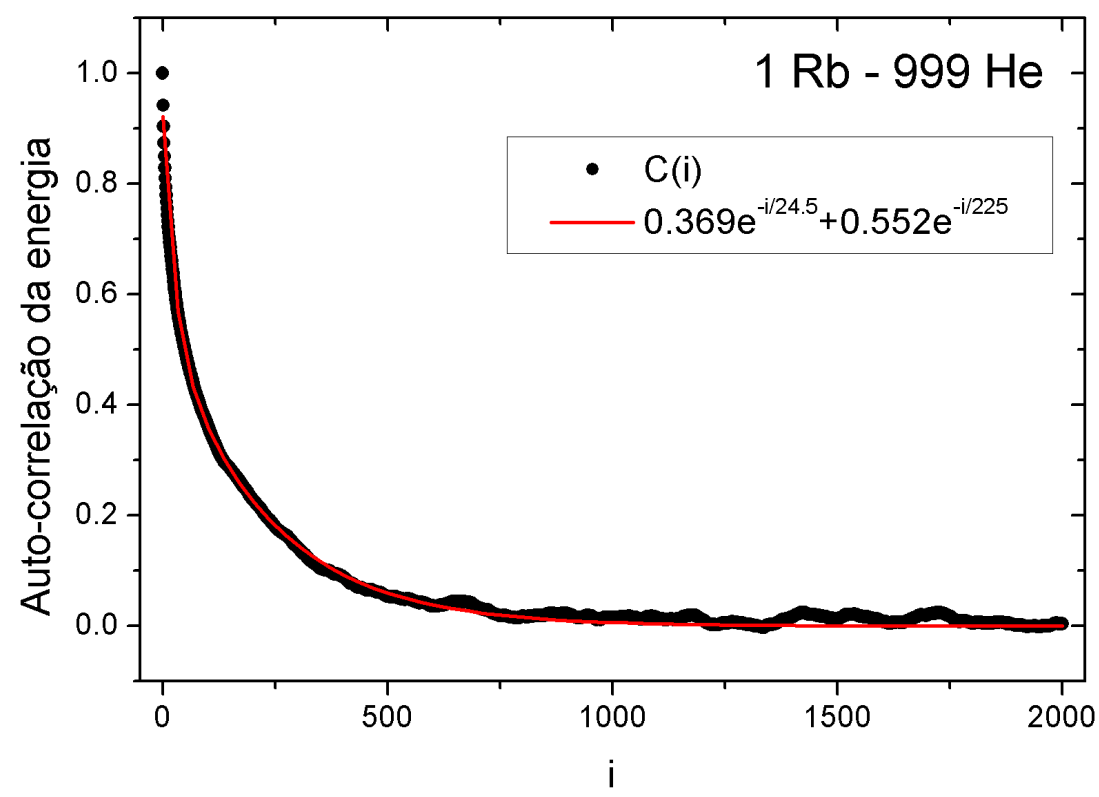

Figura 5.4: Função de auto-correlação da energia para a simulação de Rb em He líquido usando os parâmetros do potencial KTTY para a interação Rb-He.

de MQ de He líquido deste capítulo, só foi usada a base $6-311++G(2 d, 2 p)$ para o He, exceto no caso com LanL2MB e no tratamento do $\mathrm{Na}$ e $\mathrm{Na}_{2}$. Com a base $6-311++G(2 d, 2 p)$, cada átomo do solvente é representado por 10 funções bases. Usando uma base maior para o He, cc-pV5Z, com cada átomo de He representado por 55 funções bases, os resultados para o deslocamento espectral não modificaram muito para as configurações testadas. Além do mais, o custo computacional é bastante elevado para usar a base $c c-p V 5 Z$ para os átomos de He: quase 10 vezes mais tempo de CPU comparando com o uso da base $6-311++G(2 d, 2 p)$.

Cada configuração, submetida ao cálculo de $\mathrm{MQ}$, gera um valor de energia do estado excitado e é necessário fazer uma média sobre todas as 66 configurações selecionadas. O resultado do deslocamento espectral (Desl.) pode ser visto na tabela 5.3. A forma da distribuição da energia de excitação para o caso do funcional PBE1PBE com a base DZP para o $\mathrm{Rb}$ pode ser vista na figura 5.5. Usando uma função gaussiana para ajustar a distribuição dos resultados, podemos calcular a 
Tabela 5.3: Energia de excitação do Rb isolado e imerso em He líquido (Desl.) além da largura da linha de excitação HWHM com diferentes bases para o Rb e funcionais híbridos. Estes resultados foram obtidos com médias sobre configurações de uma simulação clássica com o potencial de KTTY.

\begin{tabular}{ccccc}
\hline \hline Funcional & Base do Rb & Isolado(nm) & Desl.(nm) & HWHM(nm) \\
\hline B3LYP & DZP & 778,82 & $-27,4$ & 6,4 \\
\hline B3P86 & DZP & 791,99 & $-27,9$ & 7,1 \\
\hline BHandHLYP & DZP & 812,28 & $-33,8$ & 6,7 \\
\hline \multirow{2}{*}{ O3LYP } & def2-qzvp & 908,77 & $-8,1$ & 9,2 \\
& DZP & 899,38 & $-15,1$ & 10,0 \\
\hline \multirow{2}{*}{ PBE1PBE } & DZP & 874,40 & $-20,0$ & 8,5 \\
& def2-qzvp & 869,27 & $-16,0$ & 8,1 \\
& LanL2MB & 837,73 & $-70,7$ & 13,7 \\
\hline \multirow{2}{*}{ EXPERIMENTAL [28] } & 787,34 & $-18,9$ & 5,0 \\
\hline \hline
\end{tabular}

largura da linha $\mathbf{H W M H}$, que também está exposta na tabela 5.3 .

Os resultados para o $\mathrm{Rb}$ isolado já foram descritos, quando discutimos o modelo de agregado. Usando o funcional PBE1PBE com as bases DZP e def2-qzop obtivemos excelentes valores do deslocamento espectral do Rb em He líquido, quando comparados com o valor experimental. Outro funcional que merece destaque é o O3LYP, que também apresentou um bom valor para o deslocamento espectral, porém apenas com o uso da base DZP. Para a largura de linha, vimos que a maioria de nossos resultados ficou abaixo de $10 \mathrm{~nm}$. Apesar do melhor resultado para o HWHM ter sido igual a 6,4 nm, obtido com o funcional B3LYP, todos eles superestimaram o valor experimental que é igual a 5,0 $\mathrm{nm}$.

A figura 5.5 mostra o comportamento da distribuição usando o funcional híbrido PBE1PBE com a base do Rb igual a DZP. Nota-se na figura 5.5 que a distribuição é levemente assimétrica. 


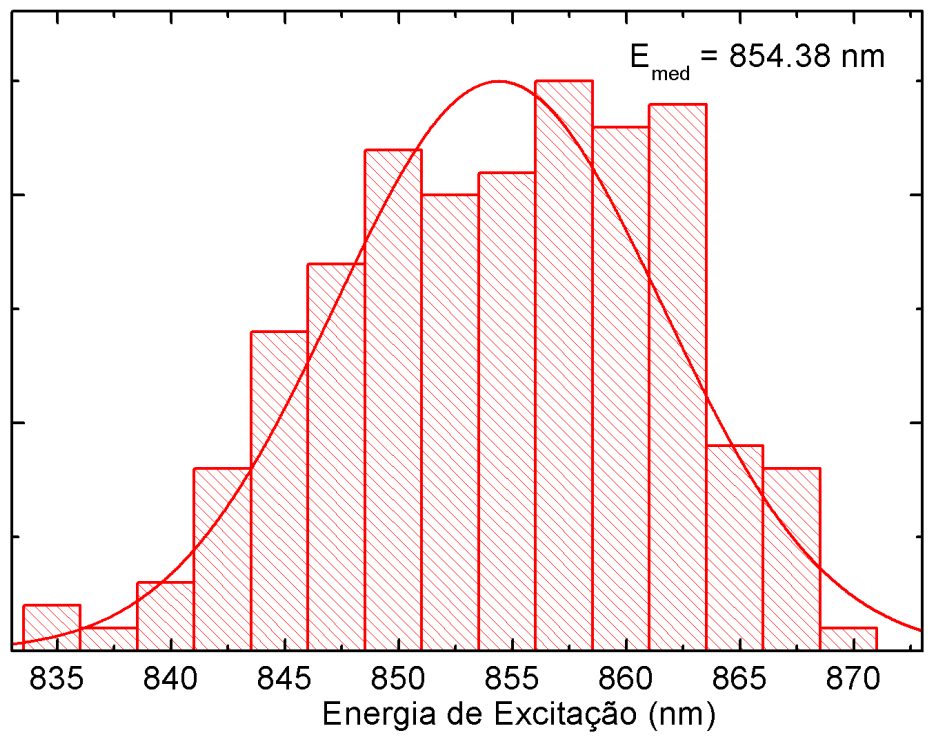

Figura 5.5: Histograma da distribuição da energia de excitação obtido com o funcional PBE1PBE e a base DZP para o Rb.

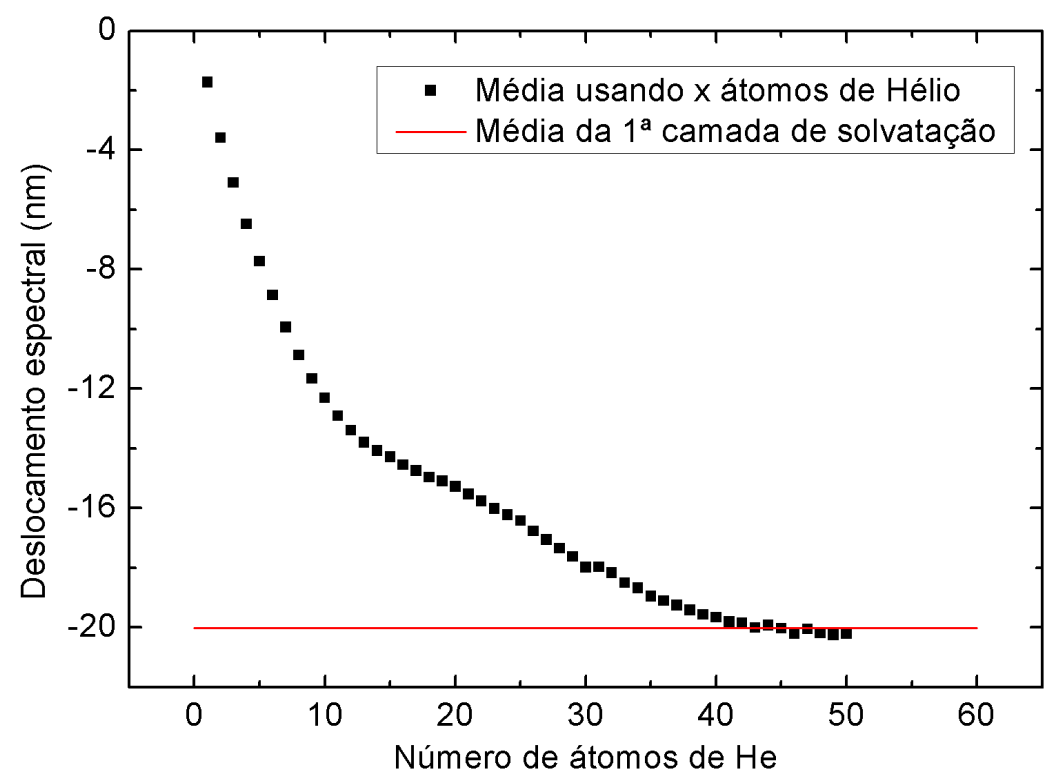

Figura 5.6: Convergência do deslocamento espectral em função do número de átomos de He mais próximos do $\mathrm{Rb}$, usando o funcional PBE1PBE e a base $D Z P$ para o $\mathrm{Rb}$.

Outra informação interessante é a convergência do deslocamento espectral em 
função do número de átomos de He. A fim de obter esta convergência, efetuamos cálculos para a média do deslocamento espectral das 66 configurações, aumentando gradativamente o número de átomos de He. Foram selecionados para o cálculo os átomo de He mais próximos do Rb. Na figura 5.6, observa-se que 43 átomos de He são suficientes para convergir à média do deslocamento espectral, obtido com primeira camada de solvatação completa, ou seja, 57 átomos de He. Esse resultado evidencia que a quantidade de átomos de $\mathrm{He}$, que influenciam no deslocamento espectral do $\mathrm{Rb}$, é menor do que a presente na primeira camada de solvatação.

\subsection{Potencial de Patil}

Para estudar as outras amostras alcalinas, vamos usar um potencial desenvolvido por Patil [38], a partir dos coeficientes de van der Waals. Inicialmente, este potencial será usado para reestudar o caso do $\mathrm{Rb}$ e, posteriormente, consideraremos os casos do $\mathrm{Na}$, Cs e o $\mathrm{Na}_{2}$. De acordo com o autor [38], a função potencial foi desenvolvida usando expressões perturbativas. A força atrativa, de longo alcance, é proveniente dos termos de van de Waals amortecidos e a repulsão é devido aos efeitos de exchange-Coulomb da função $s$ dos elétrons do He com os elétrons de valência dos átomos alcalinos. Para o He, seguimos usando os parâmetros de LJ obtidos com $\operatorname{CCSD}(\mathrm{T}) / c c-p V 5 Z$ descrito no início deste capítulo. Os parâmetros de simulação de MC (temperatura, pressão, etc.) foram mantidos a fim de preservar os sistemas correspondentes (tabela 5.1).

\subsubsection{Rb em He Líquido}

O primeiro sistema a ser tratado com o potencial de Patil [38] deve fornecer uma comparação com o potencial anterior, o KTTY. Sendo assim, decidimos iniciar com um sistema já estudado em nosso trabalho: Rb em He líquido. Os valores dos 
parâmetros do potencial LJ estão na tabela 5.4 .

Tabela 5.4: Parâmetros dos potenciais LJ usando cálculo ab-initio CCSD(T)/cc-pV5Z para a interação He-He e o potencial de Patil [38] para a interação Rb-He.

\begin{tabular}{ccc}
\hline \hline Átomo & $\epsilon(\mathrm{kcal} / \mathrm{mol})$ & $\sigma(\AA)$ \\
\hline $\mathrm{Rb}$ & 0,000888 & 14,9915 \\
$\mathrm{He}$ & 0,0089 & 2,8480 \\
\hline \hline
\end{tabular}

Com relação aos resultados da simulação clássica, houve poucas mudanças. A mais interessante pode ser observada na $G(r)$, figura 5.7. Com o uso dos parâmetros do potencial de Patil, temos agora menos átomos nas camadas de solvatação, quando comparamos com a figura 5.2. O máximo do primeiro pico ocorre próximo de 6,6 Å e possui em média 15 átomos até este ponto. A primeira camada finaliza com 53 átomos de He, 4 a menos que na simulação usando o potencial KTTY.

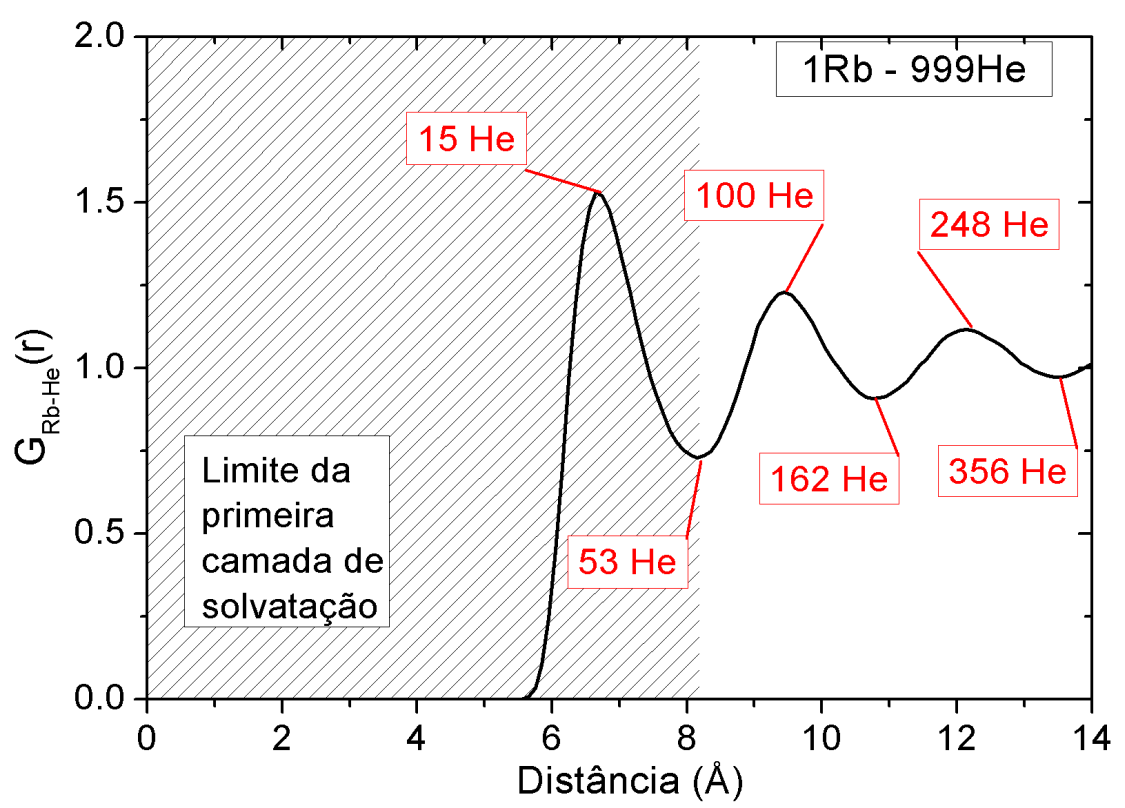

Figura 5.7: Função de distribuição radial $(G(r))$ para a simulação do Rb em He líquido usando os parâmetros do potencial de Patil para a interação $\mathrm{Rb}-\mathrm{He}$.

Sobre a auto-correlação estatística da energia, não houve mudanças significa- 
tivas, possuindo ainda um decaimento bem acentuado. Assim, selecionamos 100 configurações para os cálculos de MQ e o número de átomos de He foi reduzido até a primeira camada de solvatação. Na tabela 5.5. apresentamos os valores do deslocamento espectral e da largura de linha. Com o uso do novo potencial de Patil, obtivemos excelentes resultados para o deslocamento com o uso do funcional O3LYP. Com relação à largura de linha, o novo potencial da simulação clássica apresentou um pequeno aumento nos valores comparado ao uso do potencial KTTY, afastando-os um pouco do valor experimental.

Tabela 5.5: Energia de excitação do Rb isolado e imerso em He líquido (Desl.) além da largura da linha de excitação HWHM com diferentes bases para o Rb e funcionais híbridos. Estes resultados foram obtidos com médias sobre configurações de uma simulação clássica com o potencial de Patil.

\begin{tabular}{ccccc}
\hline \hline Funcional & Base do Rb & Isolado(nm) & Desl.(nm) & HWHM(nm) \\
\hline \multirow{2}{*}{ O3LYP } & DZP & 899,38 & $-23,3$ & 11,5 \\
& def2-qzvp & 908,77 & $-16,3$ & 10,9 \\
\hline \multirow{2}{*}{ PBE1PBE } & DZP & 874,40 & $-27,1$ & 9,5 \\
& def2-qzvp & 869,27 & $-23,1$ & 9,3 \\
\hline \multirow{2}{*}{ EXPERIMENTAL [28] } & 787,34 & $-18,9$ & 5,0 \\
\hline \hline
\end{tabular}

\subsubsection{Cs em He Líquido}

O átomo de Cs imerso em He líquido foi o segundo sistema a ser tratado com o potencial de Patil. Como um átomo de Cs em sua configuração normal possui 55 elétrons, é um grande problema encontrar uma base que descreva muito bem esse elemento, principalmente algum conjunto que descreva todos os elétrons. Porém, o uso de bases com ECP é de grande utilidade para contornar esse tipo de problema. Assim, apenas os 9 elétrons mais externos na valência serão considerados para o cálculo de $\mathrm{MQ}$, devido à base usada para tratar esse elemento. 
Para o He, seguimos usando os parâmetros de LJ obtidos com CCSD(T), descrito no início do capítulo. Para o Cs, obtivemos os parâmetros com o potencial de Patil [38]. Na tabela 5.6, encontram-se os valores dos parâmetros do potencial utilizado.

Tabela 5.6: Parâmetros dos potenciais LJ para a simulação do Cs em He líquido usando cálculo ab-initio $\operatorname{CCSD}(\mathrm{T}) / c c-p V 5 Z$ para a interação He-He e o potencial de Patil [38] para a interação Cs-He.

\begin{tabular}{ccc}
\hline \hline Átomo & $\epsilon(\mathrm{kcal} / \mathrm{mol})$ & $\sigma(\AA)$ \\
\hline Cs & 0,0006 & 16,6579 \\
$\mathrm{He}$ & 0,0089 & 2,8480 \\
\hline \hline
\end{tabular}

Como houve apenas uma troca do átomo de $\mathrm{Rb}$ por um de $\mathrm{Cs}$, as propriedades termodinâmicas não mudaram muito para a simulação clássica do sistema anteriormente tratado. Algumas características interessantes foram obtidas com a análise da função de distribuição radial, figura 5.8 . Fica clara a formação de camadas em torno do átomo de Cs, que estão relacionados com os picos e vales na figura 5.8 . A primeira camada inicia em 6,0 $\mathrm{A}$ e finaliza em $8,5 \AA$. No ponto mais alto da $G(r)$, localizado a uma distância de 6,95 ̊̊ do átomo de Cs, temos em média 20 átomos do solvente. Na primeira camada de solvatação estão presentes 58 átomos de He. Nos cálculos de mecânica quântica, reduziremos o nosso sistema até esta primeira camada. No modelo de agregado, os valores de $R_{\min }$ que apresentam os melhores valores para o deslocamento espectral, estão entre 6,5 $\AA$ e 6,7 $\AA$, bem próximo do pico da primeira camada de solvatação, e ainda concorda com o número de átomos de He.

Com relação à auto-correlação estatística entre as configurações geradas na simulação via $\mathrm{MC}$, verificamos que o intervalo de correlação é de 170 passos. Porém estamos selecionando configurações separadas de 2.000 passos de cada uma e o valor da correlação para dois estados separados por 2.000 passos é $0,4 \%$, praticamente 


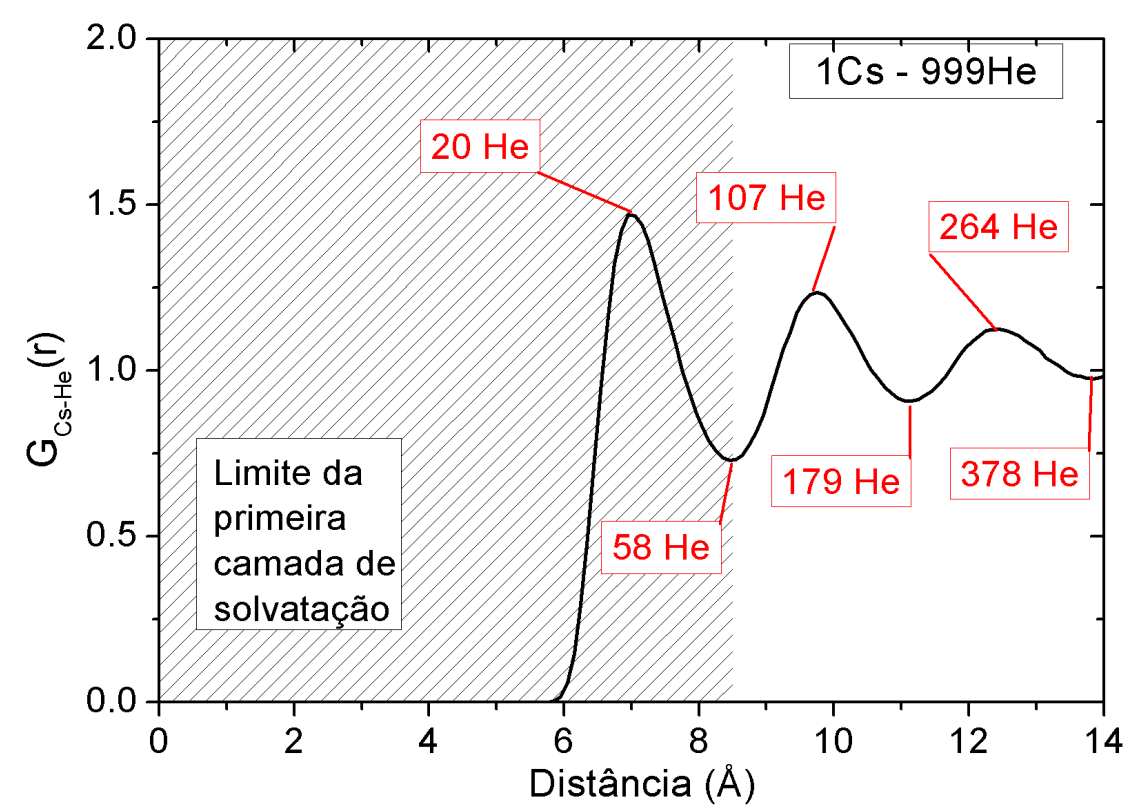

Figura 5.8: Função de distribuição radial $(G(r))$ para a simulação do Cs em He líquido usando os parâmetros do potencial de Patil para a interação Cs-He.

desprezível. Novamente, teremos 100 configurações, com o número de átomos de He reduzido à primeira camada de solvatação.

Os resultados para o deslocamento espectral do Cs em He líquido, da largura da linha e da energia de excitação do átomo isolado estão na tabela 5.7. Como podemos observar, o resultado não é muito satisfatório para as bases LanL2MB e SDDALL. O deslocamento calculado é da ordem de $-100 \mathrm{~nm}$ para a primeira e -68 $\mathrm{nm}$ para a segunda. A base def2-qzop associado aos funcionais O3LYP e PBE1PBE apresentam os melhores valores para o deslocamento, bem próximo ao experimento. Este resultado está de acordo com o obtido no modelo de agregado. Para a largura de linha obtivemos um valor menor com a base def2-qzvp, porém ainda superior ao valor experimental. 
Tabela 5.7: Energia de excitação do Cs isolado e imerso em He líquido (Desl.) além da largura da linha de excitação HWHM com diferentes bases para o Cs e funcionais híbridos. O sinal * indica que a base dos átomos de He é igual a $6-311++G(2 d, 2 p)$

\begin{tabular}{ccccc}
\hline \hline Funcional & Base dos Átomos & Isolado(nm) & Desl.(nm) & HWHM(nm) \\
\hline \multirow{2}{*}{ O3LYP } & def2-qzvp & 1035,70 & $-17,7$ & 14,6 \\
\hline \multirow{2}{*}{ PBE1PBE } & LanL2MB & 943,94 & $-104,7$ & 21,5 \\
& SDDALL & 881,32 & $-67,5$ & 17,8 \\
& def2-qzvp & 980,03 & $-25,6$ & 12,7 \\
\hline \multicolumn{2}{c}{ EXPERIMENTAL [28] } & 866,19 & $-22,2$ & 5,4 \\
\hline \hline
\end{tabular}

\subsubsection{Na em He Líquido}

Já estudado no grupo [23], o sistema $\mathrm{Na}$ em He líquido serve de base para comparar as mudanças com o sistema $\mathrm{Na}_{2}$ no mesmo ambiente. Usando os mesmos parâmetros de simulação dos sistemas anteriores, não são esperadas grandes mudanças nas propriedades termodinâmicas da simulação. Os valores dos parâmetros do potencial utilizado são os seguintes:

Tabela 5.8: Parâmetros dos potenciais LJ para a simulação do Na em He líquido usando cálculo ab-initio $\operatorname{CSD}(\mathrm{T}) / c c-p V 5 Z$ para a interação He-He e o potencial de Patil [38] para a interação Na-He.

\begin{tabular}{ccc}
\hline \hline Átomo & $\epsilon(\mathrm{kcal} / \mathrm{mol})$ & $\sigma(\AA)$ \\
\hline $\mathrm{Na}$ & 0,0013 & 11,4448 \\
$\mathrm{He}$ & 0,0089 & 2,8480 \\
\hline \hline
\end{tabular}

A função de auto-correlação estatística da simulação clássica do $\mathrm{Na}$ em $\mathrm{He}$ líquido apresenta um decaimento muito acentuado. Podemos desconsiderar o valor da correlação, pois as configurações são selecionadas de tal forma que a separação entre duas configurações subsequentes é mais de 10 vezes maior do que o intervalo de correlação. 


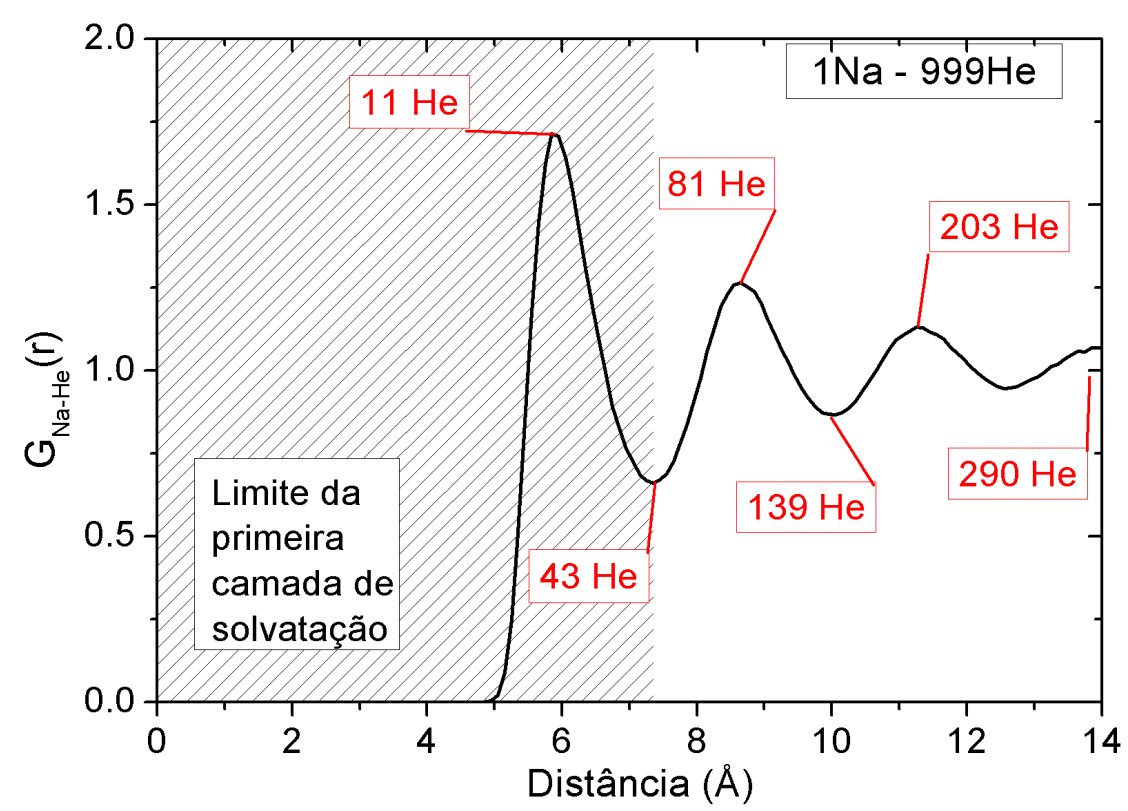

Figura 5.9: Função de distribuição radial $(G(r))$ para a simulação do Na em He líquido usando os parâmetros do potencial de Patil para a interação Na-He.

Da simulação de $\mathrm{MC}$, obtemos a função de distribuição radial, conforme a figura 5.9. A primeira camada de solvatação inicia em 5,1 $\AA$ e finaliza em 7,5 $\mathrm{A}$, na qual estão presentes em média 43 átomos de He. Muitos sistemas tratados com o modelo de agregado (tabela 4.7) apresentaram um $R_{\min }$ próximo ao pico da primeira camada de solvatação, correspondendo também ao número de átomos de solvente.

Ressaltamos que não existe resultado experimental para o deslocamento espectral do Na em He líquido, mas como existe para os elementos Rb e Cs, estima-se que o valor do deslocamento espectral do Na em He líquido esteja entre -14 nm e $-16 \mathrm{~nm}$.

Os cálculos de TDDFT foram realizado em 100 configurações estatisticamente descorrelacionadas, contendo a primeira camada de solvatação completa mais o átomo de Na. Os resultados presentes na tabela 5.9 estão em boa concordância com o obtido por Ludwig et al. [23]. Um deslocamento da ordem de $15 \mathrm{~nm}$ está exatamente no meio da faixa dos valores esperados, no qual foi obtido tanto com 
Tabela 5.9: Energia de excitação do Na isolado e imerso em He líquido (Desl.) além da largura da linha de excitação HWHM com diferentes bases para o Na e funcionais híbridos. O sinal * indica que a base dos átomos de He é igual a $6-311++G(2 d, 2 p)$

\begin{tabular}{ccccc}
\hline \hline Funcional & Base dos Átomos & Isolado(nm) & Desl.(nm) & HWHM(nm) \\
\hline \multirow{2}{*}{ O3LYP } & $6-311++G(d, p)$ & 605,04 & -15 & 7,04 \\
& def2-qzvp* & 593,79 & -11 & 5,98 \\
& sadlej* $^{*}$ & 604,39 & -12 & 6,65 \\
\hline \multirow{2}{*}{ PBE1PBE } & $6-311++G(d, p)$ & 595,26 & -15 & 4,70 \\
& def2-qzvp* & 592,01 & -13 & 4,49 \\
\hline \multirow{2}{*}{ Sugestão experimental } & 589,29 & -14 a -16 & 4,57 \\
\hline \hline
\end{tabular}

o funcional PBE1PBE quanto com o O3LYP associado a base $6-311++G(d, p)$. Da mesma forma que o $\mathrm{Rb}$ e Cs, os orbitais atômicos possuem a forma de um orbital $s$ para o último orbital ocupado, e a forma semelhante ao orbital $p$ para os três primeiros orbitais desocupados $\left(p_{x}, p_{y}\right.$ e $\left.p_{z}\right)$.

\subsection{4 $\quad \mathrm{Na}_{2}$ em He Líquido}

Como último resultado, apresentamos o $\mathrm{Na}_{2}$ em He Líquido. Não estamos interessados no espectro roto-vibracional do $\mathrm{Na}_{2}$, apenas no espectro eletrônico. Com a simulação clássica será possível calcular o raio da bolha e deslocamento da energia de excitação, duas características que vamos comparar os resultados com o agregado $\mathrm{Na}_{2}-\mathrm{He}_{14}$.

Os parâmetros da simulação de MC foram os mesmos usados nos casos anteriores, conforme a tabela 5.1. Os parâmetros para o potencial de LJ são os mesmos usados anteriormente no sistema $\mathrm{Na}$ em He líquido, mudando apenas o soluto, que passa a ser o dímero $\mathrm{Na}_{2}$ com distância fixa igual a 3,079 $\AA$, discutida no modelo 
de agregado (seção 4.4). Com relação aos resultados da simulação de $\mathrm{MC}$, foram verificadas apenas pequenas mudanças na energia potencial do sistema. Os valores calculados do volume e da densidade ficaram bem próximos para os sistemas $\mathrm{Na}$ e $\mathrm{Na}_{2}$, ambos em He líquido.

Vamos agora verificar algumas propriedades da simulação, como a função de distribuição radial e a função de auto-correlação estatística, figuras 5.10 e 5.11 , respectivamente. Fica evidente a formação de camadas de solvatação. Nesse sistema, a primeira camada começa em torno de 5,2 Å e termina em 8,0 A. Em média, estão presentes 54 átomos de He nesta camada, que tem um máximo de distribuição em 6,9 A. No modelo de agregado, os valores de $R_{\text {min }}$ ficaram entre 5,7 $\AA$ e 5,8 $\AA$, que de acordo com a função de distribuição radial, está presente na primeira camada e apresenta em média um número bem pequeno de átomos de He. Com respeito a função de auto-correlação estatística, seu comportamento apresenta um decaimento muito acentuado da mesma forma que nos outros sistemas tratados.

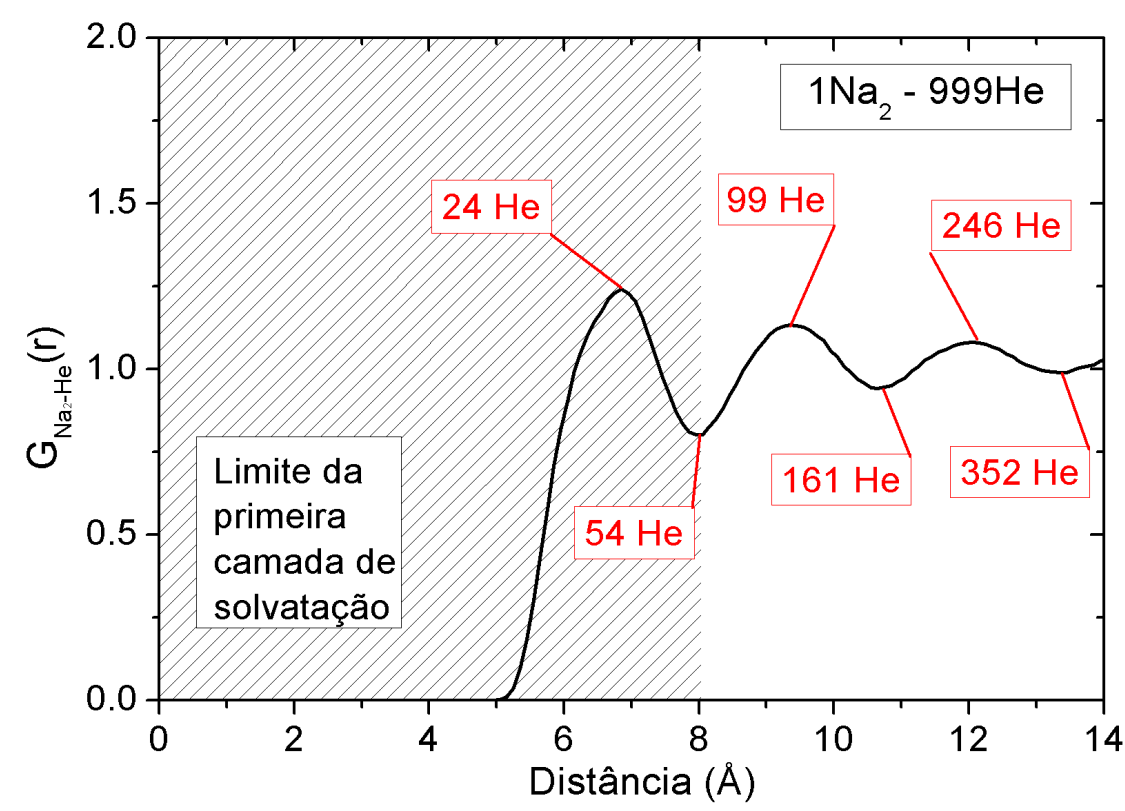

Figura 5.10: Função de distribuição radial $(G(r))$ para a simulação do $\mathrm{Na}_{2}$ em He líquido usando os parâmetros do potencial de Patil para a interação Na-He. 
O intervalo de correlação para esta simulação ficou igual a 157 passos. Como estamos trabalhando com configurações bem mais afastadas do que o intervalo de correlação, afirmamos que estamos trabalhando com configurações bem descorrelacionadas.

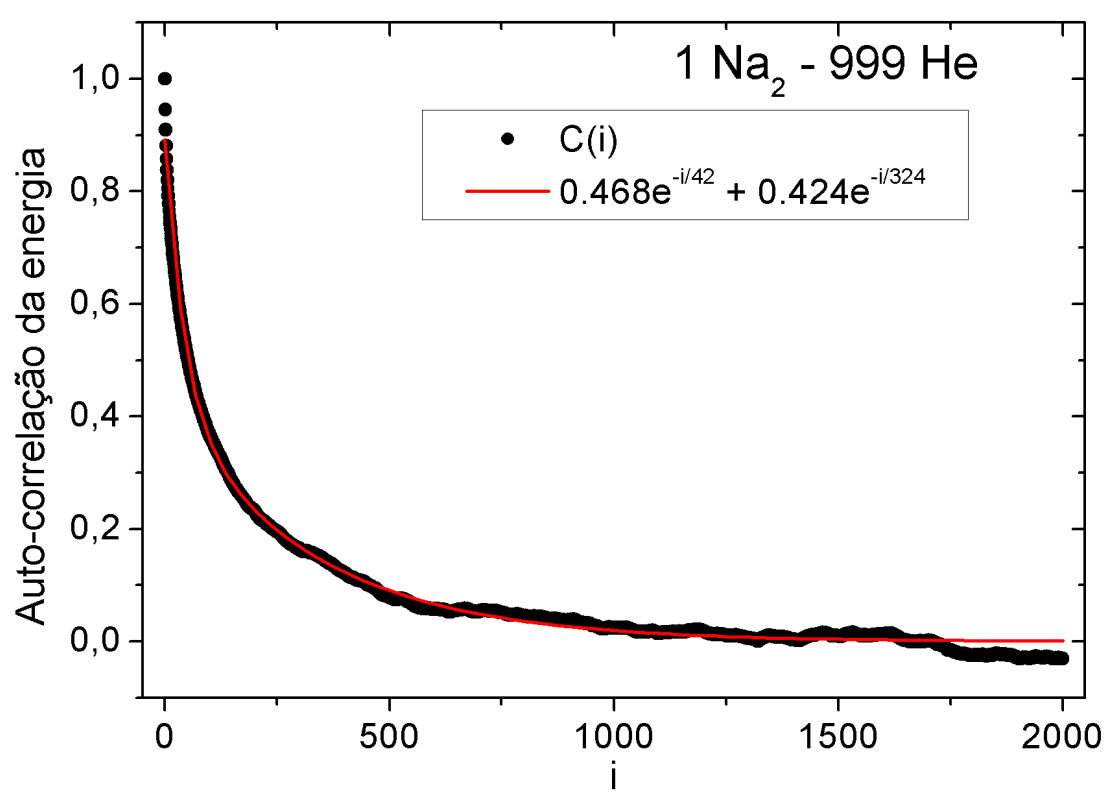

Figura 5.11: Função de auto-correlação estatística da energia para a simulação do $\mathrm{Na}_{2}$ em He líquido em função dos passos de MC.

Na tabela 5.10, estão os valores para o deslocamento espectral para a transição do estado fundamental $X^{1} \Sigma_{g}^{+}$para os estados $A^{1} \sum_{u}^{+}$e $B^{1} \Pi_{u}$. Foram usados diversos funcionais híbridos e bases. Vale lembrar que não estamos considerando mudanças no espectro rotacional ou vibracional do dímero. Assim, como no modelo de agregado de $\mathrm{He}$, obtivemos um bom resultado com o funcional PBE1PBE com a base $6-311++G(d, p)$. O valor do deslocamento espectral ficou em $551 \mathrm{~cm}^{-1} \mathrm{em}$ boa concordância com o resultado experimental. 
Tabela 5.10: Energia de excitação do $\mathrm{Na}_{2}$ isolado e imerso em He líquido para as transições $X^{1} \Sigma_{g}^{+} \rightarrow$ $A^{1} \Sigma_{u}^{+} \mathrm{e} X^{1} \Sigma_{g}^{+} \rightarrow B^{1} \Pi_{u}$.

\begin{tabular}{cccccc}
\hline \hline \multirow{2}{*}{ Funcional } & \multirow{2}{*}{ Base do Rb } & \multicolumn{2}{c}{ Isolado(eV) } & \multicolumn{2}{c}{ Desl.(cm $\left.{ }^{-1}\right)$} \\
& & $X-A$ & $X-B$ & $X-A$ & $X-B$ \\
\hline B3LYP & $6-311++G(d, p)$ & 2,105 & 2,658 & 319 & 1079 \\
\hline B3P86 & $6-311++G(d, p)$ & 2,065 & 2,666 & 336 & 933 \\
\hline O3LYP & $6-311++G(d, p)$ & 2,062 & 2,482 & 151 & 496 \\
\hline \multirow{2}{*}{ PBE1PBE } & def2-qzvp & 2,053 & 2,582 & 29 & 434 \\
& sad-lej & 2,051 & 2,582 & 44 & 505 \\
& $6-311++G(d, p)$ & 2,056 & 2,580 & 80 & 551 \\
\hline \multirow{2}{*}{ EXPERIMENTAL } & & $2,519[88]$ & & $700[28]$ \\
\hline \hline
\end{tabular}

\subsection{Conclusões Parciais}

Já foram mencionados os resultados espectroscópicos do modelo de agregado no capítulo anterior, mas vale relembrar que existe uma boa concordância entre o modelo de agregado e a simulação $\mathrm{S}-\mathrm{MM} / \mathrm{MQ}$, com valores próximos do raio da bolha e do valor do deslocamento espectral. Em muitos casos, o raio do agregado de átomos de He fica dentro da primeira camada de solvatação da simulação do sistema He líquido.

A simulação líquida gerou, em muitos casos, excelentes valores para o deslocamento espectral e também para a largura de linha. Ressaltamos que o modelo de agregado não gera a largura de linha, devido a preservação da simetria do sistema. Para o deslocamento espectral do $\mathrm{Rb}$ em He líquido, o resultado mais próximo do experimento foi obtido com o funcional PBE1PBE com a base DZP. Além disso, obtivemos excelentes resultados usando o funcional híbrido O3LYP e com a base def2-qzop. Nos outros monômeros, Cs e Na, conseguimos excelentes resultados para 
o deslocamento espectral com a combinação dos funcionais PBE1PBE e O3LYP com a base def2-qzop. Para a largura de linha, os melhores resultados são obtidos com o funcional B3LYP. No caso do dímero de $\mathrm{Na}$, o melhor resultado, para a energia de excitação isolado, e em He líquido, foi obtido com o funcional PBE1PBE e com o conjunto de bases $6-311++G(d, p)$.

Como esperado, a cavidade ou bolha foi formada em volta do átomo alcalino nas simulações clássicas. Esse espaço vazio é provocado pelo princípio de Pauli, não permitindo a existência de um mesmo orbital com mais de dois elétrons desemparelhados. Essa repulsão é muito forte entre o soluto e os átomos de solvente. Vale notar que os átomos de He que vão influenciar o soluto estão bem afastados. Por exemplo, no caso do $\mathrm{Na}$, os átomos de He vão aparecer a partir de $5 \AA$.

Uma vantagem do uso da simulação do He líquido é que como trabalharemos com uma média de vários valores de energia de excitação, teremos também um desvio padrão, com o qual é possível obter a largura da linha da excitação, e assim o valor de HWHM. Apesar do valor calculado de HWHM superestimar os resultados experimentais, os dois se encontram bem próximos. Outra vantagem é que o valor de deslocamento é gerado por uma média, que na verdade é um valor da convergência das energias de excitação em função do números de átomos de He. 


\section{Capítulo 6}

\section{Conclusões}

Nesta dissertação estudamos as mudanças ocorridas no espectro de átomos alcalinos quando imersos em He líquido. Essas mudanças são, em geral, alargamento e deslocamento da linha espectral. Os sistemas estudados foram o $\mathrm{Na}, \mathrm{Rb}, \mathrm{Cs}$ e o dímero de Na. Como já comentamos, os átomos alcalinos foram escolhidos por possuírem um espectro bem característico. Quando estes elementos estão presentes em He líquido é formada uma bolha ou cavidade devida ao princípio de exclusão de Pauli. Para todos esses sistemas realizamos dois procedimentos: usando um modelo de agregado de He e a simulação dos átomos alcalinos em He líquido.

Nosso modelo de agregado consiste no átomo alcalino cercado por 14 átomos de He, que não gera a largura da linha espectral devido à sua alta simetria. Porém, este modelo fornece excelentes resultados para o deslocamento espectral. Variando a distância $R_{X-H e}$ onde $X$ é $\mathrm{Na}, \mathrm{Rb}, \mathrm{Cs}$ ou $\mathrm{Na}_{2}$, procuramos obter a configuração de mínima energia e sobre ela, realizar os cálculos de MQ. Na simulação do He líquido procuramos selecionar potenciais para descrever as interações entre os átomos presentes. Além disso, é necessário estabelecer os parâmetros da simulação realizada em $p=1 \mathrm{~atm}$ e $T=3 \mathrm{~K}$. Assim, efetuamos a simulação do elemento alcalino mais 999 átomos de He. Selecionamos apenas algumas configurações estatisticamente descorrelacionadas para os cálculos por MQ e tentamos compartilhar os mesmos 
funcionais híbridos e bases no modelo de agregado e na simulação de He líquido.

Apenas com a simulação de He líquido foi possível obter a largura de linha, ainda que os valores apresentados ficassem um pouco acima dos resultados experimentais. Outra vantagem do uso da simulação de He líquido, é que o resultado para o deslocamento espectral apresentado é na verdade uma média de várias configurações e não apenas uma única configuração. Além do mais, esse mesmo valor pode ser obtido pela convergência do deslocamento espectral ao adicionarmos átomos de He mais próximos, a fim de completar a primeira camada de solvatação.

Em geral, conseguimos excelentes resultados do deslocamento espectral para os monômeros alcalinos em He, usando os funcionais híbridos PBE1PBE e O3LYP com a base def2-qzvp. Para o valor da energia de excitação dos monômeros isolados, os funcionais híbridos B3LYP e B3P86 associados à mesma base, apresentaram os melhores valores. No caso do $\mathrm{Na}_{2}$, bons resultados foram obtidos. Entretanto, estamos buscando novos conjuntos de bases e/ou funcionais para entender o motivo da diferença entre os valores encontrados. Verificamos também uma correspondência entre o raio da bolha ao comparar os resultados usando a simulação do He líquido e o agregado de He. Apesar da dificuldade em estimar o tamanho da bolha em He líquido, ela pode ser obtida através da função de distribuição radial.

Este trabalho abre a possibilidade de estudar estruturas maiores em He líquido. Ao tratar certas moléculas, pode-se fazer um estudo dos efeitos do solvente sobre o dipolo, mudanças de níveis vibracionais e rotacionais e muitos outros. Outra análise que pode ser efetuada é a comparação o deslocamento espectral com a variação de pressão. Já existem trabalhos experimentais que tratam as mudanças do espectro do $\mathrm{Rb}$ e Cs em diversas pressões. 


\section{Referências Bibliográficas}

[1] Bennemann, K. H. e Ketterson, J. B. The Physics of Liquid and Solid Helium (Interscience Monographs and Texts in Physics And Astronomy). John Wiley \& Sons, (1976).

[2] Guénault, T. Basic Superfluids. CRC Press, (2003).

[3] Tilley, D. R. e Tilley, J. Superfluidity and Superconductivity. Institute of Physics Publishing, Philadelphia, $3^{3}$ edição, (1990).

[4] Landau, L. Physical Review 60(4), 356-358 (1941).

[5] Bauer, H., Beau, M., Fischer, J., Reyher, H. J., Rosenkranz, J., e Venter, K. Physica B: Condensed Matter 165-166(Part 1), 137 - 138 (1990). Proceedings of the 19th International Conference on Low Temperature Physics.

[6] Bauer, H., Beau, M., Bernhardt, A., Friedl, B., e Reyher, H. J. Physics Letters A 137(4-5), 217 - 224 (1989).

[7] Kinoshita, T., Fukuda, K., Takahashi, Y., e Yabuzaki, T. Physical Review A 52(4), 2707-2716 (1995).

[8] Guo, W., Jin, D., Seidel, G. M., e Maris, H. J. Journal of Physics: Conference Series 150(2), 022020 (2009).

[9] Guo, W. e Maris, H. Journal of Low Temperature Physics 148(3), 199-206 (2007). 
[10] Classen, J., Su, C. K., Mohazzab, M., e Maris, H. J. Journal of Low Temperature Physics 110(1), 431-436 (1998).

[11] Northby, J. A. e Sanders, T. M. Physical Review Letters 18(26), 1184-1186 (1967).

[12] Coutinho, K., Canuto, S., Mukherjee, P. K., e Fricke, B. Advances in the Theory of Atomic and Molecular Systems, volume 20, chapter Spectroscopy of Atoms in Liquid Helium Environment: A Theoretical Perspective, 183-200. Springer Netherlands (2009).

[13] Tabbert, B., Günther, H., e Putlitz, G. Journal of Low Temperature Physics 109(5), 653-707 (1997).

[14] Tabbert, B., Beau, M., Günther, H., Häußler, W., Hönninger, C., Meyer, K., Plagemann, B., e zu Putlitz, G. Zeitschrift für Physik B Condensed Matter 97(3), 425-432 (1995).

[15] Yabuzaki, T., Kinoshita, T., Fukuda, K., e Takahashi, Y. Zeitschrift für Physik B Condensed Matter 98(3), 367-369 (1995).

[16] Hui, Q., Persson, J. L., Beijersbergen, J. H. M., e Takami, M. Zeitschrift für Physik B Condensed Matter 98(3), 353-357 (1995).

[17] Beau, M., Günther, H., zu Putlitz, G., e Tabbert, B. Zeitschrift für Physik B Condensed Matter 101(2), 253-262 (1996).

[18] Dalfovo, F. Zeitschrift für Physik D Atoms, Molecules and Clusters 29(1), 61-66 (1994).

[19] Ancilotto, F., Cheng, E., Cole, M. W., e Toigo, F. Zeitschrift für Physik B Condensed Matter 98(3), 323-329 (1995).

[20] Dupont-Roc, J. Zeitschrift für Physik B Condensed Matter 98(3), 383-386 (1995). 
[21] Gspann, J. Zeitschrift für Physik B Condensed Matter 98(3), 405-411 (1995).

[22] DeToffol, G., Ancilotto, F., e Toigo, F. Journal of Low Temperature Physics 102(5), 381-410 (1996).

[23] Ludwig, V., Mukherjee, P. K., Coutinho, K., e Canuto, S. Physical Review A 72(6), 062714 (2005).

[24] Coutinho, K. e Canuto, S. volume 28 of Advances in Quantum Chemistry, 89 105. Academic Press (1997).

[25] Coutinho, K. e Canuto, S. The Journal of Chemical Physics 113(20), 9132-9139 (2000).

[26] Coutinho, K. e Canuto, S. Journal of Molecular Structure: THEOCHEM 632(1-3), $235-246$ (2003).

[27] Vitiello, S. A. e Schmidt, K. E. Physical Review B 60(17), 12342-12348 (1999).

[28] Takahashi, Y., Sano, K., Kinoshita, T., e Yabuzaki, T. Physical Review Letters 71(7), 1035-1038 (1993).

[29] Bauer, H., Beau, M., Friedl, B., Marchand, C., Miltner, K., e Reyher, H. J. Physics Letters A 146(3), 134 - 140 (1990).

[30] Anton, J., Fricke, B., Mukherjee, P. K., e Fritzsche, S. Physics Letters A 372(24), $4462-4464$ (2008).

[31] Allen, M. P. e Tildesley, D. J. Computer Simulation of Liquids. Oxford University Press, $1^{a}$ edição, (1996).

[32] Coutinho, K. R. Modelo Discreto de Solvente. Solvatocromismo no Espectro de Absorção Molecular. Tese de doutoramento, Universidade de São Paulo, (1997). 
[33] Coutinho, K. e Canuto, S. DICE: A Monte Carlo program for molecular liquid simulation, , v. 2.9, (2003). Universidade de São Paulo.

[34] Salinas, S. R. A. Introdução à Física Estatística. Edusp, 2a edição, (2005).

[35] Janzen, A. R. e Aziz, R. A. The Journal of Chemical Physics 103(22), 9626-9630 (1995).

[36] Kleinekathöfer, U., Tang, K. T., Toennies, J. P., e Yiu, C. L. Chemical Physics Letters 249(3-4), $257-263$ (1996).

[37] Tang, K. T. e Toennies, J. P. The Journal of Chemical Physics 80(8), 3726-3741 (1984).

[38] Patil, S. H. The Journal of Chemical Physics 94(12), 8089-8095 (1991).

[39] Coutinho, K., Oliveira, M. J. D., e Canuto, S. International Journal of Quantum Chemistry 66(3), 249-253 (1998).

[40] Chatfield, C. The Analysis of Time Series. An Introduction. Chapman and Hall, London, $3^{a}$ ediç̧ão, (1984).

[41] Frisch, M. J., Trucks, G. W., Schlegel, H. B., Scuseria, G. E., Robb, M. A., Cheeseman, J. R., Montgomery, Jr., J. A., Vreven, T., Kudin, K. N., Burant, J. C., Millam, J. M., Iyengar, S. S., Tomasi, J., Barone, V., Mennucci, B., Cossi, M., Scalmani, G., Rega, N., Petersson, G. A., Nakatsuji, H., Hada, M., Ehara, M., Toyota, K., Fukuda, R., Hasegawa, J., Ishida, M., Nakajima, T., Honda, Y., Kitao, O., Nakai, H., Klene, M., Li, X., Knox, J. E., Hratchian, H. P., Cross, J. B., Bakken, V., Adamo, C., Jaramillo, J., Gomperts, R., Stratmann, R. E., Yazyev, O., Austin, A. J., Cammi, R., Pomelli, C., Ochterski, J. W., Ayala, P. Y., Morokuma, K., Voth, G. A., Salvador, P., Dannenberg, J. J., Zakrzewski, V. G., Dapprich, S., Daniels, A. D., Strain, M. C., Farkas, O., Malick, D. K., Rabuck, A. D., Raghavachari, 
K., Foresman, J. B., Ortiz, J. V., Cui, Q., Baboul, A. G., Clifford, S., Cioslowski, J., Stefanov, B. B., Liu, G., Liashenko, A., Piskorz, P., Komaromi, I., Martin, R. L., Fox, D. J., Keith, T., Al-Laham, M. A., Peng, C. Y., Nanayakkara, A., Challacombe, M., Gill, P. M. W., Johnson, B., Chen, W., Wong, M. W., Gonzalez, C., e Pople, J. A. Gaussian 03, Revision D.01, Wallingford, CT (2004).

[42] Vianna, D. J., Fazzio, A., e Canuto, S. Teoria Quântica de Moléculas e Sólidos. Editora Livraria da Física, 1ํ edição, (2004). São Paulo.

[43] Levine, I. N. Quantum Chemistry. Prentice-Hall, 4a edição, (1991).

[44] Morgon, N. H. e Coutinho, K. Métodos de Química Teórica e Modelagem Molecular. Livraria da Física, 1ํa edição, (2007).

[45] Jensen, F. Introduction to Computational Chemistry. John Wiley \& Sons, $1^{a}$ edição, (1999).

[46] Cizek, J. Advances in Chemical Physics 14, 35-89 (1969).

[47] Cizek, J. The Journal of Chemical Physics 45(11), 4256-4266 (1966).

[48] Bartlett, R. J., Watts, J. D., Kucharski, S. A., e Noga, J. Chemical Physics Letters 165(6), $513-522$ (1990).

[49] Kitel, C. Introduction to Solid State Physics. John Wiley \& Sons, 7a edição, (1995).

[50] Slater, J. C. Physical Review 81(3), 385-390 (1951).

[51] Hohenberg, P. e Kohn, W. Physical Review 136(3B), B864-B871 (1964).

[52] Runge, E. e Gross, E. K. U. Physical Review Letters 52(12), 997 (1984).

[53] Marques, M. A. L. e Gross, E. K. U. Annual Review of Physical Chemistry 55, 427-455 (2004). 
[54] Perdew, J. P. e Yue, W. Physical Review B 33(12), 8800-8802 (1986).

[55] Becke, A. D. Physical Review A 38(6), 3098-3100 (1988).

[56] Vosko, S. H., Wilk, L., e Nusair, M. Canadian Journal of Physics 58, 1211 (1980).

[57] Perdew, J. P., Chevary, J. A., Vosko, S. H., Jackson, K. A., Pederson, M. R., Singh, D. J., e Fiolhais, C. Physical Review B 46(11), 6671-6687 (1992).

[58] Miehlich, B., Savin, A., Stoll, H., e Preuss, H. Chemical Physics Letters 157(3), 200-206 (1989).

[59] Lee, C., Yang, W., e Parr, R. G. Physical Review B 37(2), 785-789 (1988).

[60] Perdew, J. P. Physical Review B 33(12), 8822-8824 (1986).

[61] Perdew, J. P., Burke, K., e Ernzerhof, M. Physical Review Letters 77(18), 3865-3868 (1996).

[62] Baker, J. e Pulay, P. Journal of Chemical Physics 24(10), 1184-1191 (2003).

[63] Handy, N. C. e Cohen, A. J. Molecular Physics: An International Journal at the Interface Between Chemistry and Physics 99, 403-412 (2001).

[64] Peterson, K. A., Woon, D. E., e Dunning Jr., T. H. The Journal of Chemical Physics 100(10), 7410-7415 (1994).

[65] Woon, D. E. e Dunning Jr., T. H. The Journal of Chemical Physics 98(2), 1358-1371 (1993).

[66] Wilson, A. K., van Mourik, T., e Dunning, T. H. Journal of Molecular Structure: THEOCHEM 388, 339 - 349 (1996).

[67] Woon, D. E. e Dunning Jr., T. H. The Journal of Chemical Physics 103(11), 45724585 (1995). 
[68] Thom H. Dunning, J. The Journal of Chemical Physics 90(2), 1007-1023 (1989).

[69] Binning Jr., R. C. e Curtiss, L. A. Journal of Computational Chemistry 11, 1206 1216 (2004).

[70] Rassolov, V. A., Pople, J. A., Ratner, M. A., e Windus, T. L. Journal of Chemical Physics 109(4), 1223-1229 (1998).

[71] Rassolov, V. A., Ratner, M. A., Pople, J. A., Redfern, P. C., e Curtiss, L. A. Journal of Computational Chemistry 22(9), 976-984 (2001).

[72] Hay, P. J. e Wadt, W. R. The Journal of Chemical Physics 82(1), 270-283 (1985).

[73] Hay, P. J. e Wadt, W. R. The Journal of Chemical Physics 82(1), 299-310 (1985).

[74] Wadt, W. R. e Hay, P. J. The Journal of Chemical Physics 82(1), 284-298 (1985).

[75] Hehre, W. J., Stewart, R. F., e Pople, J. A. The Journal of Chemical Physics 51(6), 2657-2664 (1969).

[76] Collins, J. B., Von Schleyer, P. R., Binkley, J. S., e Pople, J. A. The Journal of Chemical Physics 64(12), 5142-5151 (1976).

[77] Leininger, T., Nicklass, A., Kuchle, W., Stoll, H., Dolg, M., e Bergner, A. Chemical Physics Letters 255(4-6), 274-280 (1996).

[78] Weigend, F. e Ahlrichs, R. Physical Chemistry Chemical Physics 7(18), 3297-3305 (2005).

[79] Barros, C. L., de Oliveira, P. J. P., e Jorge, F. E. (2009). submitted for publication.

[80] Dunning Jr., T. H. e Hay, P. J. Modern Theoretical Chemistry , 1 (1976).

[81] Bergner, A., Dolg, M., Küchle, W., Stoll, H., e Preuszlig, H. Molecular Physics 80(6), 1431-1441 (1993). 
[82] Dolg, M., Stoll, H., Preuss, H., e Pitzer, R. Journal of Physical Chemistry 97(22), 5852-5859 (1993).

[83] Kaupp, M., Schleyer, P. V. R., Stoll, H., e Preuss, H. The Journal of Chemical Physics 94(2), 1360-1366 (1991).

[84] Sadlej, A. J. Theoretica Chimica Acta 81(4-5), 339-354 (1992).

[85] Sadlej, A. J. Theoretica Chimica Acta 79(2), 123-140 (1991).

[86] Sadlej, A. J. Theoretica Chimica Acta 81(1-2), 45-63 (1991).

[87] Lide, D. E. Handbook of Chemistry and Physics. CRC Press, 73-a edição, (1992-1993).

[88] Demtröder, W. e Stock, M. Journal of Molecular Spectroscopy 55(1-3), 476 - 486 (1975).

[89] Grebenkemper, C. J. e Hagen, J. P. Physical Review 80(1), 89 (1950).

[90] Pratt, W. P. e Zimmermann, W. Physical Review 177(1), 412-428 (1969). 


\section{Apêndice A}

\section{Standard Bubble Model}

Um modelo teórico bem simples, que representa a geração de uma cavidade por efeito de uma impureza em ambiente de He líquido, é o Standard Bubble Model (SBM) [12]. O He líquido interage com o potencial do átomo central, no caso um átomo alcalino. A mudança do potencial modifica as funções de onda, e assim as energias de excitação e emissão, sendo responsável pelas alterações nas propriedades espectroscópicas. O hamiltoniano total do sistema é

$$
H=H_{\text {free }}+H_{\text {liq }}+H_{\text {int }} .
$$

Ao hamiltoniano do átomo isolado $\left(H_{\text {free }}\right)$, é necessário adicionar um termo referente ao ambiente líquido $\left(H_{\text {liq }}\right)$ e um termo de interação do átomo alcalino com He Líquido $\left(H_{\text {int }}\right)$, que será tratado como um termo perturbativo. O termo que adiciona a energia do sistema líquido é simplesmente a soma da energia cinética ao potencial entre os átomos de $\mathrm{He}$

$$
H_{\text {liq }}=-\frac{1}{2 m_{H e}} \sum_{k} \nabla_{k}^{2}+\sum_{k<l} V\left(\vec{R}_{k}, \vec{R}_{l}\right) \text {. }
$$

O termo de interação é dado pela soma dos pares de potenciais entre os átomos de He e o átomo central. Este termo é escrito em função da densidade $\rho(\vec{R})$, como

$$
H_{\text {int }}=\sum_{k} V_{\text {int }}\left(\vec{R}_{k}, \vec{r}\right)=\int \rho(\vec{R}) V_{\text {int }}(\vec{R}, \vec{r}) d \vec{R}
$$


A densidade de He líquido em torno do átomo alcalino é nula dentro da região da cavidade de raio $R_{0}$ e perfil $\alpha$. Para distâncias acima de $R_{0}$, a densidade converge para o valor da densidade do líquido $\rho_{0}$. A densidade é descrita na seguinte forma [12]:

$$
\rho(R)= \begin{cases}0, & R \leq R_{0} \\ \rho_{0}\left[1-\left\{1+\alpha\left(R-R_{0}\right)\right\} e^{-\alpha\left(R-R_{0}\right)}\right], & R>R_{0} .\end{cases}
$$

Pode-se calcular o raio do centro de massa da distribuição do He líquido $\left(R_{b}\right)$ com a relação

$$
\int_{0}^{R_{b}} \rho(\vec{R}) d \vec{R}=\int_{R_{b}}^{\infty}\left[\rho_{0}-\rho(\vec{R})\right] d \vec{R} .
$$

A energia resultante neste modelo é formada pelos termos: energia para criar a cavidade a uma determinada pressão, energia superficial e um termo adicional da energia cinética dos átomos de He na superfície da bolha

$$
E_{\text {liq }}=\frac{4}{3} \pi R_{b}^{3} P+4 \pi R_{b}^{2} \gamma+\frac{1}{8 M} \int \frac{(\nabla \rho)^{2}}{\rho} d \vec{R},
$$

onde $P$ é a pressão que se encontra o sistema e $\gamma$ é a tensão superficial. Foi assumido que o líquido é um fluído incompressível. Para o caso do elétron como impureza, a expressão acima fica

$$
E_{e^{-}}=\frac{4}{3} \pi R_{e}^{3} P+4 \pi R_{e}^{2} \gamma+\frac{\hbar}{8 m_{e} R_{e}^{2}} .
$$

Quando tratamos a expressão acima com pressão nula, temos a relação para o raio da bolha, expressa por

$$
R_{\text {min }}=\left(\frac{h^{2}}{32 \pi m \gamma}\right)^{1 / 4} .
$$

Desta expressão, temos que o valor do raio da bolha é da ordem de $19 \AA$ [8]. O procedimento utilizado é bem simples, mas diversos complementos podem ser adicionados a fim de melhorar a descrição, e assim o valor do raio da bolha [90]. Um resultado experimental, na pressão de saturação do vapor, aponta para um raio de $21,2 \pm 0,5 \AA$ [11], próximo à previsão teórica. 
Usando a primeira ordem da teoria de perturbação, o termo de interação $H_{\text {int }}$ irá corrigir as energias de forma que apresentem as mudanças espectroscópicas da impureza em He Líquido, conforme a equação abaixo:

$$
E_{A}=E_{A O}+\left\langle\Phi_{A O}\left|H_{\text {int }}\right| \Phi_{A O}\right\rangle .
$$

Algumas correções podem ser adicionadas, no intuito de incluir os efeitos que inicialmente foram desprezados. Na referência [12], existe uma tabela comparando os resultados do deslocamento espectral experimental e o obtido com o SBM para $\mathrm{Ca}, \mathrm{Sr}, \mathrm{Ba}$ e $\mathrm{Ba}^{+}$. 